Roberto Iglesias Lopes

\title{
Avaliação dos valores séricos e urinários de CA 19-9 e TGF $\beta 1$ na obstrução parcial e completa de ureteres em ratos
}

Tese apresentada à Faculdade de Medicina da Universidade de São Paulo para obtenção de título de Doutor em Ciências.

Programa de Urologia

Orientador: Prof. Dr. Francisco Tibor Dénes

São Paulo

2014 


\section{Dados Internacionais de Catalogação na Publicação (CIP)}

Preparada pela Biblioteca da

Faculdade de Medicina da Universidade de São Paulo

Creprodução autorizada pelo autor

Lopes, Roberto Iglesias

Avaliação dos valores séricos e urinários de CA 19-9 e TGF $\beta 1$ na obstrução parcial e completa de ureteres em ratos / Roberto Iglesias Lopes. -- São Paulo, 2014.

Tese(doutorado)--Faculdade de Medicina da Universidade de São Paulo. Programa de Urologia.

Orientador: Francisco Tibor Dénes.

Descritores: 1.Obstrução ureteral 2.Ureter 3.Antígeno CA19-9 4.Fator de crescimento transformador beta 1 5.Ratos Wistar

USP/FM/DBD-023/14 
Dedicatória 
Aos meus queridos "abuelos" Eloy e Generosa, pelo exemplo de vida, que com grande sacrifício deram oportunidade a nós que viemos depois. À minha avó Tereza, por seu carinho.

A meus pais Roberto e Josefa, pelo amor e dedicação na minha educação e dos meus irmãos Silvia e Marcelo. Dedico esta tese a meus pais, ambos médicos formados pela FMUSP, que sempre foram motivo de orgulho para mim e cujos passos resolvi seguir desde pequeno. Esta vocação ganhou sentido especial quando "recebemos" meu irmão de volta, momento em que eu pude enxergar que sendo médico, poderia salvar vidas e ajudar quem precisa. Muito obrigado a minha querida família- eu amo vocês.

A meu amor Marcinha, pela alegria constante que você traz à minha vida e pelo apoio e compreensão em meus momentos de ausência. Estaremos juntos até o fim. 


\section{Agradecimentos}

Ao Prof. Dr. Francisco Tibor Dénes, pela orientação na elaboração desta tese e pelo apoio à minha formação profissional, acadêmica e pessoal. Para mim, você é o exemplo de Professor, por sua capacidade técnica, pelo interesse em continuamente estar aprendendo, pela preocupação na formação de novas gerações e principalmente por sua honestidade e retidão moral.

Ao Prof. Dr. Miguel Srougi, professor titular de Urologia da Faculdade de Medicina da Universidade de São Paulo, por sua dedicação em manter o Serviço de Urologia da FMUSP como um dos mais conceituados em âmbito nacional e internacional.

Ao Prof. Dr. Homero Bruschini, responsável pelo Programa de Pós-Graduação, por permitir a realização deste trabalho.

Ao Prof. Dr. Antônio Carlos Seguro e à Profa. Dra. Kátia Ramos Leite, pelo suporte fornecido a todas as etapas do trabalho e pelos valiosos ensinamentos e sugestões durante toda tese.

À Dra. Sabrina Reis, exemplo de amor à pesquisa científica, pelos conselhos de grande valia no trabalho e por sua amizade.

Ao acadêmico Matheus Bartolamei, pelo auxílio na execução do trabalho.

Sou grato às equipes do Laboratório de Investigação Médica de Urologia e Nefrologia, especialmente à Nayara Vianna, Iran Amorim Silva e Talita Sanches.

Aos colegas do Grupo de Uropediatria da Disciplina de Urologia do HCFMUSP, em especial ao Prof. Dr. Amílcar Martins Giron e Dr. Marcos Gianetti Machado, pelo companheirismo, profissionalismo e união nas atividades assistenciais, de ensino e pesquisa no HCFMUSP. 
Aos colegas da pós-graduação, em especial ao Dr. Nelson Dip Júnior, com quem tive maior convívio e que se tornou um grande amigo.

Aos Drs. José Cury, José Pontes Júnior, Alexandre Danilovic e Luiz Carlos Neves de Oliveira, por minha inserção no Curso de Graduação da Disciplina de Urologia. Devo muito ao Dr. Pontes e ao Dr. Danilovic, que são grandes amigos e excelentes pesquisadores, com quem constantemente posso compartilhar idéias.

Ao Prof. Dr. Carlos Roberto Ribeiro de Carvalho, professor titular de Pneumologia da FMUSP e ao Prof. Dr. Alfredo José Mansur, responsável pelo Ambulatório Geral do Instituto do Coração e meu orientador de iniciação científica, brilhantes médicos e investigadores, que são os responsáveis por despertar meu interesse genuíno pela pesquisa científica.

Ao Dr. Roberto Nicomedes Lopes, urologista dedicado e competente, meu pai e meu melhor amigo, por seu apoio incondicional, por sua confiança inabalada em meu potencial e por tudo aquilo que me ensinou e que ainda tem para me ensinar.

Ao Dr. Cristóvão Machado Barbosa Filho, por seu incentivo e por sua amizade.

À Dra. Josefa Iglesias Fernandez, minha pediatra favorita e minha mãe, que abdicou de sua brilhante carreira de médica assistente da Neonatologia do HCFMUSP para cuidar da família. 
"São nossas escolhas que revelam o que realmente somos, muito mais do que nossas qualidades.”

J. K. Rowling 
Esta tese está de acordo com as seguintes normas, em vigor no momento desta publicação:

Universidade de São Paulo. Faculdade de Medicina. Serviço de Biblioteca e Documentação. Guia de apresentação de dissertações, teses e monografias. Elaborado por Anneliese Carneiro da Cunha, Maria Julia de A. L. Freddi, Maria F. Crestana, Marinalva de Souza Aragão, Suely Campos Cardoso, Valéria Vilhena. $3^{\text {a }}$ Ed, São Paulo: Serviço de Biblioteca e Documentação, 2011.

Referências: adaptado de International Committe of Medical Journals Editors (Vancouver).

Abreviaturas dos títulos dos periódicos de acordo com List of Journals Indexed in Index Medicus. 
Esta tese recebeu Auxílio à Pesquisa FAPESP, processo 2011/50201-7 


\section{Sumário}

Lista de Siglas

xii

Lista de Símbolos

xiv

Lista de Figuras

$\mathrm{XV}$

Lista de Tabelas

xvii

Resumo

Xviii

Summary

xix

1. Introdução

1.1. Definição e Epidemiologia

1.2. Fisiopatologia da obstrução

1.3. Avaliação da uropatia obstrutiva

1.4. Marcadores de obstrução do trato urinário

1.5. TGF $\beta 1$

1.6. CA 19-9

1.7. Justificativa do estudo

2. Objetivos

3. Material e Métodos 28

3.1. Bioética

3.2. Instalações

3.3. Animais 30

3.4. Anestesia 31

3.5. Técnica cirúrgica

3.6. Coleta de amostras

3.7. Análise dos riscos 
3.9. Estudo anatomopatológico do rim e do ureter

3.10. Estudo imuno-histoquímico do rim e do sistema coletor 38

3.11. Análise laboratorial 40

3.12. Análise estatística 44

4. Resultados 46

4.1. Análise dos riscos 47

4.2. Estudo anatomopatológico do rim e do ureter 47

4.3. Análise laboratorial 51

4.4. Estudo imuno-histoquímico do rim e do sistema coletor 57

5. Discussão 60

6. Conclusões 71

7. Anexos 73

8. Referências bibliográficas 75 Apêndice 


\section{Lista de Siglas}

ANOVA. Análise de variância múltipla

BSA. Albumine from bovine serum BPUO Bilateral partial ureteral obstruction

CA $19-9$ Antígeno de carboidrato 19-9

CTGF Fator de crescimento de tecido conectivo

CUUO Complete unilateral ureteral obstruction

ECM. Matriz extracelular EDTA Ethylenediamine tetraacetic acid EGF. Epidermal growth factor ELISA Enzyme linked immunosorbent assay

EMT Transição epitélio mesenquimal

GADD45 $\gamma$ Growth arrest and DNA damage molecule HRP. Horseradish peroxidase ICAM-1 Molécula intercelular de adesão-1

IGF-1 Insulin growth factor-1

MCP-1 Fator quimiotático para monócitos MMP Metaloproteinase de matriz mRNA messenger Ribonucleic acid

$\mathrm{NF} \kappa \beta$ Nuclear factor $\kappa \beta$

Ngal. .Neutrophil-gelatinase associated lipocalin

PAI-1 .Inibidor da ativação do plaminogênio-1

PBS Phosphate buffered saline 
ROS.

Reactive oxygen species

SRAA

Sistema renina-angiotensina-aldosterona

TGF $\beta 1$ Transforming growth factor $\beta 1$

TIMPs Inibidores teciduais das metaloproteinases

TNF- $\alpha$ Fator de necrose tumoral- $\alpha$ tPA Ativador de plasminogênio tipo tecidual $\mathrm{uPA}$ Ativador de plasminogênio tipo uroquinase UPJO Ureteropielic junction obstruction UUO Unilateral ureteral obstruction

VEGF Vascular endothelial growth factor $\alpha-$ SMA $\alpha$ - actina de músculo liso 


\section{Lista de Símbolos}

$\mathrm{cm}$

centímetro

dl decilitro

g grama

G gauge

kg. quilograma $\mathrm{mg}$ miligrama $\min$ minuto $\mathrm{ml}$ mililitro $\mathrm{mm}$ milímetro

$\mathrm{nm}$ nanômetro pg. picograma rpm rotações por minuto

U unidade $\mu 1$ microlitro ${ }^{\circ} \mathrm{C}$. graus Celsius 


\section{Lista de Figuras}

Figura 1 - Processos de apoptose, inflamação e fibrose na uropatia obstrutiva

Figura 2 - Ação do fator de transcrição nuclear $\kappa \mathrm{B}(\mathrm{NF} \kappa \mathrm{B})$ na inflamação

Figura 3 - Processo de transição epitelial-mesenquimal

Figura 4 - Sinalização intracelular envolvendo proteínas Smad pelo TGF $\beta 1$

Figura 5 - Processo molecular e celular de resposta à uropatia obstrutiva

Figura 6 - Incisão mediana (A) e manipulação de alças intestinais e retroperitônio (B)

Figura 7 - Exposição do retroperitônio (A), dissecção do hilo renal (B), nefrectomia (C) e fechamento da parede (D)

Figura 8 - Ligadura completa do ureter com fio inabsorvível

Figura 9 - Envelopamento do m. psoas do rato para criação de obstrução parcial; passagem do ponto medial (A), lateral (B) para criação de túnel muscular, evitando-se sua oclusão completa $(\mathrm{C})$

Figura 10 - Processo imuno-histoquímico

Figura 11 - Processo da quimioluminescência (Luminex ${ }^{\mathrm{TM}} \mathrm{xMAP}$ )

Figura 12 - Teste ELISA para detecção do CA 19-9 nas amostras séricas e urinárias

Figura 13 - Grupo 4: Obstrução ureteral unilateral completa

Figura 14 - Grupo 5: Obstrução ureteral unilateral parcial

Figura 15 - Grupo 6: Obstrução ureteral parcial bilateral

Figura 16 - Comparação de cortes histológicos de rins controle (A), com obstrução parcial (B) e com obstrução completa (C) 
Figura 17 - Gráficos em boxplot comparando as concentrações séricas e urinárias de TGF $ß 1$ nos sete grupos do estudo

Figura 18 - Gráficos em boxplot comparando as concentrações séricas e urinárias de CA 19-9 nos sete grupos do estudo

Figura 19 - Comparação dos ratos com obstrução a ratos não obstruídos

Figura 20 - Comparação dos ratos com obstrução completa e obstrução parcial a ratos não obstruídos

Figura 21 - Expressão do CA 19-9 em unidades renais não obstruídas, com obstrução parcial e com obstrução completa

Figura 22 - Fotomicrografia exemplificando a expressão de CA 19-9 no citoplasma de células epiteliais tubulares dos grupos 1 (A), 2 (B) e 3 (C)

Figura 23 - Fotomicrografia exemplificando a expressão de CA 19-9 no citoplasma de células tubulares renais em rins de ratos do grupo 5 à direita (A) e à esquerda $(\mathrm{B})$ 


\section{Lista de Tabelas}

Tabela 1 - Valores dos achados anatomopatológicos do rim esquerdo

Tabela 2 - Valores dos achados anatomopatológicos do rim direito

Tabela 3 - Valores da creatinina sérica, creatinina urinária, volume minuto e do clearance de creatinina

Tabela 4 - Valores das concentrações séricas e urinárias dos marcadores estudados 


\section{Resumo}

Lopes RI. Avaliação dos valores séricos e urinários de CA 19-9 e TGF $ß 1$ na obstrução parcial e completa de ureteres em ratos [tese]. São Paulo: Faculdade de Medicina, Universidade de São Paulo; 2014.

Introdução: A alteração dos níveis normais de marcadores séricos e urinários ocorre na presença de dano renal associado à uropatia obstrutiva. Valores séricos e e urinários de TGF $ß 1$ e CA 19-9 ainda não foram avaliados em modelo experimental de uropatia obstrutiva.

Material e Métodos: Ratos foram divididos em sete grupos: referência, sham operation, nefrectomia unilateral, ligadura completa de ureter unilateral, obstrução parcial de ureter unilateral, obstrução parcial de ambos ureteres, nefrectomia unilateral associada à obstrução parcial do ureter contralateral. Morfometria renal e ureteral, concentrações séricas e urinárias de TGF ß1 e CA 19-9 e expressão tecidual renal de CA 19-9 foram analisadas. A correlação destes marcadores com os grupos submetidos a obstrução completa, obstrução parcial ou sem obstrução foi realizada.

Resultados: Achados anatomopatológicos correlacionaram-se positivamente à intensidade da obstrução ureteral e negativamente aos níveis urinários de CA 19-9. Subexpressão acentuada do CA 19-9 foi observada em unidades renais com obstrução completa. Não foram encontradas diferenças estatisticamente significativas para os marcadores TGF $ß 1$ urinário, TGF $ß 1$ sérico e para o CA 19-9 sérico.

Conclusões: O CA 19-9 urinário correlacionou-se negativamente com o grau de obstrução ureteral. A análise imuno-histoquímica demonstrou a expressão do CA 19-9 no citoplasma das células epiteliais tubulares, sugerindo produção renal do marcador. O TGF $\beta 1$ sérico e urinário não apresentaram modificações de acordo com o grau de severidade e tempo de obstrução, o que pode estar relacionado a remodelamento renal menos intenso em resposta à uropatia obstrutiva nestes ratos.

Descritores: Obstrução ureteral, Ureter, Antígeno CA 19-9, Fator de crescimento transformador beta 1, Ratos Wistar 


\section{Summary}

Lopes RI. Seric and urinary evaluation of CA 19-9 and TGF $\beta 1$ in a rat model of partial or complete ureteral obstruction [thesis]. São Paulo: University of São Paulo Medical School; 2014.

Introduction: Abnormal levels of serum and urinary markers occur in the presence of renal damage associated to obstructive uropathy. Urinary and serum TGFß1 and CA 199 have not yet been evaluated in an experimental model of obstructive uropathy.

Material and Methods: Rats were divided into seven groups: reference, sham operation, unilateral nephrectomy, complete unilateral ureteral obstruction, partial unilateral ureteral obstruction, partial bilateral ureteral obstruction, and unilateral nephrectomy with contralateral partial ureteral obstruction. Kidney and ureter morphometry, TGFß1 and CA 19-9 serum and urinary concentrations and CA 19-9 renal tissue expression were analysed. Correlation of these markers to complete, partial obstruction or unobstructed groups was performed.

Results: Pathological findings correlated positively with the degree of ureteral obstruction, but negatively with urinary CA 19-9 levels. Marked underexpression of CA 19-9 was observed in kidneys with complete ureteral obstruction. No statistically significant differences were found for urinary and serum TGFß1 and also for serum CA 19-9.

Conclusions: Urinary CA $19-9$ correlated negatively with ureteral obstruction grade. Immunohistochemistry depicted CA 19-9 expression on epithelial tubular cells cytoplasm, suggesting renal origin. Serum and urinary TGFß1 did not show alterations in response to severity and length of urinary obstruction, which might be associated with less intense renal remodeling. 
Descriptors: Ureteral obstruction, Ureter, CA 19-9 antigen, Transforming growth factor $ß 1$, Wistar rats. 
1.INTRODUÇÃO 


\subsection{DEFINIÇÃO E EPIDEMIOLOGIA}

A uropatia obstrutiva é uma entidade relativamente comum, que ocorre em todas as idades acometendo desde recém-nascidos até idosos. A obstrução é classificada de acordo com o grau, duração e sítio de obstrução. A obstrução é definida como completa ou parcial em relação ao grau de obstrução, aguda ou crônica em relação à duração e obstrução do trato urinário alto ou baixo de acordo com sua localização. A uropatia obstrutiva pode ocorrer em decorrência de lesões funcionais ou anatômicas no trato urinário desde os túbulos renais até o meato uretral (Klahr, 2000).

As causas de obstrução do trato urinário alto podem ser extrínsecas ou intrínsecas. Causas intrínsecas podem ser intraluminais ou intramurais, com o cálculo ureteral sendo a principal causa de obstrução intraluminal, que é geralmente aguda. As causas intramurais acontecem em decorrência de lesões funcionais ou anatômicas no trato urinário. Dentre as causas anatômicas, que são menos frequentes como causa de obstrução, destacam-se estenoses ureterais, tumores benignos e malignos da pelve e ureter, válvulas e pólipos ureterais. As desordens funcionais incluem a estenose da junção ureteropiélica e a estenose da junção ureterovesical, que são mais comuns em crianças (Klahr, 2000).

Classicamente, a uropatia obstrutiva é definida como uma obstrução anatômica ou funcional ao fluxo urinário em qualquer nível do trato urinário, que resultará na deterioração da função renal. A definição mais atual e mais adequada para uropatia obstrutiva é qualquer obstrução urinária que impeça o desenvolvimento funcional do rim de maneira normal. Nefropatia obstrutiva está presente quando a obstrução causa dano renal funcional ou anatômico. 
Em uma série de autópsias em aproximadamente 59 mil pessoas, em indivíduos variando de neonatos a idosos, foram observados cerca de 3,1\% casos de hidronefrose. Não houve diferença entre os sexos na prevalência de hidronefrose até os 20 anos de idade. A hidronefrose foi mais prevalente em mulheres de 20 a 60 anos, com gravidez e malignidades ginecológicas como causas principais da hidronefrose. Em homens, houve maior prevalência após 60 anos, fato explicado pela hiperplasia prostática benigna. Hidronefrose aparece em 2-2,5\% das crianças submetidas a autópsias (Pais Jr. et al., 2007).

Em crianças, a uropatia obstrutiva congênita é responsável por um número significativo de pacientes com lesão renal. O diagnóstico de dilatação do trato urinário superior é relativamente frequente, já a partir do período antenatal, identificando-se a obstrução ao nível da junção pieloureteral (UPJO) ou uretero-vesical em 1/1.200-1.500 nascidos vivos, sendo bilateral em 10-40\% dos casos (Peters et al., 2012). A obstrução do trato urinário é causa de $9,3 \%$ das insuficiências renais agudas no período neonatal (Miklovicova et al., 2008) e a uropatia obstrutiva é a causa principal de insuficiência renal na infância e na adolescência, sendo responsável por cerca de $17 \%$ dos transplantes renais antes de 17 anos e é a principal causa de doença renal crônica terminal em crianças menores de 2 anos, nos Estados Unidos (Daïkha-Dahmane et al., 1997).

Com a possibilidade do diagnóstico ultrassonográfico antenatal de hidronefrose, é possível identificar casos que requerem atenção no período peri e pós-natal. Os exames funcionais e de imagem, realizados após o nascimento, permitem a seleção dos pacientes com obstrução significativa do trato urinário, que necessitam de tratamento. Em outros casos, entretanto, constata-se que a dilatação renal uni ou bilateral não se associa à obstrução significativa, visto que a função do(s) rim(s) permanece preservada no médio prazo. Enquanto na maioria das crianças e recém-nascidos com hidronefrose leve, um curso 
benigno da doença é esperado (com resolução ou melhora espontânea sem necessidade de intervenção cirúrgica), em crianças com dilatações do trato urinário mais acentuadas e com comprometimento funcional, a intervenção cirúrgica precoce é geralmente necessária após um curto período de seguimento clínico e o atraso na cirurgia pode resultar em perda permanente da função renal (Yang et al., 2010; Shokeir et al., 2005). Evidentemente, o seguimento desses pacientes implica na realização de repetidos exames laboratoriais, funcionais e de imagem, através dos quais é possível comprovar-se a estabilidade funcional das mesmas.

Outra situação intrigante ocorre nos pacientes pediátricos que se submetem a cirurgias de desobstrução da junção pielo-ureteral ou uretero-vesical e que no seguimento clínico continuam mantendo por longo prazo uma dilatação significativa da unidade tratada (Miklovicova et al., 2008; Imaji et al., 2002). Estes pacientes também necessitam exames repetidos, para confirmar a estabilidade funcional, ou seja, a ausência de dano renal.

\subsection{FISIOPATOLOGIA DA OBSTRUÇÃO}

$\mathrm{O}$ espectro das anormalidades renais varia muito na uropatia obstrutiva. $\mathrm{O}$ extremo da anormalidade renal congênita, a displasia renal, é raramente notada em material de biópsia ou espécimes de nefrectomia. Em biópsias de casos de estenose da junção ureteropiélica, a incidência de lesões túbulo-intersticiais é limitada e as alterações glomerulares são os achados mais comuns, denotando que a uropatia obstrutiva é uma doença espectral (Rosen et al., 2008).

Enquanto estudos nas décadas de 70 e 80 concentravam-se nos efeitos hemodinâmicos e nas consequências funcionais da uropatia do trato urinário, nos últimos 
15 anos os trabalhos focam principalmente elucidar eventos celulares e moleculares (Chevalier, 2006).

O processo fisiopatológico de destruição de néfrons na uropatia obstrutiva é inicialmente resultado da combinação de aumentos da pressão tubular e da atrofia isquêmica. Em geral, a obstrução ureteral leva ao declínio do fluxo sanguíneo renal e da taxa de filtração glomerular do rim obstruído e aumento do fluxo sanguíneo renal no rim contralateral intacto. No entanto, os efeitos da obstrução ureteral no fluxo sanguíneo renal e na taxa de filtração glomerular dependem da duração, da gravidade da obstrução e do estado diurético. Muitas anormalidades na função tubular ocorrem na uropatia obstrutiva como diminuição da reabsorção de solutos e água, incapacidade de concentração urinária e excreção inadequada de hidrogênio e potássio. Vários hormônios circulantes e fatores parácrinos estão implicados na vasoconstricção (Wen et al., 1999).

A obstrução ureteral leva à ativação do sistema renina-angiotensina-aldosterona (SRAA), infiltração renal por leucócitos (especialmente macrófagos) e apoptose tubular. Néfrons são perdidos por glomerulosclerose e formação de glomérulos atubulares, além de lesão progressiva que leva à atrofia tubular e fibrose intersticial (Chevalier, 1996; El-Dahr et al., 1991; Chevalier, 2008). Obstrução crônica do trato urinário leva ao predomínio da ação de vasoconstritores endógenos renais como angiotensina, tromboxanas e endotelina sobre substâncias vasodilatadoras como prostaglandinas, quininas e óxido nítrico (Yarger et al., 1980; El-Dahr et al., 1993; Fujinaka et al., 2000). A ativação do SRAA pela obstrução do trato urinário resulta em aumento significativo na resistência vascular renal, redução do fluxo sanguíneo renal e da taxa de filtração glomerular (El-Dahr et al., 1993). A angiotensina é um estímulo importante para geração de citocinas fibrogênicas como fator de crescimento (TGF $ß 1$ ), que em resposta, medeia uma série de efeitos deletérios da 
obstrução ureteral (Klahr et al., 1995; Yoo et al., 2000; Shin et al., 2005). Diversas citocinas são liberadas pelas células intersticiais inflamatórias, bem como por células tubulares, especialmente o fator de crescimento TGF $\beta 1$ e fator de necrose tumoral TNF- $\alpha$, processo representado na Figura 1 (Meldrum et al., 2007).

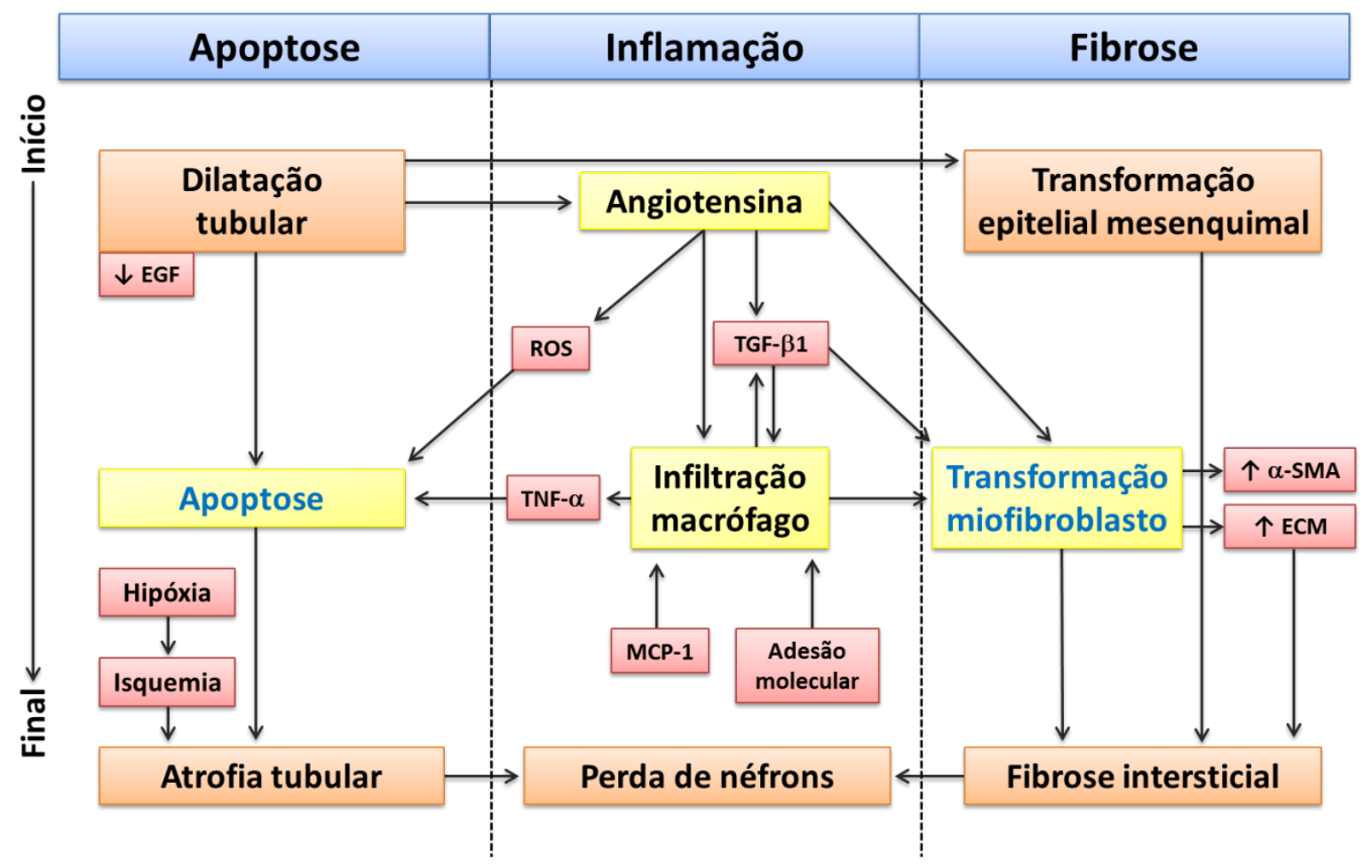

Figura 1 - Processos de apoptose, inflamação e fibrose na uropatia obstrutiva. O TGF $\beta 1$ apresenta papel central nesse processo. (Traduzido e modificado de Chevalier et al., 2010)

O dano tecidual e a regeneração tecidual na uropatia obstrutiva é resultado do remodelamento que ocorre, em que pode haver predomínio da proliferação celular ou da apoptose celular (Chuang et al., 1998). Os mecanismos pelos quais a obstrução ureteral leva ao dano renal estão gradativamente sendo elucidados. Incluem o estiramento mecânico resultante do acúmulo de urina com subsequente distensão tubular, hipóxia causada pela 
redução da perfusão renal, aumento do stress oxidativo, upregulation de fatores inflamatórios como proteína quimiotática de macrófagos, vasoconstritores como angiotensina II e endotelina, bem como citocinas derivadas de macrófagos, especialmente o fator de crescimento pró-fibrótico TGF $\beta 1$, que juntos contribuem para a lesão renal causada pela uropatia obstrutiva. A maioria desses fatores age principalmente através de dois tipos de receptores de membrana: receptores de proteína $\mathrm{G}$ e receptores do tipo tirosina-quinase, que através de vias de sinalização intracelular controlam processos celulares fundamentais como ciclo celular e a sobrevida celular (Rodriguez-Peña et al., 2008).

A apoptose no rim obstruído correlaciona-se com a severidade e duração da dilatação tubular (Kim et al., 2006). O estiramento mecânico das células tubulares é um dos estímulos principais para apoptose, com redução da expressão da oncoproteína antiapoptótica Bcl-2 em túbulos dilatados de rins de ratos neonatos submetidos à obstrução ureteral unilateral completa (UUO), que evoluíram com apoptose. A ativação precoce de protooncogenes, como c-Fos e c-Jun, foi demonstrada após obstrução ureteral e o aumento de antígenos ou proteínas de células em proliferação como Ki-67 e c-myc também foi notada (Chuang et al., 1997; Chuang et al., 1998; Silverstein et al., 2003). A geração de radicais livres, decorrente da redução de antioxidantes endógenos (como catalase), agrava a apoptose renal e substâncias como fator de necrose tumoral TNF- $\alpha$, citocromo c e a ativação de caspases foram implicadas no processo apoptótico após UUO (Choi et al., 2000).

Obstrução ureteral unilateral completa no rato neonato está associada à infiltração intersticial de macrófagos, que são atraídos por uma variedade de citocinas e quimiocinas (Rice et al., 2004). O fator de crescimento TGF $\beta 1$ apresenta papel central na infiltração de 
macrófagos (Diamond et al., 1995). O SRAA intrarenal é altamente ativado após UUO e o recrutamento de monócitos parece estar mediado, ao menos em parte, pela ativação do fator de transcrição nuclear $\kappa \mathrm{B}(\mathrm{NF} \kappa \mathrm{B})$ pela angiotensina, representado na Figura 2 (Klahr et al., 1995). UUO crônica aumenta a expressão renal e a excreção urinária da proteína quimiotática de monócitos MCP-1, com níveis que acompanham a severidade da obstrução. A localização dos macrófagos no rim obstruído é largamente dependente da expressão de moléculas de adesão como selectinas, molécula intercelular de adesão-1 (ICAM-1) e proteínas de matriz como a osteopontina (Ricardo et al., 1996; Shikata et al., 1999; Shappell et al., 2000; Naruse et al., 2002; Diamond et al., 1995). Os macrófagos infiltrantes em resposta liberam fatores solúveis que induzem apoptose celular tubular. A apoptose das células epiteliais tubulares renais leva à atrofia tubular. O macrófago é capaz de liberar uma variedade de produtos que pode promover lesão glomerular incluindo enzimas proteolíticas como colagenase e elastase, radicais livres de oxigênio, produtos derivados da ciclooxigenase e da lipooxigenase, fator de crescimento derivado de plaquetas, fatores de coagulação e fatores de ativação de plaquetas. 


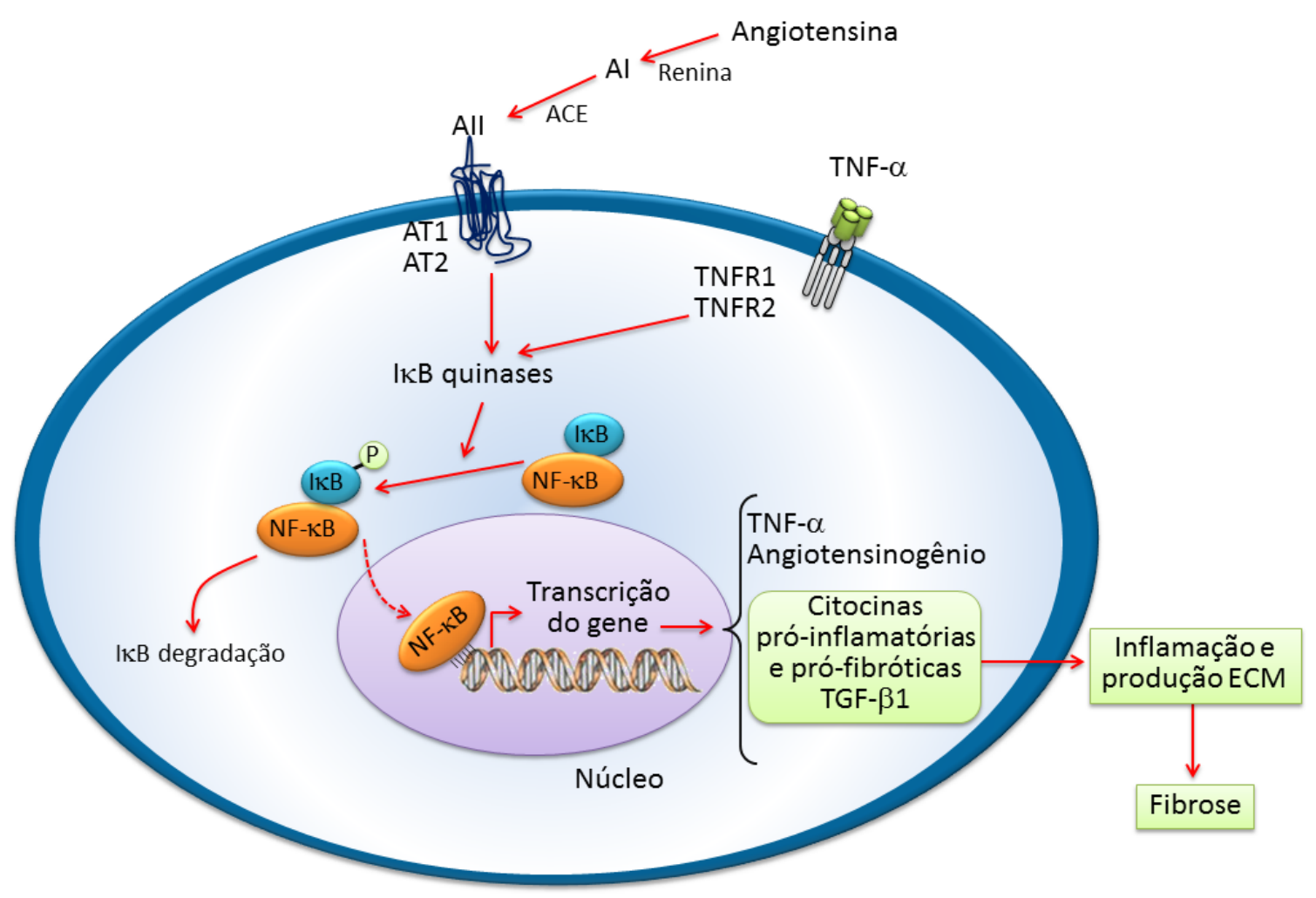

Figura 2 -Ação do fator de transcrição nuclear $\kappa \mathrm{B}(\mathrm{NF} \kappa \mathrm{B})$ na inflamação. (Traduzido e modificado de Bascands et al, 2005)

Após UUO prolongada, o espaço intersticial é invadido por fibroblastos, que parecem originar-se da transformação de células epiteliais tubulares (no processo chamado de transição epitelial-mesenquimal ou EMT) bem como da proliferação de fibroblastos residentes intersticiais e células-tronco intersticiais (Picard et al., 2008). Com UUO continuada, os fibroblastos expressam $\alpha$-actina de músculo liso ( $\alpha$-SMA) e sofrem transformação em miofibroblastos com posterior ativação, levando a produção de citocinas fibrogênicas como TGF $\beta 1$ e TNF- $\alpha$ que causam fibrose intersticial progressiva, com declínio concomitante de fatores fibrinolíticos (Bor et al., 2006; Meldrum et al., 2007). Há enorme interesse nesse processo, visto que a fibrose intersticial renal é a via comum para todos os tipos de doença renal crônica. 
O processo de transição epitelial-mesenquimal inicialmente demostrado por Iwano et al. e confirmado posteriormente em diversos trabalhos, baseia-se na demonstração de que células tubulares renais podem sofrer transformação fenotípica em fibroblastos, um dos mecanismos principais contribuindo para fibrose intersticial após obstrução ureteral (Iwano et al., 2002; Yamashita et al., 2005; Sakairi et al., 2007; Inoue et al., 2009; Aldheni et al., 2009). Como consequência da dilatação tubular, ocorre perda da adesão epitelial tubular, seguida da perda de características epiteliais pela célula tubular com downregulation de marcadores epiteliais como E-caderina, com subsequente aquisição de traços mesenquimais como expressão de $\alpha$-actina de músculo liso ( $\alpha$-SMA), vimentina e reorganização de actina (Cheng et al., 2010). Essa reorganização é seguida da ruptura da membrana basal tubular e migração da célula no espaço intersticial, onde o miofibroblasto pode contribuir para a expansão da matriz extracelular. (Figura 3).
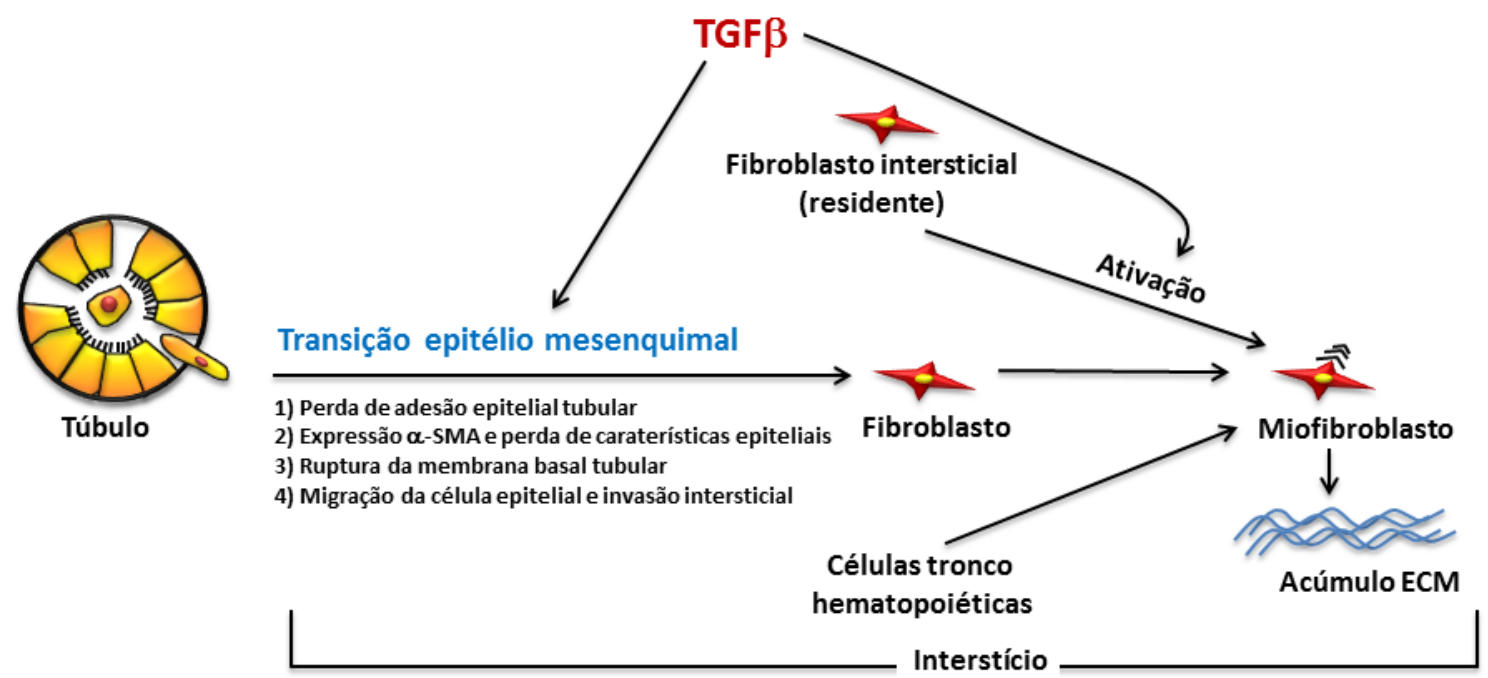

Figura 3 - Processo de transição epitelial-mesenquimal. (Traduzido de Bascands et al., 2005) 
O TGF $ß 1$ desempenha papel central nesse processo complexo de transição epitéliomesenquimal, atuando através da sinalização intracelular envolvendo a família de proteínas Smad que podem estimular a fibrose como Smad 2 e Smad 3 ou inibir a fibrose como Smad7, representado na Figura 4 (Bascands et al., 2005; Diamond et al., 1995). Consequentemente, após UUO, os níveis de Smad 2 e Smad3 aumentam enquanto Smad7 é degradada, consequentemente amplificando as ações fibrogênicas doTGFß1. Outro mediador das ações do TGF $\beta 1$ é o fator de crescimento de tecido conectivo CTGF.

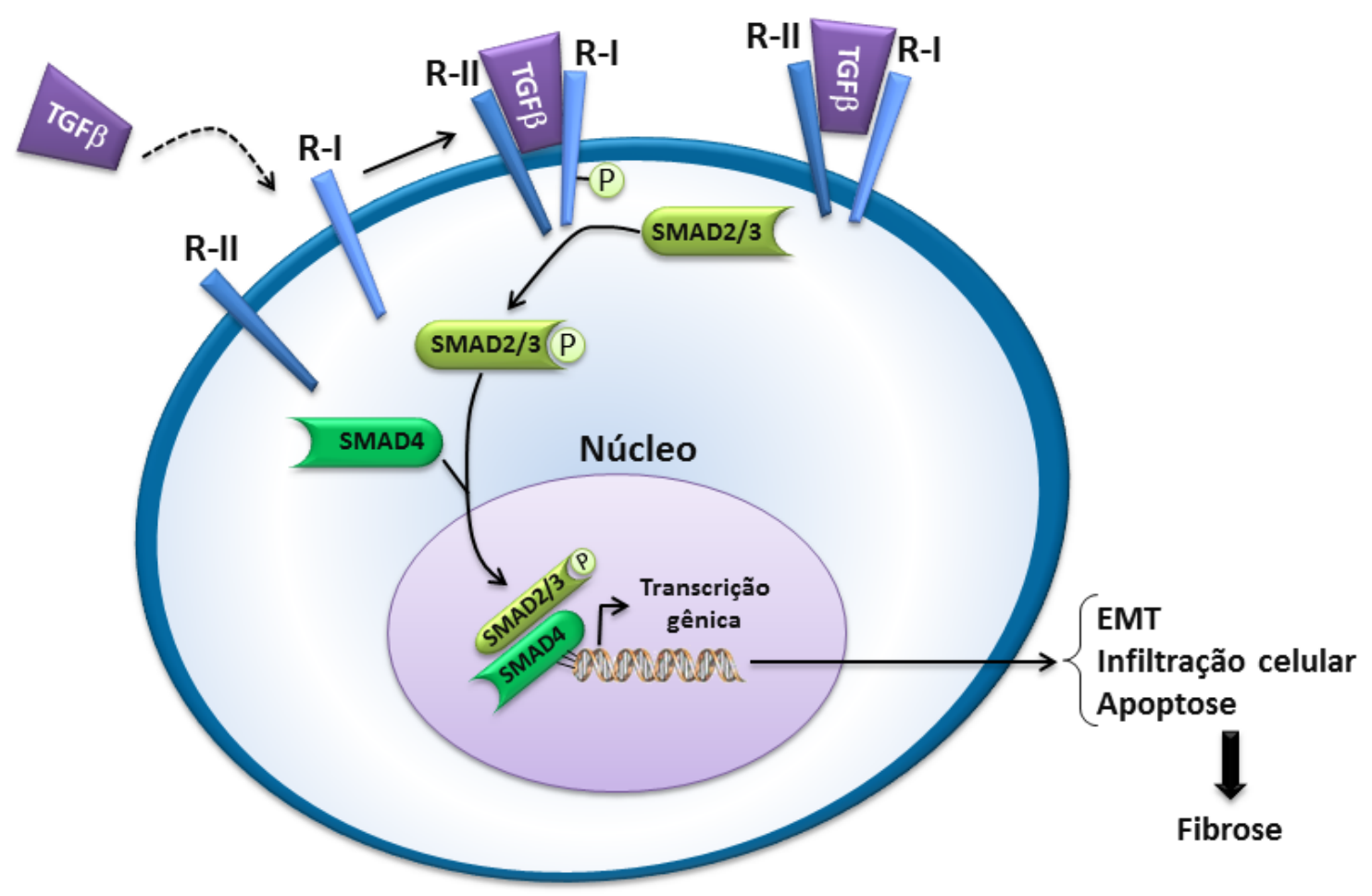

Figura 4 - Sinalização intracelular envolvendo a família de proteínas Smad pelo TGF $\beta 1$. (Traduzido e modificado de Bascands et al., 2005) 
Os miofibroblastos são as células responsáveis pela geração e deposição de matriz extracelular rica em colágeno I e III, levando a fibrose irreversível e disfunção orgânica (Lin et al., 2008; Kang et al., 2009). Moléculas stress-responsivas a danos no DNA e alterações no microambiente celular, como a mólecula growth arrest and DNA damage GADD45 $\gamma$, estão aumentadas na uropatia obstrutiva. GADD45 $\gamma$ induz upregulation de fatores relacionados à fibrose como o TGF $\beta 1$ e as metaloproteinases MMP-1, MMP-9 e MMP-10 (Shin et al., 2008).

A fibrose túbulo-intersticial é o resultado de um desbalanço entre a síntese e degradação de matriz extracelular (ECM). A matriz extracelular tubular patológica é composta por colágeno tipo I, III, IV, V, VI, XV, laminina e fibronectina. A degradação da matriz extracelular é largamente dependente do sistema de plasminogênio constituído por plasmogênio, ativadores de plasminogênio e plasmina, que é a via de ativação primária de metaloproteinases latentes. A protease de serina plasmina é gerada a partir de seu precursor plasminogênio por dois tipos diferentes de ativadores de plasminogênio: tipo uroquinase (uPA) e tipo tecidual (tPA). A plasmina pode degradar diretamente proteínas de matriz como fibronectina, laminina, proteoglicanas e colágeno tipo IV e ativa pró-MMP1 e próMMP-3. MMP-3 ativa subsequentemente MMP-9. Outro ponto de controle na degradação de matriz extracelular é através da inibição da atividade de metaloproteinases de matriz por inibidores teciduais das metaloproteinases TIMPs ou inibidor de ativador do plasminogênio PAI-1 (Zhang et al., 2003; Bascands et al., 2005). Todo o processo celular e molecular descrito acima está representado na figura 5. 


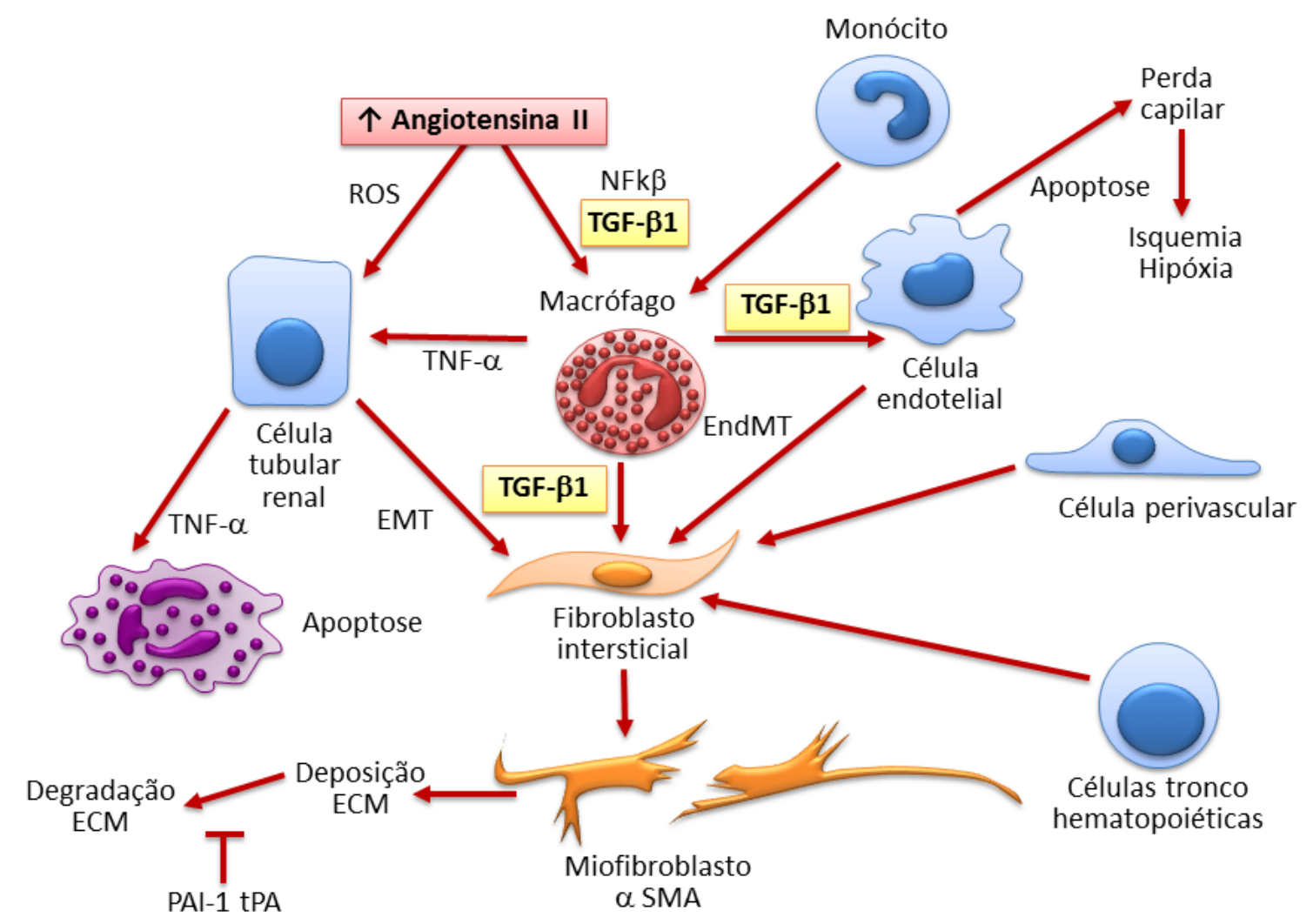

Figura 5 - Processo molecular e celular de resposta à uropatia obstrutiva. (Extraído e traduzido de: Chevalier RL, et al., 2009)

\subsection{AVALIAÇÃO DA UROPATIA OBSTRUTIVA}

Conforme sua intensidade, a obstrução ureteral pode causar graus variados de lesão anatômica e funcional ao rim. No aspecto funcional, a alteração da filtração glomerular é a consequência mais importante. Além dessa alteração, a persistência da obstrução parcial por médio e longo prazo acarreta dilatação progressiva a montante, geralmente identificada nos exames de imagem.

Os exames classicamente utilizados nessas situações clínicas são a urografia excretora, o renograma radioisotópico (Chiou et al., 2004; Arap et al., 1984), o teste de 
Whitaker (Ryan et al., 1989) e a ultrassonografia (Kis et al., 1998; Imaji et al., 2002), esta última com avaliação dos jatos ureterais na bexiga (Bessa Jr et al., 2008) e do índice de resistividade dos vasos intrarenais (Pope et al., 1996).

Infelizmente, apesar de confirmar a dilatação piélica ou ureteral, esses exames apresentam especificidade limitada na caracterização de obstrução propriamente dita, que é o fator que se associa à lesão renal. Adicionalmente, esses exames ou são ionizantes ou invasivos ou examinador-dependentes, apresentando vários fatores de erro inerentes à idade e situação clínica, que podem dificultar a sua interpretação.

Devido a essas limitações dos exames disponíveis, têm-se procurado identificar marcadores séricos e urinários, os quais, produzidos pelo rim ou epitélio transicional do rim, têm sua expressão elevada para níveis anormais na presença de dano renal, consequentemente refletindo a gravidade da obstrução do trato urinário. A dosagem quantitativa desses marcadores possibilitaria diferenciar pacientes com obstrução anatômica ou funcional significativa daqueles com dilatação não obstrutiva do trato urinário e reduziria o grau de invasividade, subjetividade e proficiência operador-dependente.

\subsection{MARCADORES DE OBSTRUÇÃO DO TRATO URINÁRIO}

$\mathrm{O}$ estudo de marcadores urinários baseia-se na fisiopatologia da uropatia e nefropatia obstrutivas que envolvem respostas inflamatória, neuro-humoral e vascular importantes com migração de leucócitos e liberação de diversas citocinas, ativação do sistema renina-angiotensina-aldosterona (SRAA), infiltração de fibroblastos, desequilíbrio entre proliferação e apoptose celular, alteração em moléculas de adesão, disfunção e atrofia tubular, acúmulo de matriz extracelular, isquemia e hipóxia e finalmente, fibrose renal. A 
característica histológica clássica da uropatia obstrutiva é a deposição de colágeno aumentada na matriz extracelular (Chevalier et al., 2004). A concentração de um número de moléculas regendo esses diferentes processos é tão elevada que pode ser verificada na urina, no soro e no tecido renal durante a ocorrência de uropatia obstrutiva incluindo quimiocinas, citocinas e fatores de crescimento.

Duas estratégias diferentes têm sido adotadas no estudo de marcadores não invasivos de uropatia obstrutiva. A primeira estratégia é baseada na análise da proteômica urinária. Essa avaliação baseia-se no fato de que a urina é uma excelente fonte de biomarcadores de doença renais, visto que é estimado que aproximadamente $70 \%$ das proteínas urinárias originam-se do rim e das vias urinárias em indivíduos saudáveis. Nessa estratégia, o proteoma urinário inteiro (perfil de proteínas urinárias completo de um indivíduo) é avaliado com sondas (probes) para uma variedade de biomarcadores, que se correlaciona com a gravidade da uropatia obstrutiva. A avaliação da composição proteica integral da urina através de eletroforese apresentou elevado fator preditivo relacionado à dilatação obstrutiva, permitindo predizer vários meses antes, a evolução clínica de neonatos com obstrução da junção ureteropiélica (Decramer et al., 2006; Decramer et al., 2007; Caubet et al., 2010; Mesrobian et al., 2010; Mesrobian et al., 2010; Drube et al., 2010). Apesar dessa ideia ser bastante atraente, é extremamente difícil e onerosa, impossibilitando seu emprego rotineiro na prática clínica.

A segunda estratégia é baseada no conhecimento obtido a partir de modelos animais de uropatia obstrutiva, que identificou uma série de marcadores urinários individuais associados à uropatia obstrutiva grave. Possivelmente, a combinação desses marcadores poderá permitir predizer quais os pacientes necessitarão de cirurgia e em quais pacientes a obstrução ureteral irá melhorar ou, ao menos, permanecerá estável. Com o 
crescente interesse por estas substâncias, a cada dia surgem novos marcadores baseando-se no conhecimento do processo de uropatia obstrutiva que culmina em fibrose renal. Substâncias que participam de passos chave da uropatia obstrutiva já foram estudadas com base no mecanismo em que participam: 1) resposta vascular: endotelina-1 (Taha et al., 2007), vascular endothelial growth factor VEGF (Grenda et al., 2007); 2) migração de leucócitos: proteína quimiotática de monócitos MCP-1 (Grandaliano et al., 2000; Bartoli et al., 2011; Stephan et al., 2002), interleucinas (Madsen et al., 2012); 3) fatores de crescimento: o fator de crescimento epidermal EGF (Oka et al., 1999; Chevalier et al., 1999), o insulin-like growth factor-1 IGF-1 (Marshall et al., 1991; Chevalier et al., 2000; Serel et al., 2000) ; 4) disfunção tubular: kidney injury molecule-1 KIM-1 (Wasilewska et al., 2011), N-acetil-ß-D-glucosaminidase, $\gamma$-glutamil transferase e fosfatase alcalina (Everaert et al., 1998; Taha et al., 2007; Shokeir et al., 2009) ; 5) acúmulo de matriz extracelular: metaloproteinases (Nicksa et al., 2010; Iimura et al., 2004); 6) isquemia e lesão renal aguda: neutrophil-gelatinase associated lipocalin Ngal (Kuwabara et al., 2009); 7) fibrose: TGF $\beta 1$ (Murer et al., 2006; Madsen et al., 2011); 8) microproteínas urinárias: ß2-microglobulina (Dommergues et al., 2000).

Em levantamento da literatura, foram avaliados 33 trabalhos clínicos prospectivos controlados e 23 trabalhos laboratoriais relacionados com os diversos marcadores identificados no PubMed até então (maio 2007), porém o mais promissor foi o TGF ß1 (Shokeir et al., 2008). Infelizmente, apesar de sua potencial utilidade como marcador, as dosagens de TGF ß1 são pouco rotineiras e de alto custo, razão pela qual sua utilização em clínica é ainda inviável. 


\subsection{TGF- $\beta 1$}

A fibrose intersticial renal é a consequência comum das obstruções ureterais crônicas. A fibrogênese desenvolve-se como resultado de desbalanço entre síntese de matriz extracelular, sua deposição e sua degradação. Muitas citocinas secretadas por células inflamatórias estimulam a proliferação de fibroblastos e regulam a síntese de matriz extracelular. Dentre essas citocinas, TGF $\beta 1$ tem papel principal na regulação da síntese da matriz extracelular, aumentando a síntese de proteínas de matriz extracelular e inibindo a degradação da matriz extracelular tanto pelo aumento da atividade de inibidores de protease e diminuição das metaloproteinases, como pelo estímulo a receptores de proteínas de matriz extracelular (Kaneto et al., 1993). TGF ß regula a transcrição de fatores como colágenos I,III e IV, fibronectina, laminina e integrinas. É também quimiotático para fibroblastos e favorece a proliferação de fibroblastos. Sua produção é estimulada por angiotensina II, decorrente da ativação do SRAA, que ocorre na uropatia obstrutiva.

Esta substância (TGF ß1), principal moduladora do processo de cicatrização após lesão tissular, tem sua expressão elevada no sangue e urina após agressão inflamatória ou traumática do rim, normalizando-se após a eliminação do fator causal por mecanismo de feedback. Persistindo fatores de lesão ao rim, a sua expressão permanece elevada. Por sua ação no tecido renal, os componentes da matriz extracelular se acumulam, acarretando fibrose. Esse processo também faz parte dos mecanismos de cicatrização das inúmeras doenças renais crônicas.

Em estudos experimentais, demonstrou-se a expressão aumentada de TGF ß1 com obstrução ureteral unilateral. Em ratos adultos, a expressão de TGF $\beta 1$ mRNA aumentou gradualmente com o tempo em rins submetidos à UUO (Walton et al., 1992). A expressão 
aumentada de TGF $\beta 1$ mRNA foi observada no parênquima renal de ratos adultos com obstrução completa unilateral. Os níveis de TGF $\beta 1$ mRNA foram progressivamente elevando-se durante 14 dias de obstrução ureteral e a expressão dessa substância ocorreu nos túbulos renais ao invés dos glomérulos (Kaneto et al., 1993). Os túbulos renais, principalmente os túbulos proximais foram os principais contribuidores para elevação de TGFß1 mRNA relacionada à UUO em ratos adultos submetidos à microdissecção de segmentos do néfron (Fukuda et al., 2001). A administração de enalapril, um inibidor da enzima conversora de angiotensina I, melhorou o aumento de TGF $ß 1$ mRNA, porém não aboliu completamente esse aumento nos rins obstruídos (Kaneto et al., 1993). A expressão tubular de mRNA dos receptores do TGF $\beta$, TGF $\beta$ R1 e TGF $ß R 2$, aumentou tanto em rins obstruídos como nos rins contralaterais em relação ao grupo sham em ratos adultos submetidos à UUO por período de até 28 dias, demonstrando sua participação na resposta fibrótica causada pela uropatia obstrutiva (Sutaria et al., 1998). Em ratos adultos submetidos à UUO completa em período de duração de até 42 dias, observou-se que o pico de expressão do TGF $ß 1$ e seus receptores TGF $ß R 1$, TGF $ß R 2$ e TGF $ß R 3$ foi no $21^{\circ}$ dia após a ligadura ureteral, que acompanharam achados histopatológicos de gravidade como severidade da hidronefrose, peso renal, espessamento da serosa e da camada muscular além de fibrose renal (Chuang et al., 2000). Em um estudo experimental, ratos adultos foram submetidos à UUO parcial ou completa e comparados a ratos sham, controle ou ratos com hidronefrose congênita e com 14 dias de UUO, foram estudadas a severidade dos rins hidronefróticos, a fibrose túbulo-intersticial, atrofia renal, apoptose tubular e o nível de TGF $\beta 1$ de extratos renais foi avaliado por ELISA. Os níveis de TGF $ß 1$ foram significativamente maiores em todos os grupos com hidronefrose (experimental ou congênita) em relação ao grupo sham e controle e acompanharam as alterações 
histopatológicas mencionadas acima (Zhou et al., 2002). Em outro trabalho, foi realizada obstrução ureteral unilateral completa intra-útero em ovelhas durante período de nefrogênese (com 90 dias) e após 10 dias, rins foram retirados para análise. Após 10 dias de UUO, as unidades renais obstruídas apresentaram aumento do TGF $\beta 1$ mRNA e de sua proteína (TGF ß1), além de aumento dos níveis de receptores do TGF ß1 I (TGF ßR1) e II (TGF ßR2), em relação aos animais em que realizou-se sham operation (Yang et al., 2001).

Várias substâncias para inibição do aumento do TGF ß1 em modelos de obstrução ureteral em ratos foram utilizadas. A vitamina E, que possui ação antioxidante, causou melhora nos níveis TGF $\beta 1$ a nível transcripcional (diminuição do TGF $\beta 1$ mRNA) em ratos adultos com obstrução unilateral completa e das consequências da expressão do TGFß1, com redução no aumento de radicais livres pós-UUO (Kuemmerle et al., 1997). Foi demonstrado que anticorpo anti-TGF $\beta$ melhorou a apoptose tubular e a fibrose intersticial em ratos submetidos à UUO, pela redução do TGF $\beta$ no tecido renal (Miyajima et al., 2000). Oligodeoxinucleotídeos TGF $ß 1$ antisense transinfectados em fibroblastos intersticiais de ratos adultos com UUO resultaram no bloqueio bem sucedido do TGF $\beta 1$ mRNA, com diminuição dos níveis de TGF $\beta 1$ mRNA, colágeno tipo I mRNA e da fibrose intersticial renal (Isaka et al., 2000; Chae et al., 2006). O fator de crescimento de tecido conectivo CTGF, é uma proteína fibrogênica induzida pelo TGF $ß 1$ e a sua expressão aumentada promove fibrose renal. Oligodeoxinucleotídeos CTGF antisense transinfectados em culturas de fibroblastos renais de rato atenuaram o aumento de fibronectina induzida por TGF $\beta 1$ e da expressão de $\alpha 1$ colágeno mRNA, demonstrando que o CTGF pode ser um alvo para terapia celular no tratamento da fibrose túbulo-intersticial (Yokoi et al., 2001). 
Em outro estudo, a inibição da fibrose renal causada por UUO em ratos adultos foi obtida pela transferência gênica de Smad-7, que regula negativamente o TGF $\beta$ (Lan et al., 2003). Em um estudo similar de UUO em camundongos adultos, o aumento de Smad-7 também preveniu a resposta inflamatória renal (Wang et al., 2005). Em experimento com camundongos submetidos a até 14 dias de UUO, foi observada a inibição dose-dependente da expressão de TGF $\beta 1$ e de colágeno tipo I (associado ao retardo no aparecimento de fibrose renal), com a administração de TGF $ß 1$ siRNA, que é um tipo de RNA que causa interferência no processo translacional (Hwang et al., 2006). A inibição da fibrose renal em ratos adultos com uropatia obstrutiva também foi obtida com inibição do mecanismo de quinases associadas ao receptor do TGF $\beta 1$, que medeiam a fosforilação de moléculas proteicas sinalizadoras (sendo as pSmad2 e pSmad3, as mais importantes), que tem papel fundamental no mecanismo de ação intracelular do TGF ß1 (Moon et al., 2006). Em estudo com camundongos submetidos à UUO, o TGF $ß 1$ induziu a expressão do gene de $ß 1$ integrina dependente de Smad-3, levando a transição epitelial-mesenquimal. O bloqueio da sinalização pela ß1-integrina preveniu a progressão da fibrose renal (Yeh et al., 2010). Administração de paclitaxel em ratos adultos submetidos à UUO também preveniu a fibrose renal pela supressão da fosforilação de $\operatorname{Smad} 2$ e Smad3 associadas à cascata de sinalização intracelular do TGF ß (Zhang et al., 2010). Ratos transgênicos adultos Klotho, que são portadores de proteína Klotho, submetidos à UUO, tiveram supressão dos efeitos do TGF ß1, incluindo diminuição da transição epitelial-mesenquimal, diminuição da resposta inflamatória associada à obstrução e da subsequente fibrose renal. Houve inibição da fosforilação da Smad2 (Doi et al., 2011). 
Em estudos clínicos, também foi observada correlação positiva dos níveis do TGF ß1 com uropatia obstrutiva. Palmer et al. foi o primeiro a documentar níveis urinários de TGF $\beta 1$ em crianças. Nesse estudo, foi observado aumento dos níveis de TGF ß1 urinário em urina da pelve renal em crianças com estenose da junção ureteropiélica submetidas à pieloplastia, em comparação à urina coletada por sonda uretral dessas crianças e urina coletada da bexiga em crianças com refluxo vesicoureteral (submetidas à reimplante ureteral) e crianças de grupo controle (Palmer et al., 1997). Furness et al. foi o primeiro a identificar o TGF ß1 como marcador urinário, em urina coletada na bexiga, de uropatia obstrutiva significativa com sensibilidade superior a 90\%, para um cutoff de TGF $\beta 1$ de 61 $\mathrm{pg} / \mathrm{mg}$ de creatinina. Demonstrou adicionalmente que os valores da urina coletada da pelve renal foram significativamente superiores aos valores obtidos nas amostras urinárias vesicais (cerca de duas vezes) e muito elevados em relação a controles normais ( 8 vezes superiores aos valores basais de controles). Os valores urinários de TGF $\beta 1$ foram maiores em crianças menores que 2 anos de idade em relação a crianças mais velhas, em que se especula falha no processo de remodelação e produção estável do TGF ß1 (Furness et al., 1999). Em estudo similar em crianças com uropatia obstrutiva, El-Sherbiny et al. confirmou os achados reportados por Furness et al. Os valores da urina coletada da pelve renal foram significativamente superiores aos valores obtidos nas amostras urinárias vesicais (cerca de quatro vezes) e muito elevados em relação a controles normais (superior a 12 vezes os valores basais de controles). No grupo com uropatia obstrutiva, submetido à pieloplastia, houve tendência de queda no valor urinário vesical do TGF $\beta 1$ coletado 3 meses após a cirurgia ( $\mathrm{p}<0.08$ ). O valor de cutoff, após realização de curva ROC, foi de $29 \mathrm{pg} / \mathrm{mg}$ de creatinina nesse estudo, provavelmente por se tratar de coorte de crianças mais velhas (ElSherbiny et al., 2002). Outro estudo demonstrou resultados similares (Sager et al., 2009). 
$\mathrm{Na}$ avaliação da urina de crianças com estenose de junção pielo-ureteral, foi demonstrada a elevação pré-operatória dos níveis urinários do TGF $ß 1$, bem como decaimento gradual e progressivo, com a normalização dos valores um ano depois da cirurgia reparadora. Os resultados demonstraram sensibilidade de 100\%, especificidade de 80\%, e acurácia geral de 90.8\% deste marcador para diagnóstico da obstrução (Taha et al., 2007).

Em estudo de coorte prospectivo, 42 recém-nascidos com hidronefrose com seguimento médio superior a 1 ano, foram divididos em 2 grupos: grupo observação e grupo cirurgia. A principal novidade do estudo foi de que houve correlação do TGF ß1 urinário em amostra vesical com o grau de hidronefrose em ambos os grupos e consequentemente o TGF $\beta 1$ urinário em amostra vesical pode ser útil na redução do número de ultrasonografias e renogramas durante o seguimento clínico desses pacientes. Além disso, reforçou-se a idéia de que o TGF $ß 1$ urinário é uma ferramenta não invasiva útil após a pieloplastia (Almodhen et al., 2009).

Em trabalho com crianças com uropatia obstrutiva, hidronefrose não obstrutiva e controles normais, demonstrou-se que a concentração urinária média de TGF $ß 1$ dos pacientes com uropatia obstrutiva foi significativamente maior que no grupo de hidronefrose não obstrutiva e no grupo controle, e nesses dois últimos grupos os valores foram similares (Zieg et al., 2011). 


\subsection{CA 19-9}

O antígeno de carboidrato sérico CA 19-9 ou antígeno de Lewis é um glicolípideo, que foi estabelecido a partir de linhagem celular de câncer de cólon (Kawai et al., 2008; La'ulu et al., 2007). O nível de CA 19-9 encontra-se elevado em algumas condições benignas. Estudos imuno-histoquímicos demonstraram expressão do antígeno CA 19-9 em diversos tecidos normais como pâncreas, vesícula biliar, estômago, cólon, árvore brônquica, endométrio, glândulas salivares e próstata. Raramente está aumentado em indivíduos saudáveis ou com doença benigna, com alteração em cerca de $0,8 \%$ em indivíduos assintomáticos. Destes pacientes assintomáticos, com CA 19-9 elevado, somente 2,8\% foram diagnosticados com afecção maligna; portanto o CA $19-9$ não é recomendado como screening (Kim et al., 2009).

CA 19-9 é um antígeno amplamente utilizado como marcador no diagnóstico e controle de pacientes com câncer (Bedi et al., 2009). Está presente em epitélio humano normal, sendo sintetizado em grande quantidade com o desenvolvimento de carcinomas gastrointestinais, como pâncreas, fígado e dutos biliares, acumulando-se no sangue e secreções (Waanders et al., 2009; Singh et al., 2011; Bernhard et al., 2010; Kondo et al., 2010; Hess et al., 2008). Está aumentado em condições como gravidez (Ercan et al., 2012), doenças benignas como endometriose (Kurdoglu et al., 2009), em tumores mucinosos de ovário (Kelly et al., 2010). Recentemente, níveis urinários elevados de CA 19-9 foram associados ao diagnóstico não invasivo de câncer de bexiga (Pal et al., 2011).

Inicialmente, a elevação do CA 19-9 associada à hidronefrose, uropatia obstrutiva ou tumores ureterais foi reportada em uma série de relatos de caso, curiosamente na maioria por autores japoneses (Ito et al., 1994; Kondoh et al., 1996; Iwaki et al., 1996; Inayama et 
al., 1996; Takase et al., 1996; Aoki et al., 1999; Shudo et al., 1999; Aida et al., 2002; Inamoto et al., 2004). Nas hidronefroses, o mecanismo de elevação desse marcador poderia ser explicado por provável síntese excessiva pela mucosa da pélvis renal e epitélio tubular ou diminuição do clearance devido à uropatia obstrutiva (Meyer et al., 2004).

O primeiro estudo que correlacionou o CA 19-9 sérico com a presença de hidronefrose benigna foi um estudo do tipo caso-controle prospectivo. O CA 19-9 sérico apresentou média de 30,6 \pm 32,2 $(5-170 \mathrm{U} / \mathrm{ml})$ no grupo de hidronefrose em relação à média de 12,6 $\pm 10,2(5-52 \mathrm{U} / \mathrm{ml})$ no grupo sem hidronefrose, com $\mathrm{p}<0,0001$. Nesse estudo, a elevação do CA 19-9 no grupo com hidronefrose foi correlacionada a fatores adicionais como bilateralidade, infecção urinária, proteinúria, aumento da uréia sérica, obstrução grave e dilatação acentuada (Suzuki et al., 2002).

Outro estudo caso-controle, comparou 54 pacientes com hidronefrose benigna com 25 controles assintomáticos sem hidronefrose na ultrasonografia do trato urinário e sem doença benigna ou maligna causando aumento do CA 19-9. O objetivo primário era avaliar o CA 19-9 sérico e urinário em relação à presença ou ausência de hidronefrose. O CA 19-9 urinário e sérico foram mais elevados no grupo com hidronefrose em relação ao controle, com correlação linear positiva entre o CA 19-9 sérico e urinário (Aybek et al., 2006).

Um trabalho prospectivo caso-controle avaliou 30 pacientes com hidronefrose decorrente de litíase renal e 20 controles saudáveis. Foi realizada dosagem do CA 19-9 sérico antes da litotripsia extracorpórea por ondas de choque e 30 minutos após a sessão de litotripsia a dosagem foi repetida. Observou-se que o CA 19-9 era mais alto nos pacientes com hidronefrose do que nos controles previamente a litotripsia e que os valores de CA 199 não se alteraram após a realização do procedimento (Akgül et al., 2007). 
Em estudo recente, avaliou-se o valor preditivo do CA 19-9 sérico e urinário no diagnóstico e seguimento de crianças com obstrução unilateral da junção ureteropiélica significativa que necessitaram de pieloplastia desmembrada. Os valores do CA 19-9 sérico e urinário foram maiores no grupo com uropatia obstrutiva que no grupo controle e foi observado que o CA 19-9 urinário demonstrou queda significativa com 3 meses após a desobstrução e atingiu níveis normais em 9 meses. Como conclusão principal, foi feita proposta do CA 19-9 urinário como biomarcador de nefropatia obstrutiva congênita, já que se correlacionou positivamente com diâmetro ântero-posterior da pelve e negativamente com função renográfica (Kajbafzadeh et al., 2009; Kajbafzadeh et al., 2010).

\subsection{JUSTIFICATIVA DO ESTUDO}

Dois marcadores serão avaliados nesse estudo: o TGF $ß 1$ e o CA 19-9. O TGF ß1 foi estudado em trabalhos clínicos e experimentais, porém sua concentração sérica e urinária ainda não foi avaliada em modelo experimental de uropatia obstrutiva até o momento. Da mesma forma, não se identificou nenhum trabalho avaliando o CA 19-9 em animais com obstrução ureteral variada. O CA 19-9 além de ser avaliado na urina e no soro em ratos submetidos à obstrução unilateral ou bilateral, terá sua expressão imunohistoquímica analisada no tecido renal a fím de verificar os sítios de imunoexpressão preferencial nesse modelo de obstrução ureteral. 
2.OBJETIVOS 
1) Em um estudo em ratos, pretende-se avaliar os valores séricos e urinários de marcadores (TGF ß1 e CA 19-9) em dois tempos diversos, após obstruções ureterais parciais (uni ou bilaterais) ou completas (unilaterais). De acordo com os resultados, avaliaremos a utilidade do TGF $\beta 1$ e do CA 19-9 como marcadores confiáveis de obstrução significativa do trato urinário e de lesão renal.

2) Avaliar a presença de expressão tecidual renal do marcador CA 19-9 após obstruções ureterais parciais (uni ou bilaterais) ou completas (unilaterais). De acordo com os resultados, verificaremos a localização da expressão do CA 19-9 após obstrução ureteral, dado que não está descrito na literatura. 
3.MATerial E MÉtodos 


\subsection{BIOÉTICA}

Foi realizado estudo experimental na Faculdade de Medicina da Universidade de São Paulo (FMUSP), no período compreendido entre agosto de 2010 e agosto de 2012, aprovado pela Comissão de Ética para Análise de Projetos de Pesquisa - CAPPesq da Diretoria Clínica do Hospital das Clínicas e da FMUSP, em 11 de fevereiro de 2010 (Anexo A).

\subsection{INSTALAÇÕES}

Para a realização dos procedimentos cirúrgicos com os animais e seguimento pósoperatório foram utilizadas as dependências do Laboratório de Pesquisa Básica da Nefrologia LIM-12, que conta com infra-estrutura técnica e humana especializadas para a cirurgia e manutenção de animais utilizados em pesquisa.

Para armazenamento das amostras e realização dos exames laboratoriais e anatomopatológicos, foram utilizadas as instalações do Laboratório de Investigação Médica da Disciplina de Urologia da Faculdade de Medicina da Universidade de São Paulo (FMUSP), LIM-55. 


\subsection{ANIMAIS}

Quarenta e três ratos adultos da raça Wistar, pesando aproximadamente de 200 a 250 gramas, fornecidos pelo Centro de Bioterismo da Faculdade de Medicina da Universidade de São Paulo (CB/FMUSP) foram utilizados e subdivididos em sete grupos de estudo, com cada grupo submetido a diferentes procedimentos cirúrgicos, abaixo relacionados:

- Grupo 1 (6 ratos): referência (controle)

- Grupo 2 (6 ratos): cirurgia fantasma (sham)

- Grupo 3 (6 ratos): nefrectomia unilateral (Nx. unilateral)

- Grupo 4 (6 ratos): ligadura completa de ureter unilateral (CUUO)

- Grupo 5 (6 ratos): obstrução parcial de ureter unilateral (PUUO)

- Grupo 6 (7 ratos): obstrução parcial de ambos ureteres (BPUO)

- Grupo 7 (6 ratos): nefrectomia unilateral + obstrução parcial de ureter contralateral (PUUO rim único)

Os animais foram alocados em gaiolas coletivas de polietileno, sendo separados pelos grupos a que pertenciam e foram mantidos nas condições de temperatura constante, iluminação de 13 horas de escuro e 11 horas de claro. Todos os grupos tiveram acesso à água ad libitum e foram alimentados com dieta comum para roedores. 


\subsection{ANESTESIA}

A anestesia foi realizada com a administração intraperitoneal de tribromoetanol, a 2,5\% (25 mg/ml), com dose de $20 \mathrm{mg} / 100 \mathrm{~g}$ de peso do rato. A anestesia foi feita por punção em fossa ilíaca esquerda com agulha de insulina $27,5 \mathrm{G}$ 1/2” $(13 \times 3,8)$.

\subsection{TÉCNICA CIRÚRGICA}

Após anestesia, os animais foram fixados à mesa cirúrgica com ataduras e submetidos à depilação manual e antissepsia tópica.

A cirurgia fantasma (sham) constou de laparotomia simples com incisão mediana, manipulação de alças intestinais e do retroperitônio, seguida de exposição do ureter (Figuras 6A e 6B). Finalizou-se com administração intraperitoneal de antibiótico (norfloxacina $5 \mathrm{mg} / \mathrm{kg}$ ) e fechamento da parede abdominal (aponeurose em sutura contínua com prolene 5.0 e pele em sutura com pontos separados com nylon 5.0).
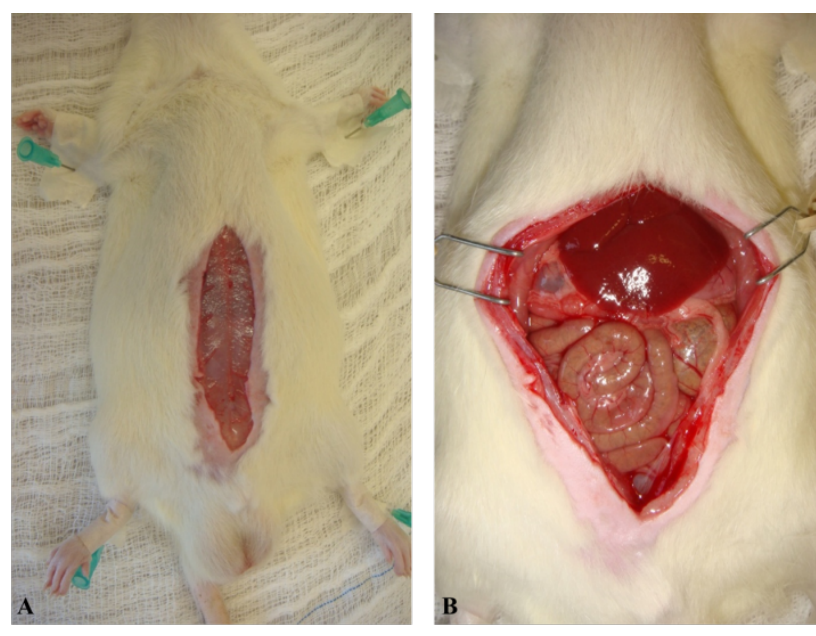

Figura 6 - Incisão mediana (A) e manipulação de alças intestinais e retroperitônio (B) 
A nefrectomia unilateral (Nx. unilateral) foi realizada por laparotomia mediana, com exposição do retroperitônio (preferencialmente o esquerdo, pela facilidade), dissecção, ligadura e secção dos vasos do pedículo e ureter com fio inabsorvível e retirada do órgão (Figuras 7A, 7B, 7C e 7D). Finalizou-se com a administração de antibiótico e fechamento da parede, como descritos anteriormente.
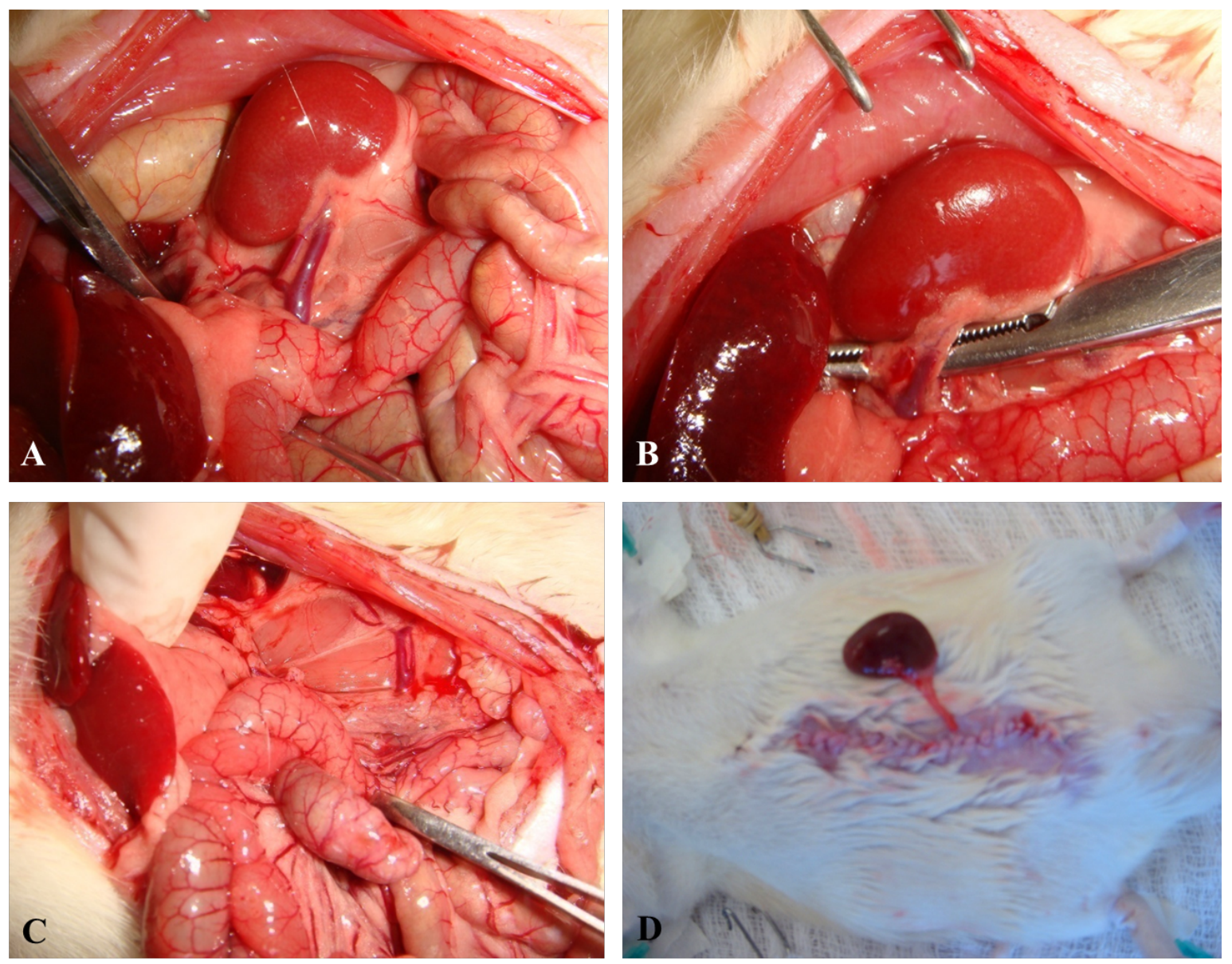

Figura 7 - Exposição do retroperitônio (A), dissecção do hilo renal (B), nefrectomia (C) e fechamento da parede (D) 
A obstrução completa do ureter unilateral (CUUO) foi feita por laparotomia mediana, exposição do retroperitônio (preferencialmente o esquerdo), dissecção e ligadura dupla do ureter com fio inabsorvível, secção do mesmo entre os pontos de ligadura (Figura 8). Finalizou-se com a administração de antibiótico e fechamento da parede, como descritos anteriormente.

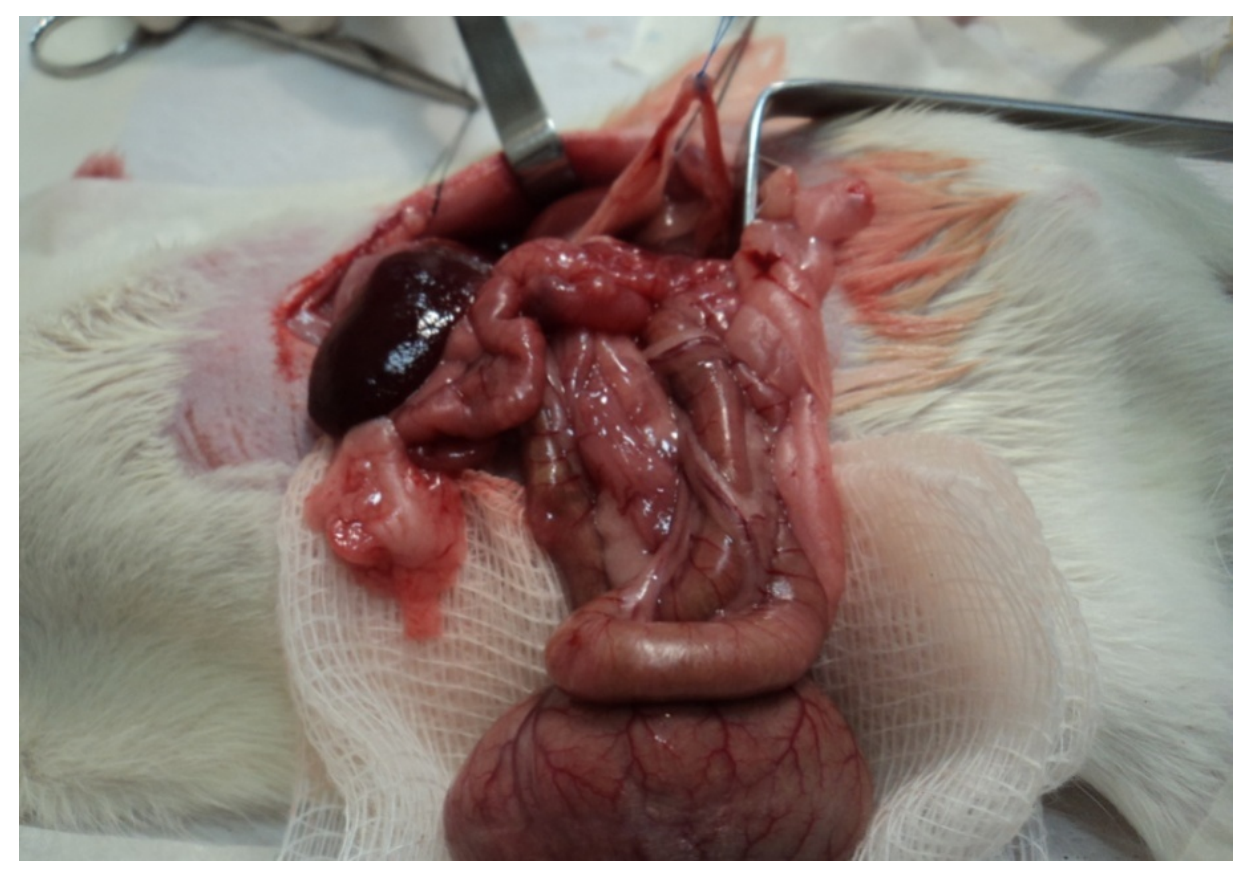

Figura 8 - Ligadura completa do ureter com fio inabsorvível 
A obstrução parcial do ureter foi obtida por laparotomia mediana, exposição do retroperitônio e dissecção do ureter (nos casos unilaterais apenas o esquerdo). Envelopamento do(s) ureter(es) no músculo psoas, com duas suturas simples de fio inabsorvível 4.0 transfixando o psoas lateral e medialmente ao ureter, amarrando-o sobre o ureter. Desse modo, cria-se um túnel muscular que comprime o ureter, evitando-se sua oclusão completa ou transfixação, conforme técnica descrita por Ulm e Miller, 1962 (Figuras 9 A, 9B e 9C). Finalizou-se com a administração de antibiótico e fechamento da parede, como descritos anteriormente.
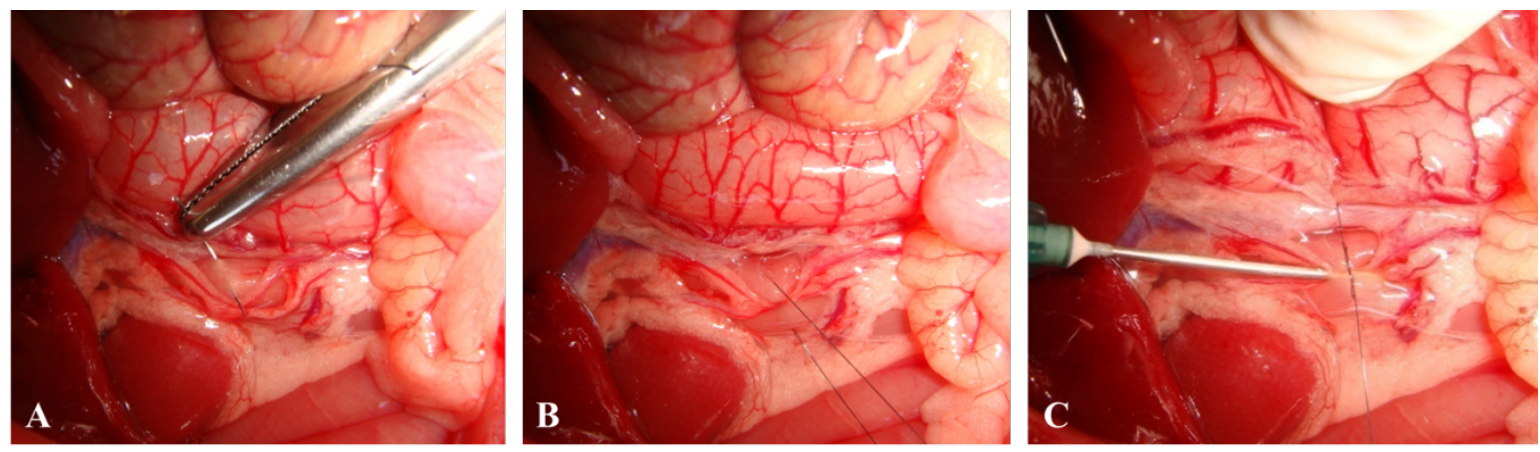

Figura 9 - Envelopamento do m. psoas do rato para criação de obstrução parcial. Passagem do ponto medial (A), lateral (B) para criação de túnel muscular, evitando-se sua oclusão completa $(\mathrm{C})$

\subsection{COLETA DE AMOSTRAS}

Para a coleta de amostras urinárias, em que o volume mínimo recomendado para cada teste era de $1,5 \mathrm{ml}$ ou superior, foi necessária a alocação individual dos ratos em gaiolas metabólicas com recipientes de coleta, a fim de obtermos volume necessário para 
no mínimo 3 amostras urinárias por animal (uma para dosagem de creatinina urinária, uma para dosagem de TGF $\beta 1$ urinário e finalmente uma para dosagem de CA 19-9). Os animais foram mantidos com água ad libitum somente, sem dieta comum para roedores, por período de 24 horas antes das etapas de procedimento cirúrgico. Decidimos por coleta em período de 24 horas, devido à necessidade de volume total de urina elevado e para facilitar cálculo do clearance de creatinina para cada rato individualmente. A urina obtida com a instalação do animal em gaiola metabólica individual com recipiente de coleta foi posteriormente recolhida em eppendorfs de 1,5 ml, que foram identificados e armazenados no refrigerador. Inicialmente foram coletadas amostras de sangue e urina de 6 ratos do grupo 1, para a dosagem inicial de TGF $ß 1$ e CA 19-9, cujos valores serviram de referência. No grupo 1, os animais ficaram em gaiolas metabólicas por 24 horas com água ad libitum e no dia seguinte foram submetidos a procedimento cirúrgico para coleta de amostras de sangue e retirada dos rins.

Nos outros grupos, inicialmente cada rato foi submetido ao procedimento cirúrgico proposto de acordo com o grupo a que pertenciam. A seqüência de coleta foi a seguinte: para coleta de amostras urinárias, os animais ficaram em gaiolas metabólicas por 24 horas com água ad libitum no dia anterior à segunda laparotomia a que foram submetidos, ou seja, no $13^{\circ}$ dia ou $27^{\circ}$ dia após cirurgia inicial.

No $14^{\circ}$ dia após a cirurgia inicial, a metade dos ratos de cada grupo foi anestesiada para nova laparotomia. Os ureteres foram estudados ao nível da obstrução parcial do segmento inserido no músculo psoas, para se confirmar se houve a oclusão completa da luz ou permeabilidade parcial pela instilação de azul de metileno na pelve renal e a observação da progressão do contraste até a bexiga. Em seguida, foi realizada a coleta de sangue e 
retirada dos rins, seguida de sacrifício dos mesmos. No $28^{\circ}$ dia após a cirurgia, os ratos restantes de cada grupo foram submetidos ao mesmo procedimento.

As amostras sanguíneas foram obtidas por meio de punção cardíaca subxifoidal com agulha de 20G. Foram coletados cerca de 10 a $12 \mathrm{ml}$ de sangue total, acondicionados em tubos com anticoagulante EDTA à concentração de $1 \mathrm{mg} / \mathrm{ml}$, a fim de evitar a ocorrência de hemólise na coleta, que poderia interferir na análise bioquímica. No mesmo ato, os rins submetidos a ligaduras completas ou obstrução parcial foram removidos juntamente com os ureteres (até o nível da obstrução total no caso de ligadura total, ou até além do envelopamento no músculo psoas no caso de obstrução parcial).

Subsequentente, os ratos foram sacrificados com a secção da aorta e exsanguinados, sendo a seguir desprezados de acordos com as normas preconizadas pelo Centro de Bioterismo da Faculdade de Medicina da Universidade de São Paulo (CB/FMUSP).

Para os exames bioquímicos, as amostras de plasma foram processadas por centrifugação do sangue total $(3.500 \mathrm{rpm} / 15 \mathrm{~min})$ do sangue total. Após a centrifugação, houve separação do soro dos animais, que foram estocados em refrigerador em eppendorfs individuais de 1,5 ml (3 eppendorfs por animal, já que era recomendada obtenção de 1,5 ml de amostra para cada teste - dosagem de creatinina, TGF $B 1$ e CA 19-9), para posterior análise. Todos os eppendorfs foram colocados em pequenas caixas com grade interna, afim de que tubos permanecessem na posição vertical e foram identificados de acordo com o animal e o grupo a que pertenciam. As dosagens foram realizadas ao mesmo tempo, ao término de todas as coletas, para evitar variações no método e otimização do uso dos kits. 


\subsection{ANÁLISE DOS RISCOS}

Os animais submetidos ao experimento foram avaliados quanto a complicações inerentes ao procedimento anestésico ou cirúrgico (infecção da ferida cirúrgica, íleo paralítico, sangramentos, lesões inadvertidas de outros órgãos), as quais podem acarretar morte do animal. Nesse caso, os mesmos foram submetidos a exame necroscópico para averiguação da causa mortis. Um número equivalente de animais foi submetido adicionalmente ao mesmo procedimento, para manter o número de ratos em cada grupo.

\subsection{CUIDADOS PÓS-OPERATÓRIOS}

No pós-operatório, os animais foram acondicionados em gaiolas coletivas para seis animais, identificadas conforme a data e o tipo de cirurgia realizada. As gaiolas foram submetidas à limpeza diária para preservação da higiene. Os animais foram alimentados com água e ração ad libitum, preservando-se o ambiente com temperatura e umidade estáveis. Os animais foram avaliados diariamente quanto à atividade, alimentação, evacuação, resposta aos estímulos, etc. A ferida cirúrgica foi examinada diariamente, sendo tratada com assepsia e medicação tópica conforme necessário. 


\subsection{ESTUDO ANATOMOPATOLÓGICO DO RIM E DO URETER}

Os rins retirados foram submetidos à aferição do peso (em gramas) e tamanho renal longitudinal (em centímetros), além do diâmetro do ureter (em milímetros) e da pelve renal (em centímetros). Após incisão bivalve da peça, com remoção de toda urina do sistema pielocalicial com papel absorvente, os rins foram fixados em formol a $10 \%$ e armazenados para posterior estudo anatomopatológico. Foi medida a espessura do córtex renal (em milímetros).

\subsection{ESTUDO IMUNO-HISTOQUÍMICO DO RIM E DO SISTEMA}

\section{COLETOR}

Um estudo imuno-histoquímico dos rins, com pesquisa do antígeno CA 19-9, foi objeto de estudo (não há dados na literatura médica a respeito), com finalidade de comprovar a localização do sítio de sua produção.

O kit utilizado para localização do antígeno CA 19.9 no estudo imuno-histoquímico foi o anticorpo de rato de cam anti-CA19.9, clone C241:5:1:4 (DBS), fornecido pela firma Biogenex Laboratories Inc. ${ }^{\circledR}$ (San Ramon, CA, USA). Esse anticorpo monoclonal de rato para proteína CA 19-9 é obtido a partir de um imunogênio de linhagem celular de adenocarcinoma coloretal humano (COLO205) em ascites liofilizadas, diluídas em solução salina tamponada com fosfato (PBS), $\mathrm{pH} 7,6$, contendo 1\% BSA (Albumin, from bovine serum - Sigma) e 0,09\% de azida de sódio. Sucintamente, esse anticorpo é designado para localização específica da proteína CA 19-9 em secções teciduais embebidas em parafina e fixadas em formol. O príncipio do procedimento envolve a demonstração de antígenos por 
imuno-histoquímica em processo de duas etapas: a primeira etapa consiste na ligação do anticorpo primário ao antígeno de interesse e a segunda na detecção do antígeno ligado por um cromógeno. O anticorpo cora o citoplasma em células positivas. O tecido usado como controle positivo para esse anticorpo foi tecido colônico (recomendado).

Como anticorpo secundário foi utilizado, o kit N-Histofine ${ }^{\circledR}$ Simple Stain Mouse PO (Rat) da firma Nichirei Biosciences Inc. (Tsukiji, Chuo-Ku, Tokyo, Japan). Este reagente é utilizado em secções de tecido de rato fixadas em formol (a 10 ou 20\%) e embebidas em parafina. O N-Histofine ${ }^{\circledR}$ é preparado para que o reagente interaja com o anticorpo primário ligado ao antígeno estudado no tecido histológico. Dessa forma, a atividade enzimática do complexo resulta em depósito de cor, marcando o local dos antígenos (Figura 10).

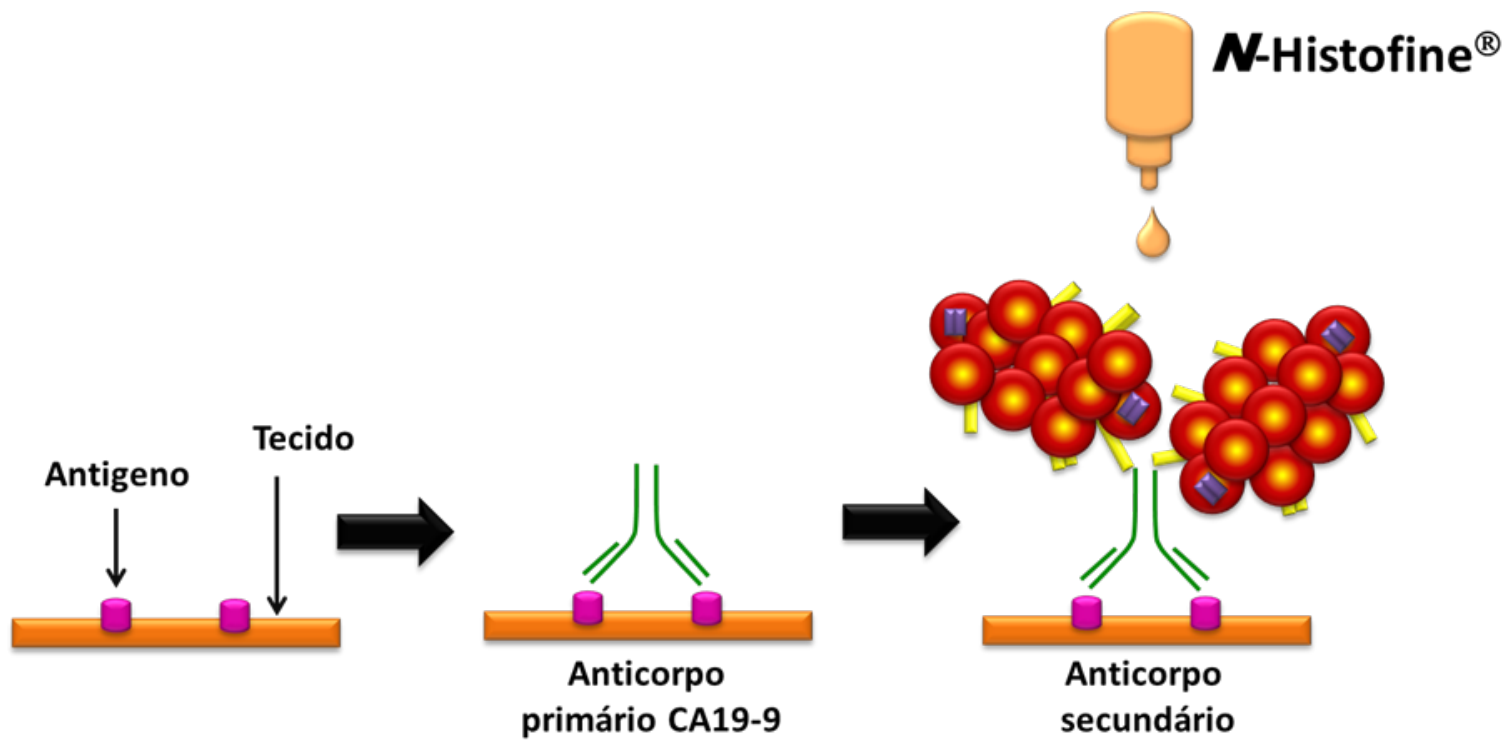

Figura 10 -Processo imuno-histoquímico

Os anticorpos foram mantidos estocados e foram utilizados de acordo com a recomendação dos fabricantes. 


\subsection{ANÁLISE LABORATORIAL}

Cada amostra de urina e soro foi submetida à dosagem de TGF 31 e de CA 19-9 em duplicata, utilizando-se os seguintes kits:

Para o TGF B1: kit de teste Luminex Milliplex ${ }^{\mathrm{TM}}$ MAP TGFß1 Single Plex kit (da empresa Millipore Corporation. ${ }^{\circledR}$, St. Charles, MO, USA), fornecidos e realizados pela firma Gênese Produtos Diagnósticos Ltda (São Paulo, SP, Brasil). Essa tecnologia chamada de quimioluminescência (Luminex ${ }^{\mathrm{TM}} \mathrm{xMAP}$ ) envolve um processo que cora microesferas de poliestireno com dois fluoróforos. Utilizando proporções precisas destes dois fluoróforos, podem ser criados 100 conjuntos diferentes de microesferas, cada uma delas com uma assinatura baseada em código de cores, que podem ser identificadas pelo instrumento Luminex. Os kits Milliplex ${ }^{\mathrm{TM}}$ foram desenvolvidos com estas microesferas e se fundamentam no imunoensaio. Anticorpos de captura específicos para cada analito estão imobilizados a microesferas através de ligações covalentes não reversíveis. Depois que o analito (amostra) se liga aos anticorpos de superfície localizados na superfície das microesferas, a detecção final é feita através de um terceiro marcador fluorescente, a estreptavidina-ficoeritrina (PE) ligada ao anticorpo de detecção. O resultado final é um ensaio "sanduíche" realizado através das microesferas. O equipamento Luminex 100 movimenta estas esferas em fila única através de dois lasers diferentes em um citômetro de fluxo. O primeiro feixe de laser detecta e classifica a microesfera de acordo com o código de cor para o ensaio e o segundo laser quantifica o sinal reportado em cada microesfera (Figura 11). 


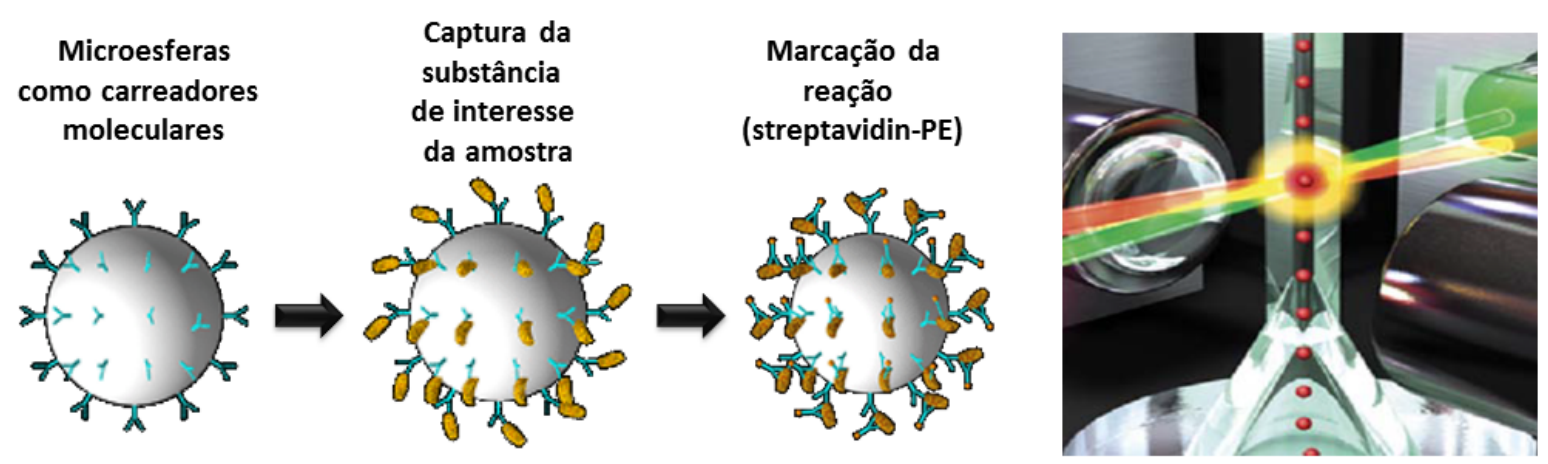

Figura 11 - Processo da quimioluminescência (Luminex ${ }^{\mathrm{TM}}$ xMAP) $^{\mathrm{N}}$

Estes kits estão disponíveis em formato simples e pronto para o uso, com cada kit contendo todos os componentes necessários (incluindo padrões, controles de qualidade, microesferas exclusivas conjugadas a anticorpos, anticorpos de detecção, tampão de ensaio e tampão de lavagem) para ensaio em 96 cavidades em microplaca de titulação. O volume de amostra necessário é menor que $50 \mu 1$. A concentração mínima detectável de TGF $ß 1$ nas amostras é de $10 \mathrm{pg} / \mathrm{ml}$.

Inicialmente, preparam-se os reagentes. Para preparo de padrão de TGF $ß 1$, usa-se $250 \mu \mathrm{l}$ de assay buffer (tampão de ensaio) para obter concentração padrão de 10.000 pg/ml. Pela adição de alíquotas de diluições seriadas de tampão de ensaio (de $150 \mu 1$ ) e de $50 \mu 1$ da última solução obtida, concentrações de TGF $\beta 1$ variadas são obtidas.

Posteriormente, adiciona-se $200 \mu 1$ de tampão de ensaio em cada poço da placa. Mistura-se por 10 minutos em temperatura ambiente e após remove-se a vácuo. Adicionase $25 \mu 1$ de padrões do TGF $\beta 1$ ou controles de TGF $\beta 1$ nos poços apropriados. Adiciona-se então $25 \mu \mathrm{l}$ de tampão de ensaio para poços das amostras. Em seguida, $25 \mu 1$ de matriz sérica são adicionados aos padrões de TGF $\beta 1$ e controles de TGF $\beta 1$. Adiciona-se $25 \mu 1$ de amostras nos poços apropriados, seguido de $25 \mu 1$ de microesferas misturadas (mixed 
beads) em cada poço. Incuba-se por 2 horas em temperatura ambiente. É feita a remoção do fluido por vácuo e lavagem da placa por 2x com $200 \mu$ de tampão de lavagem (wash buffer). Adiciona-se $25 \mu \mathrm{l}$ de anticorpos de detecção, incubando-se por 1 hora em temperatura ambiente. Adiciona-se $25 \mu$ de estreptavidina-ficoeritrina. Incuba-se por 30 minutos em temperatura ambiente e novamente faz-se a remoção do fluido por vácuo e lavagem da placa por 2 x com $200 \mu 1$ de tampão de lavagem (wash buffer). Adiciona-se 100 $\mu 1$ de sheath fluid em cada poço e lê-se a placa no Luminex.

Para o CA 19-9: kit de teste enzyme linked immunosorbent assay ELISA (Rat Carbohydrate antigen 19-9®, MBS729408), fabricado pela MyBioSource (San Diego, CA, USA) fornecido pela firma Biogen (São Paulo, SP, Brasil). A solução de parada altera a coloração de azul para amarelo e a intensidade de coloração é medida a $450 \mathrm{~nm}$ usando espectrofotômetro. A fim de medir a concentração de CA 19-9 na amostra, o kit inclui um conjunto de padrões para calibração. Os padrões de calibração utilizados são analisados ao mesmo tempo em que as amostras e permitem ao investigador produzir curva padrão de densidade óptica versus CA 19-9. A concentração do CA 19-9 é determinada pela comparação da densidade óptica das amostras com a curva padrão.

O princípio do ELISA aplica uma técnica chamada de quantitative sandwich immunoassay. A placa de microtitulação fornecida nesse kit contém poços revestidos para a medição quantitativa de CA 19-9 e utiliza um anticorpo anti CA 19-9 e um anticorpo policlonal CA 19-9 HRP conjugado. A amostra de ensaio e o tampão são incubados juntamente com CA 19-9 HRP conjugado na placa pré-revestida por uma hora. Após o período de incubação, os poços (wells) são decantados e lavados cinco vezes. Os poços são incubados com substrato para enzima HRP. O produto da reação enzima-substrato forma um complexo de cor azul. Finalmente, uma solução de parada (stop solution) é adicionada 
para parar a reação, que transformará a solução em amarelo (Figura 12). A intensidade de cor é medida em espectrofotômetro a $450 \mathrm{~nm}$ em um leitor de microplacas. A intensidade da cor é inversamente proporcional à concentração de CA 19-9 das amostras, visto que o CA 19-9 presente nas amostras e o CA 19-9 HRP conjugado competem pelo anticorpo anti CA 19-9 no sítio de ligação. Segundo informações do fabricante, a sensibilidade neste ensaio detecta concentrações de até $0,01 \mathrm{U} / \mathrm{ml}$.

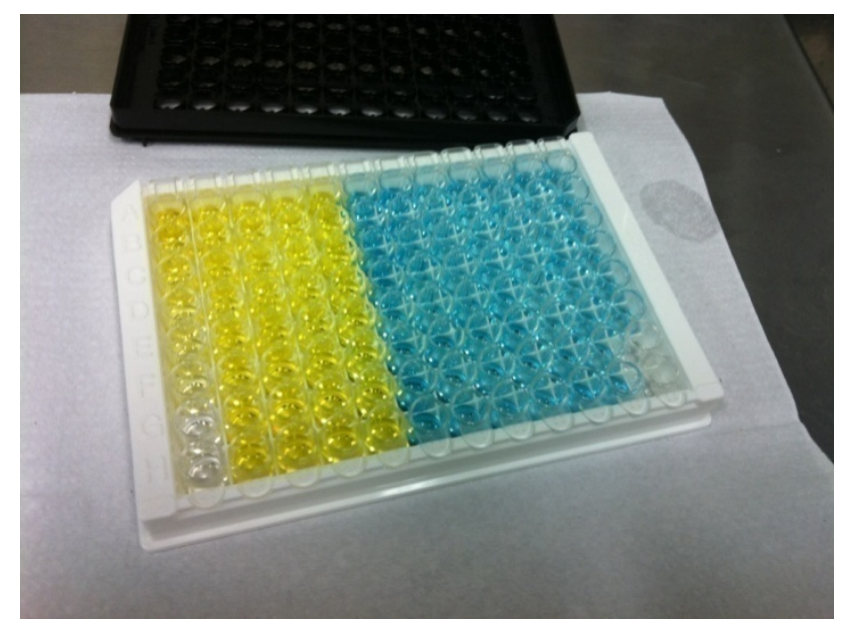

Figura 12 -Teste ELISA demostrando o produto da reação enzima-substrato que transforma a solução de amarelo para azul

Inicialmente, realiza-se a preparação dos reagentes. Todos os componentes do kit e das amostras são trazidos à temperatura ambiente $\left(18-25^{\circ} \mathrm{C}\right)$ antes da utlização. Pipeta-se $10 \mu 1$ de solução tampão de lise em $100 \mu 1$ e deposita-se nos poços, mistura-se e deixa-se repousar durante uma hora. Essa etapa é necessária quando a amostra é fluido de cultura de células, fluido corporal (urina, por exemplo) ou homogeneizado de tecidos. Para amostras séricas ou plasmáticas, esta etapa não é necessária. Para solução de lavagem, dilui-se $10 \mathrm{ml}$ 
de concentrado de solução de lavagem (100x) com $990 \mathrm{ml}$ de água destilada para preparação de 1 litro de wash solution.

Inicia-se o experimento, fixando-se o número desejado de cavidades no suporte e em seguida, adiciona-se $100 \mu \mathrm{l}$ de padrões ou de amostras para o poço apropriado do anticorpo na microplaca pré-revestida. Adiciona-se $50 \mu \mathrm{l}$ de conjugado a cada poço, misturando-se bem a solução e após cobre-se a placa e incuba-se a mesma durante 1 hora a $37^{\circ} \mathrm{C}$. Lava-se a placa subsequentemente. Adiciona-se $50 \mu 1$ de substrato A e $50 \mu 1$ de substrato B a cada poço. Adiciona-se $50 \mu 1$ de solução de parada em cada poço. Lê-se a densidade óptica a $450 \mathrm{~nm}$ utilizando-se espectrofotômetro.

\section{Para dosagem da creatinina sérica e urinária dos ratos e posteriormente} cálculo do clearance de creatinina: foi utilizado kit de creatinina da empresa Labtest Diagnóstica SA (Lagoa Santa, MG, Brasil). A mensuração da creatinina urinária e sérica foram realizadas por método de Jaffé e realizado conforme manual do fabricante.

\subsection{ANÁLISE ESTATÍSTICA}

Os dados foram tabulados, correlacionando-se os valores quantitativos individuais de TGF $ß 1$ e de CA 19-9 com os resultados obtidos nos estudos anatomopatológicos renais, em cada grupo de ratos.

Inicialmente foi realizada uma análise descritiva dos dados de acordo com o grupo onde as variáveis qualitativas foram descritas como número e porcentagem e as quantitativas como média \pm desvio padrão e testes paramétricos ou não paramétricos foram aplicados de acordo com a distribuição de normalidade das variáveis. 
Os valores das médias de peso renal, tamanho renal, diâmetro do ureter, diâmetro da pelve renal e espessura do córtex renal foram comparados entre as unidades renais nos grupos do estudo pelo teste de Kruskal-Wallis, exceto para a comparação do tamanho renal realizada por ANOVA.

A comparação entre as médias dos grupos do estudo para os marcadores séricos e urinários TGF $ß 1$ foi feita por teste de Kruskal-Wallis e do CA 19-9 foi feita por análise de variância múltipla ANOVA (Altman, 1991; Singer, 2000). O teste ANOVA foi realizado também para comparação entre os valores de creatinina sérica, creatinina urinária, volume urinado em 24 horas e clearance de creatinina.

Foi feita análise das médias dos valores deséricos e urinários TGF ß1 e de CA 19-9, comparando-se os ratos obstruídos (grupos 4,5, 6 e 7) aos não obstruídos (grupos 1,2 e 3) pelo teste "t" de Student. Foi feita comparação do mesmo modo utilizando teste ANOVA, da influência da obstrução completa (grupo 4), obstrução parcial (grupos 5,6 e 7) aos ratos não obstruídos, para estes marcadores supracitados.

Com o objetivo de avaliar o comportamento qualitativo da expressão imunohistoquímica de CA 19-9, as proporções foram comparadas entre as unidades renais com obstrução completa, parcial e sem obstrução pelo teste de chi-quadrado.

A influência do tempo (tempo zero, 14 dias e 28 dias após procedimento inicial) na expressão dos marcadores principais do estudo TGF ß1 e de CA 19-9 foi avaliada pelo teste ANOVA.

Toda análise estatística foi realizada no software estatístico SPSS 19.0 for Windows (SPSS Inc.).

Todos os testes estatísticos realizados foram bi-caudais e um p-valor menor do que 0,05 foi considerado para indicar significância estatística. 
4.RESULTADOS 


\subsection{ANÁLISE DOS RISCOS}

Quarenta e cinco ratos foram utilizados em nosso trabalho experimental. Somente dois ratos foram excluídos do estudo, um por óbito logo após procedimento (relacionado à intercorrência anestésica) e outro rato do grupo 6 foi excluído do estudo, porque o azul de metileno não progrediu (a obstrução ureteral que deveria ser parcial, tornou-se completa; portanto, o animal foi eliminado da pesquisa). Nenhum dos ratos apresentou outras complicações pós-operatórias como deiscência ou infecção da ferida, íleo paralítico, sangramentos, lesões inadvertidas de outros órgãos.

\subsection{ESTUDO ANATOMOPATOLÓGICO DO RIM E URETER}

Os grupos de estudo (1-7) foram comparados quanto peso renal (em gramas), tamanho longitudinal do rim (em centímetros), diâmetro dos ureteres (em milímetros) e das pelves renais (em milímetros) e espessura cortical renal (em milímetros).

Pela comparação dos grupos do estudo, observamos que o grau de obstrução leva a achados anatomopatológicos mais graves com correlação da intensidade da obstrução ureteral com a severidade do hidroureter e da hidronefrose, aumento do tamanho e peso renal e atrofia do córtex renal, conforme demonstrado nas Tabelas 1 e 2 e nas figuras 13-16. 
Tabela 1 - Valores dos achados anatomopatológicos do rim esquerdo (expressos em média \pm desvio-padrão)

\begin{tabular}{|c|c|c|c|c|c|}
\hline Grupo do estudo & $\begin{array}{l}\text { Peso renal } \\
\text { (g.) }\end{array}$ & $\begin{array}{c}\text { Tamanho } \\
\text { longitudinal } \\
\text { rim (cm.) }\end{array}$ & $\begin{array}{c}\text { Diâmetro } \\
\text { ureteral } \\
(\mathrm{mm} .)\end{array}$ & $\begin{array}{c}\text { Diâmetro } \\
\text { pelve renal } \\
(\mathbf{m m} .)\end{array}$ & $\begin{array}{c}\text { Espessura } \\
\text { do córtex } \\
\text { renal (mm.) }\end{array}$ \\
\hline $\begin{array}{c}\text { Grupo } 1 \\
\text { (controle) }\end{array}$ & $1,28 \pm 0,21$ & $1,93 \pm 0,16$ & $3,67 \pm 0,51$ & $4,67 \pm 0,51$ & $3,28 \pm 0,18$ \\
\hline $\begin{array}{c}\text { Grupo } 2 \\
\text { (sham) }\end{array}$ & $1,52 \pm 0,29$ & $2,0 \pm 0,08$ & $3,83 \pm 0,41$ & $4,83 \pm 0,4$ & $3,2 \pm 0,6$ \\
\hline $\begin{array}{c}\text { Grupo } 3 \\
\text { (Nx. unilateral) }\end{array}$ & $1,32 \pm 0,14$ & $1,95 \pm 0,1$ & $3,83 \pm 0,41$ & $4,83 \pm 0,4$ & $3,16 \pm 0,18$ \\
\hline $\begin{array}{l}\text { Grupo } 4 \\
\text { (CUUO) }\end{array}$ & $8,55 \pm 2,14^{*}$ & $3,0 \pm 0,12^{*}$ & $11,1 \pm 2,8^{*}$ & $14,0 \pm 2,0^{*}$ & $1,38 \pm 0,43^{*}$ \\
\hline $\begin{array}{l}\text { Grupo } 5 \\
\text { (PUUO) }\end{array}$ & $1,78 \pm 0,29$ & $2,4 \pm 0,1^{*}$ & $5,6 \pm 0,81 *$ & $6,83 \pm 0,98 *$ & $2,3 \pm 0,32 *$ \\
\hline $\begin{array}{l}\text { Grupo } 6 \\
\text { (BPUO) }\end{array}$ & $2,0 \pm 0,57$ & $2,32 \pm 0,12^{*}$ & $6,0 \pm 0,82 *$ & $7,14 \pm 0,69 *$ & $2,44 \pm 0,37^{*}$ \\
\hline $\begin{array}{c}\text { Grupo } 7 \\
\text { (PUUO rim } \\
\text { único) }\end{array}$ & $1,36 \pm 0,8$ & $1,93 \pm 0,81$ & $3,83 \pm 0,4$ & $4,83 \pm 0,4$ & $3,0 \pm 0,12$ \\
\hline Valor de $p$ & $<0,0001$ & $<0,0001$ & $<0,0001$ & $<0,0001$ & $<0,0001$ \\
\hline
\end{tabular}


Tabela 2 -Valores dos achados anatomopatológicos do rim direito (expressos em média \pm desvio-padrão)

\begin{tabular}{|c|c|c|c|c|c|}
\hline Grupo do estudo & $\begin{array}{l}\text { Peso renal } \\
\text { (g.) }\end{array}$ & $\begin{array}{c}\text { Tamanho } \\
\text { longitudinal } \\
\text { rim (cm.) }\end{array}$ & $\begin{array}{c}\text { Diâmetro } \\
\text { ureteral } \\
(\mathrm{mm} .)\end{array}$ & $\begin{array}{l}\text { Diâmetro } \\
\text { pelve renal } \\
(\mathrm{mm} .)\end{array}$ & $\begin{array}{l}\text { Espessura } \\
\text { do córtex } \\
\text { renal }(\mathbf{m m} .)\end{array}$ \\
\hline $\begin{array}{c}\text { Grupo 1 } \\
\text { (controle) }\end{array}$ & $1,31 \pm 0,11$ & $1,91 \pm 0,11$ & $3,83 \pm 0,4$ & $5 \pm 0$ & $3,21 \pm 0,9$ \\
\hline $\begin{array}{c}\text { Grupo } 2 \\
\text { (sham) }\end{array}$ & $1,53 \pm 0,25$ & $2,01 \pm 0,07$ & $3,67 \pm 0,51$ & $4,83 \pm 0,4$ & $3,2 \pm 0,12$ \\
\hline $\begin{array}{c}\text { Grupo } 3 \\
\text { (Nx. unilateral) }\end{array}$ & $1,48 \pm 0,20$ & $2,33 \pm 0,12 *$ & $4 \pm 0$ & $5 \pm 0$ & $3,7 \pm 0,12 *$ \\
\hline $\begin{array}{l}\text { Grupo } 4 \\
\text { (CUUO) }\end{array}$ & $1,90 \pm 0,25^{*}$ & $2,16 \pm 0,5^{*}$ & $3,67 \pm 0,5$ & $4,67 \pm 0,51$ & $3,3 \pm 0,21$ \\
\hline $\begin{array}{l}\text { Grupo } 5 \\
\text { (PUUO) }\end{array}$ & $1,56 \pm 0,19$ & $2,03 \pm 0,1$ & $3,83 \pm 0,4$ & $4,83 \pm 0,4$ & $3,1 \pm 0,16$ \\
\hline $\begin{array}{l}\text { Grupo } 6 \\
\text { (BPUO) }\end{array}$ & $1,90 \pm 0,32^{*}$ & $2,25 \pm 0,11^{*}$ & $5,86 \pm 0,37^{*}$ & $7 \pm 0 *$ & $2,38 \pm 0,35^{*}$ \\
\hline $\begin{array}{c}\text { Grupo } 7 \\
\text { (PUUO rim } \\
\text { único) }\end{array}$ & $2,18 \pm 0,45^{*}$ & $2,3 \pm 0,06^{*}$ & $5,33 \pm 0,81^{*}$ & $6,67 \pm 0,5^{*}$ & $2,78 \pm 0,9^{*}$ \\
\hline Valor de p & $<0,0001$ & $<0,0001$ & $<0,0001$ & $<0,0001$ & $<0,0001$ \\
\hline
\end{tabular}
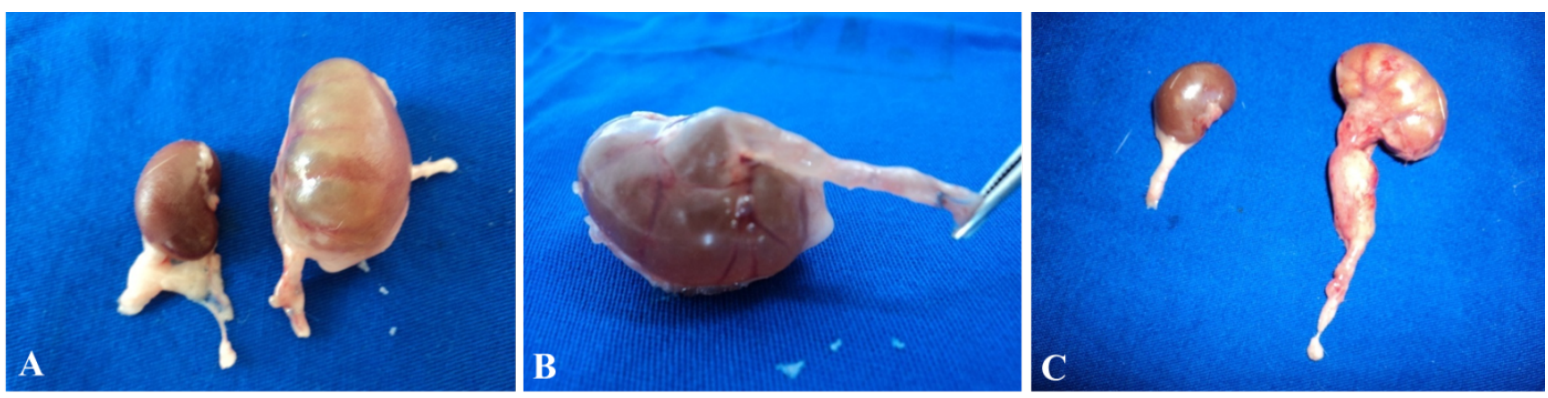

Figura 13 - CUUO: Obstrução ureteral unilateral completa. Aumento do tamanho longitudinal do rim obstruído em relação ao contralateral (A). Ureterohidronefrose importante com 14 dias (B) e com 28 dias (C) a partir do ponto de obstrução 


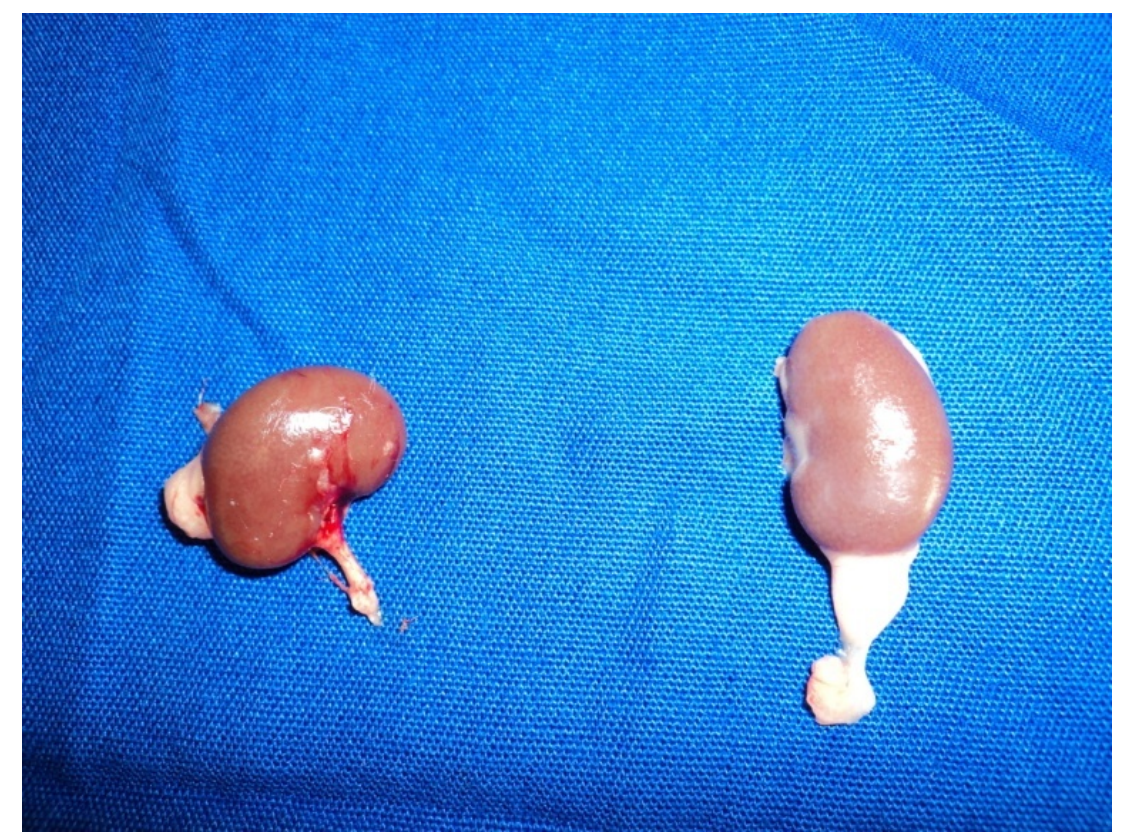

Figura 14 - PUUO: Obstrução ureteral unilateral parcial. Aumento do tamanho longitudinal renal e da ureterohidronefrose do rim obstruído em relação ao contralateral (normal)
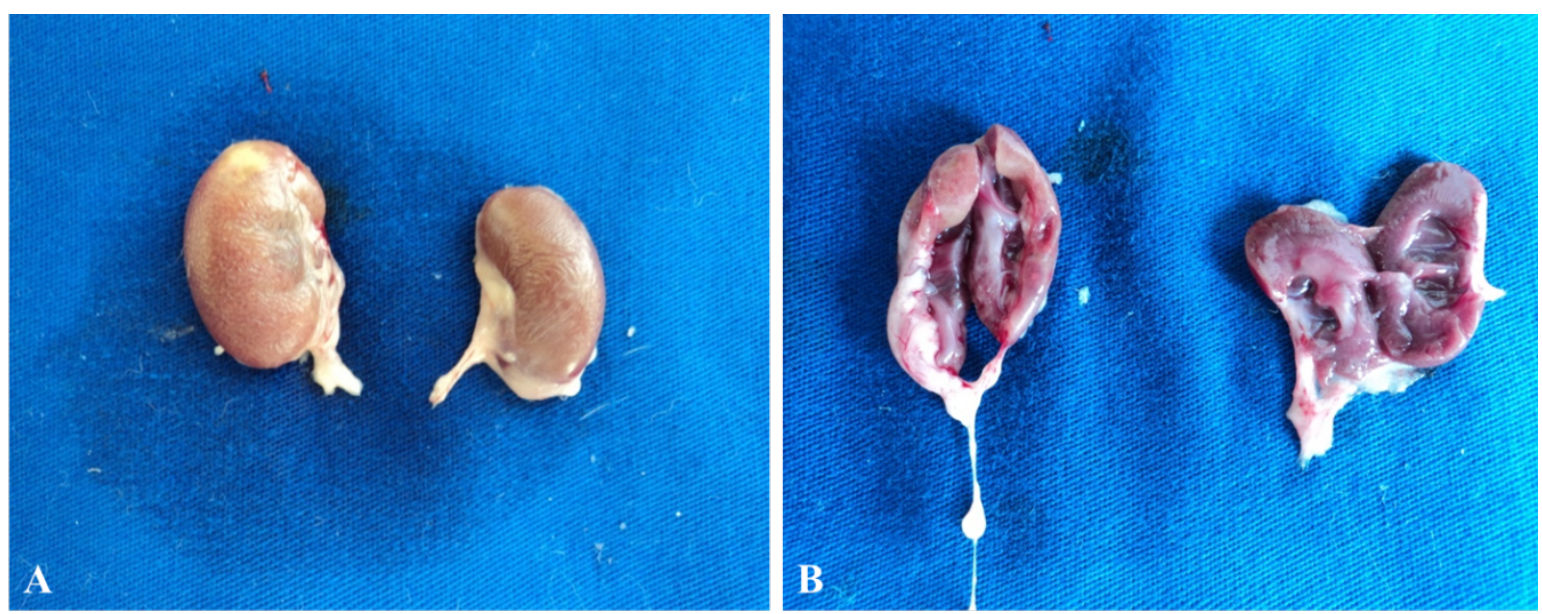

Figura 15 - BPUO: Obstrução ureteral parcial bilateral. Aumento do tamanho longitudinal renal (A) e diminuição do parênquima renal (B) 

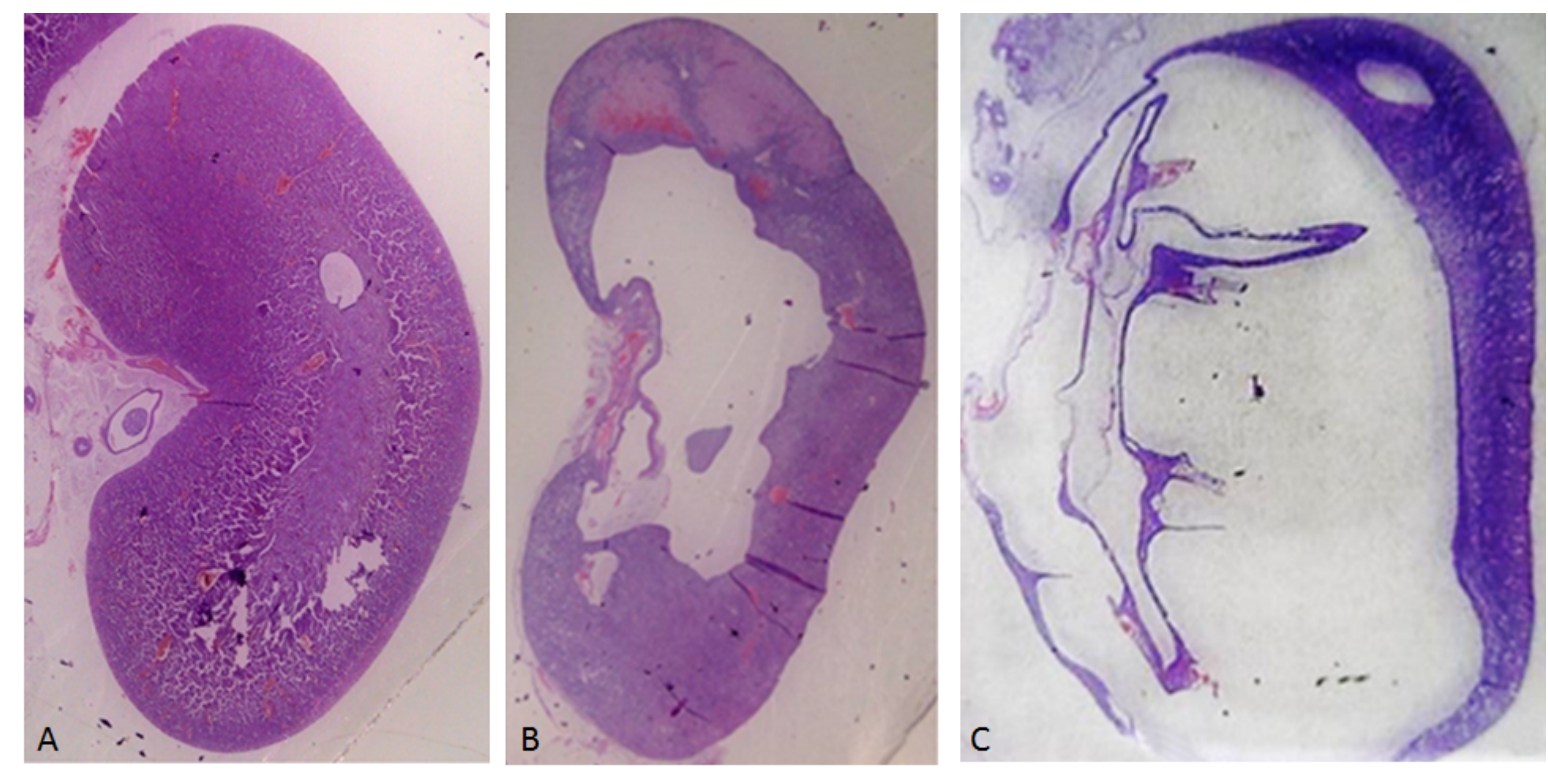

Figura 16 - Comparação de cortes histológicos de rins controle (A), com obstrução parcial (B) e com obstrução completa (C)

\subsection{ANÁLISE LABORATORIAL}

A comparação entre as médias dos grupos do estudo para creatinina sérica, creatinina urinária, volume urinado em 24 horas, clearance de creatinina e para os marcadores séricos e urinários TGF ß1 e CA 19-9 foi realizada. Não foram encontradas diferenças estatisticamente significativas entre os grupos do estudo para o clearance de creatinina, concentração sérica de TGF $\beta 1$, concentração urinária deTGF $\beta 1$, concentração sérica de CA 19-9 e concentração urinária de CA 19-9 (valor de p não apresentou diferença significativa entre os grupos). Os resultados estão resumidos nas Tabelas 3 e 4 e representados nas figuras 17 e 18 : 
Tabela 3 - Valores da creatinina sérica, creatinina urinária, volume minuto e do clearance de creatinina (expressos em média \pm desvio-padrão)

\begin{tabular}{ccccc}
\hline Grupo do estudo & $\begin{array}{c}\text { Cr sérica } \\
(\mathbf{m g} / \mathbf{d l})\end{array}$ & $\begin{array}{c}\text { Cr urinária } \\
(\mathbf{m g} / \mathbf{d l})\end{array}$ & $\begin{array}{c}\text { Volume minuto } \\
(\mathbf{m l} / \mathbf{m i n})\end{array}$ & $\begin{array}{c}\text { Clearance de } \\
\text { creatinina } \\
(\mathbf{m l} / \mathbf{m i n} / \mathbf{1 0 0 g} \text { rato })\end{array}$ \\
\hline $\begin{array}{c}\text { Grupo 1 } \\
\text { (controle) }\end{array}$ & $0,64 \pm 0,05$ & $64,2 \pm 12,3$ & $0,0128 \pm 0,003$ & $0,5 \pm 0,1$ \\
\hline $\begin{array}{c}\text { Grupo 2 } \\
\text { (sham) }\end{array}$ & $0,78 \pm 0,23$ & $98,6 \pm 20,5$ & $0,0123 \pm 0,003$ & $0,58 \pm 0,2$ \\
$\begin{array}{c}\text { Grupo 3 } \\
\text { (Nx. unilateral) }\end{array}$ & $0,71 \pm 0,15$ & $60,1 \pm 13,2$ & $0,0127 \pm 0,004$ & $0,43 \pm 0,06$ \\
$\begin{array}{c}\text { Grupo 4 } \\
\text { (CUUO) }\end{array}$ & $0,65 \pm 0,16$ & $75,5 \pm 24,4$ & $0,0124 \pm 0,0025$ & $0,56 \pm 0,2$ \\
$\begin{array}{c}\text { Grupo 5 } \\
\text { (PUUO) }\end{array}$ & $0,63 \pm 0,07$ & $59,8 \pm 22,1$ & $0,0136 \pm 0,0027$ & $0,51 \pm 0,1$ \\
$\quad \begin{array}{c}\text { Grupo 6 } \\
\text { (BPUO) }\end{array}$ & $0,65 \pm 0,08$ & $64,4 \pm 22,7$ & $0,014 \pm 0,005$ & $0,56 \pm 0,1$ \\
\hline $\begin{array}{c}\text { Grupo 7 } \\
\text { (PUUO rim único) }\end{array}$ & $0,72 \pm 0,05$ & $72,0 \pm 13,2$ & $0,0125 \pm 0,003$ & $0,48 \pm 0,1$ \\
\hline Valor de p & 0,436 & 0,025 & 0,3 & 0,6 \\
\hline
\end{tabular}


Tabela 4 - Valores das concentrações séricas e urinárias dos marcadores estudados (expressos em média \pm desvio-padrão)

\begin{tabular}{|c|c|c|c|c|}
\hline $\begin{array}{l}\text { Grupo do } \\
\text { estudo }\end{array}$ & $\begin{array}{l}\text { TGF ß1 sérico } \\
(\mathrm{pg} / \mathrm{ml})\end{array}$ & $\begin{array}{c}\text { TGF B1 urinário } \\
(\mathrm{pg} / \mathrm{ml})\end{array}$ & $\begin{array}{c}\text { CA 19-9 } \\
\text { sérico } \\
(\mathrm{U} / \mathrm{ml}) \\
\end{array}$ & $\begin{array}{c}\text { CA 19-9 } \\
\text { urinário } \\
(\mathrm{U} / \mathrm{ml})\end{array}$ \\
\hline $\begin{array}{c}\text { Grupo 1 } \\
\text { (controle) }\end{array}$ & $\begin{array}{l}\mathbf{3 0 . 9 6 9 , 0 1} \pm \mathbf{1 6 . 8 5 4 , 9 8} \\
(11.085,75-51.853,8)\end{array}$ & $\begin{array}{l}\mathbf{2 9 , 7 9} \pm \mathbf{1 6 , 4 1} \\
(10,46-53,56)\end{array}$ & $\begin{array}{l}\mathbf{1 , 6 1} \pm \mathbf{0 , 1 6} \\
(1,38-1,79)\end{array}$ & $\begin{array}{l}\mathbf{1 , 0 4} \pm \mathbf{0 , 1 4} \\
(0,83-1,19)\end{array}$ \\
\hline $\begin{array}{c}\text { Grupo } 2 \\
\text { (sham) }\end{array}$ & $\begin{array}{c}\mathbf{2 9 . 6 7 5 , 7 9} \pm \mathbf{1 4 . 0 4 5 , 5 4} \\
(11.084,25-53.632,02)\end{array}$ & $\begin{array}{c}\mathbf{4 2 , 5 7} \pm \mathbf{1 9 , 5 5} \\
(10,46-58,23)\end{array}$ & $\begin{array}{l}\mathbf{1 , 4 4} \pm \mathbf{0 , 2 5} \\
(1,18-1,73)\end{array}$ & $\begin{array}{c}\mathbf{1 , 0 0} \pm \mathbf{0 , 1 1} \\
(0,86-1,16)\end{array}$ \\
\hline $\begin{array}{c}\text { Grupo } 3 \\
\text { (Nx.unilateral) }\end{array}$ & $\begin{array}{c}\mathbf{3 6 . 9 6 0 , 6 1} \pm \mathbf{1 4 . 6 6 8 , 2 3} \\
(15.642,53-60.276,87)\end{array}$ & $\begin{array}{l}\mathbf{8 0 , 3 3} \pm \mathbf{1 1 0 , 0 3} \\
(26,06-304,5)\end{array}$ & $\begin{array}{c}\mathbf{1 , 3 0} \pm \mathbf{0 , 2 9} \\
(0,99-1,72)\end{array}$ & $\begin{array}{l}\mathbf{1 , 0 9} \pm \mathbf{0 , 1 6} \\
(0,92-1,33)\end{array}$ \\
\hline $\begin{array}{l}\text { Grupo } 4 \\
\text { (CUUO) }\end{array}$ & $\begin{array}{c}\mathbf{3 0 . 8 0 0 , 0 9} \pm \mathbf{8 . 8 3 5 , 5 6} \\
(16.017,04-40.841,35)\end{array}$ & $\begin{array}{c}\mathbf{6 0 , 9 4} \pm \mathbf{4 3 , 8 4} \\
(32,24-149,38)\end{array}$ & $\begin{array}{c}\mathbf{1 , 3 5} \pm \mathbf{0 , 3 1} \\
(0,86-1,74)\end{array}$ & $\begin{array}{l}\mathbf{0 , 9 3} \pm \mathbf{0 , 0 7} \\
(0,81-1,03)\end{array}$ \\
\hline $\begin{array}{l}\text { Grupo } 5 \\
\text { (PUUO) }\end{array}$ & $\begin{array}{c}\mathbf{4 2 . 2 4 9 , 4 1} \pm \mathbf{1 2 . 8 2 3 , 6 2} \\
(27.259,15-55.759,41)\end{array}$ & $\begin{array}{c}\mathbf{5 4 , 0 3} \pm \mathbf{7 7 , 0} \\
(10,46-210,41)\end{array}$ & $\begin{array}{c}\mathbf{1 , 4 3} \pm \mathbf{0 , 2 0} \\
(1,18-1,72)\end{array}$ & $\begin{array}{l}\mathbf{0 , 9 4} \pm \mathbf{0 , 1 4 9} \\
(0,74-1,10)\end{array}$ \\
\hline $\begin{array}{l}\text { Grupo } 6 \\
\text { (BPUO) }\end{array}$ & $\begin{array}{c}\mathbf{2 9 . 8 1 2 , 2 1} \pm \mathbf{1 4 . 0 9 5 , 8 1} \\
(11.859,71-46.798,47)\end{array}$ & $\begin{array}{c}\mathbf{5 6 , 4 6} \pm \mathbf{2 9 , 7} \\
(19,44-105,77)\end{array}$ & $\begin{array}{c}\mathbf{1 , 4 1} \pm \mathbf{0 , 8 8} \\
(1,27-1,54)\end{array}$ & $\begin{array}{l}\mathbf{1 , 0 1} \pm \mathbf{0 , 1 1} \\
(0,90-1,21)\end{array}$ \\
\hline $\begin{array}{c}\text { Grupo } 7 \\
\text { (PUUO rim } \\
\text { único) }\end{array}$ & $\begin{array}{c}\mathbf{3 1 . 5 0 7 , 3 9} \pm \mathbf{7 . 2 2 0 , 4 0} \\
(24.525,91-40.443,37)\end{array}$ & $\begin{array}{c}\mathbf{2 9 , 6 7} \pm \mathbf{1 0 , 9 1} \\
(19,44-48,65)\end{array}$ & $\begin{array}{l}\mathbf{1 , 5 1} \pm \mathbf{0 , 2 8} \\
(1,12-1,90)\end{array}$ & $\begin{array}{l}\mathbf{0 , 9 4} \pm \mathbf{0 , 0 8} \\
(0,79-1,04)\end{array}$ \\
\hline Valor de p & 0,582 & 0,687 & 0,366 & 0,267 \\
\hline
\end{tabular}



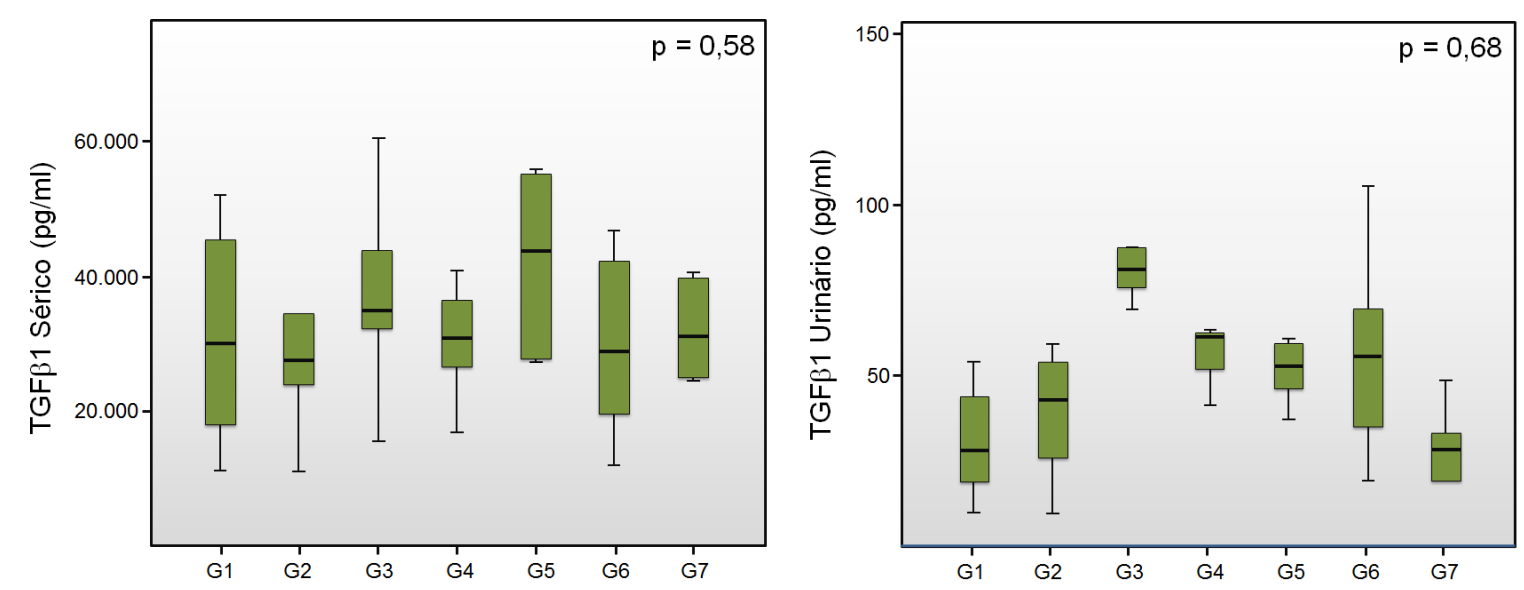

Figura 17 - Gráficos em boxplot comparando as concentrações séricas e urinárias de TGF $ß 1$ nos sete grupos do estudo
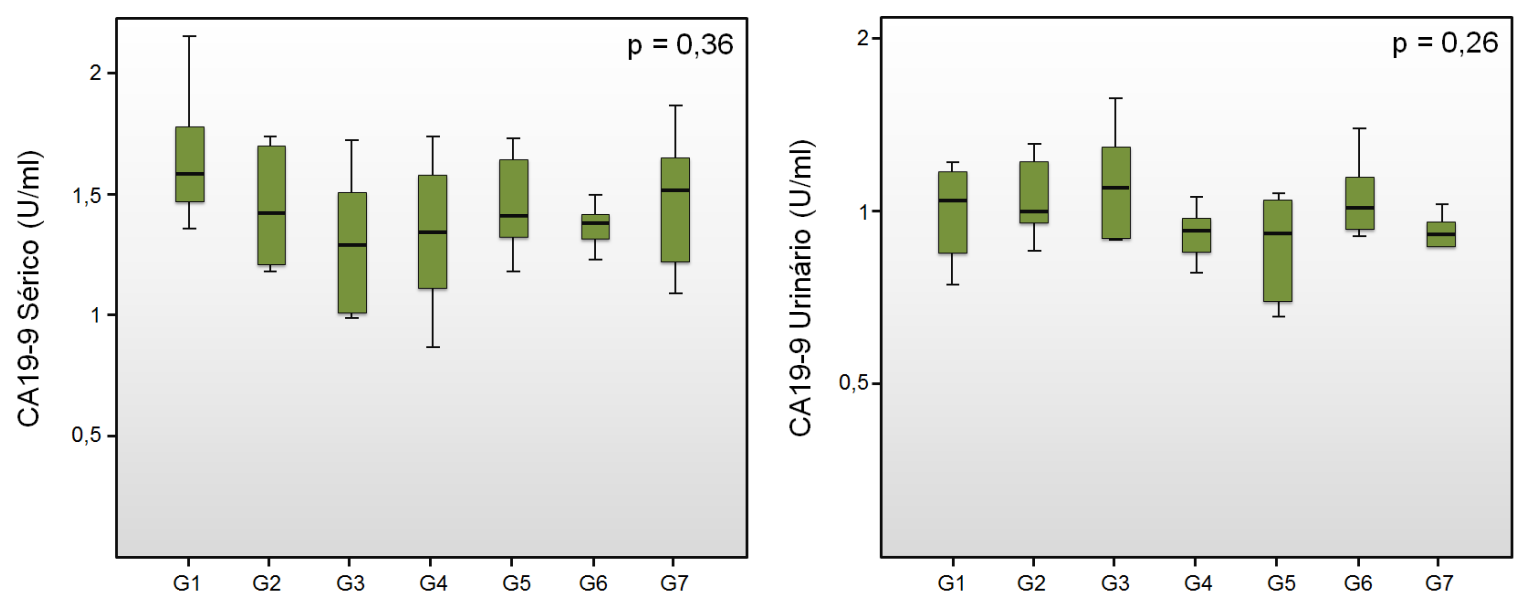

Figura 18 -Gráficos em boxplot comparando as concentrações séricas e urinárias de CA 19-9 nos sete grupos do estudo 
Na comparação dos ratos com uropatia obstrutiva (grupos 4, 5, 6 e 7, com n=25) com ratos não obstruídos (grupos 1, 2 e 3 , com $n=18$ ), foi verificada redução estatisticamente significativa da concentração do CA 19-9 urinário, representada na Figura 19, comparadas as médias ( \pm desvio padrão) de $0,96 \pm 0,10 \mathrm{U} / \mathrm{ml}$ do grupo obstruído com $1,04 \pm 0,13 \mathrm{U} / \mathrm{ml}$ do grupo não obstruído, com valor de $\mathrm{p}=0,028$. A mesma comparação (média \pm desvio padrão) foi realizada entre estes grupos para as concentrações de TGF $ß 1$ sérico $(33.441,07 \pm 11.703,57 \mathrm{pg} / \mathrm{ml}$ do grupo obstruído vs $32.535,13 \pm 14.680,72 \mathrm{pg} / \mathrm{ml}$ do grupo não obstruído, com $p=0,823)$, concentrações de TGF $ß 1$ urinário $(50,52 \pm 45,0$ $\mathrm{pg} / \mathrm{ml}$ do grupo obstruído vs $50,9 \pm 65,11 \mathrm{pg} / \mathrm{ml}$ do grupo não obstruído, com $\mathrm{p}=0,982$ ) e concentrações do CA 19-9 sérico $(1,43 \pm 0,22 \mathrm{U} / \mathrm{ml}$ do grupo obstruído vs 1,34 \pm 0,27 U/ml do grupo não obstruído, com $p=0,272$ ) e não foram encontradas diferenças estatísticas.

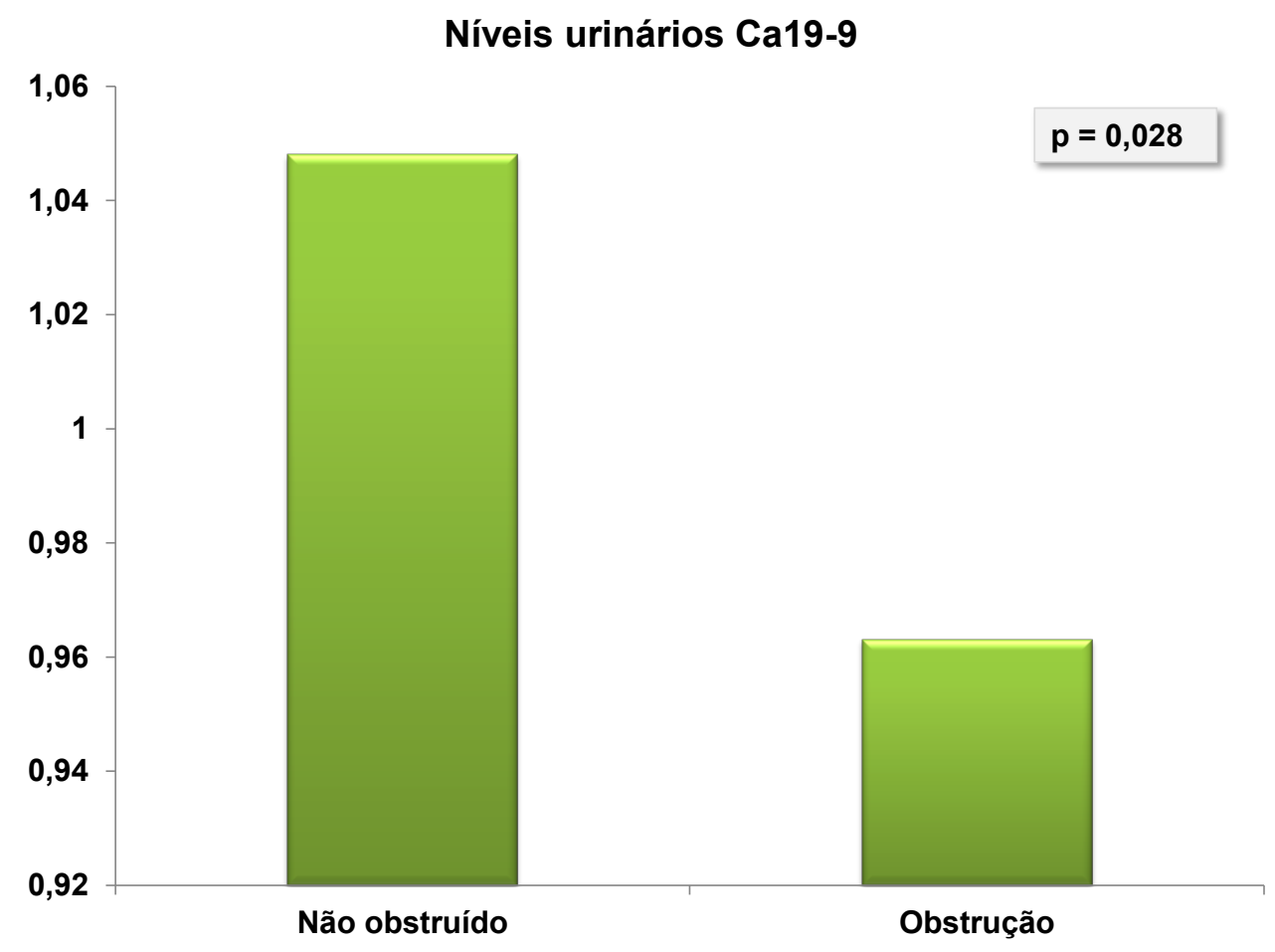

Figura 19 - Comparação dos ratos com obstrução $(n=25)$ com ratos não obstruídos $(n=18)$ 
Na comparação da influência da obstrução completa (grupo 4, com n=6), obstrução parcial (grupos 5, 6 e 7, com n=19) aos ratos não obstruídos (grupos 1, 2 e 3, com n=18) na concentração sérica e urinária doTGF $\beta 1$ e de CA 19-9, foi notada tendência de decréscimo progressivo do CA 19-9 urinário com a severidade da obstrução ureteral (Figura 20). As médias ( \pm desvio padrão) dos grupos de ratos não obstruídos, com obstrução parcial e com obstrução completa foram de $1,04 \pm 0,13 \mathrm{U} / \mathrm{ml}, 0,97 \pm 0,11 \mathrm{U} / \mathrm{ml}$ e $0,93 \pm 0,07 \mathrm{U} / \mathrm{ml}$, respectivamente, com $\mathrm{p}=0,073$ [com $\mathrm{p}=0,067$, comparando-se somente o grupo não obstrutivo $(n=18)$ com o grupo de obstrução parcial $(n=19)$ e $p=0,051$, comparando-se somente o grupo não obstrutivo $(n=18)$ com o grupo de obstrução completa $(n=6)]$. A mesma comparação (média \pm desvio padrão) foi realizada entre estes grupos para as concentrações de TGF $ß 1$ sérico $(30.800,09 \pm 8.835,56$ pg/ml do grupo com obstrução completa vs $34.275,06 \pm 12.565,31 \mathrm{pg} / \mathrm{ml}$ do grupo com obstrução parcial vs $32.535,13 \pm$ 14.680,72 pg/ml do grupo não obstruído, com $\mathrm{p}=0,832)$, concentrações de TGF $ß 1$ urinário $(60,94 \pm 43,84$ pg/ml do grupo com obstrução completa vs 47,23 \pm 46,14 pg/ml do grupo com obstrução parcial vs 50,9 $\pm 65,1$ pg/ml do grupo não obstruído, com p = 0,867) e concentrações do CA 19-9 sérico $(1,35 \pm 0,316 \mathrm{U} / \mathrm{ml}$ do grupo com obstrução completa vs $1,45 \pm 0,19 \mathrm{U} / \mathrm{ml}$ do grupo com obstrução parcial vs $1,34 \pm 0,27 \mathrm{U} / \mathrm{ml}$ do grupo não obstruído, com $\mathrm{p}=0,377$ ) e não foram encontradas diferenças estatísticas. 


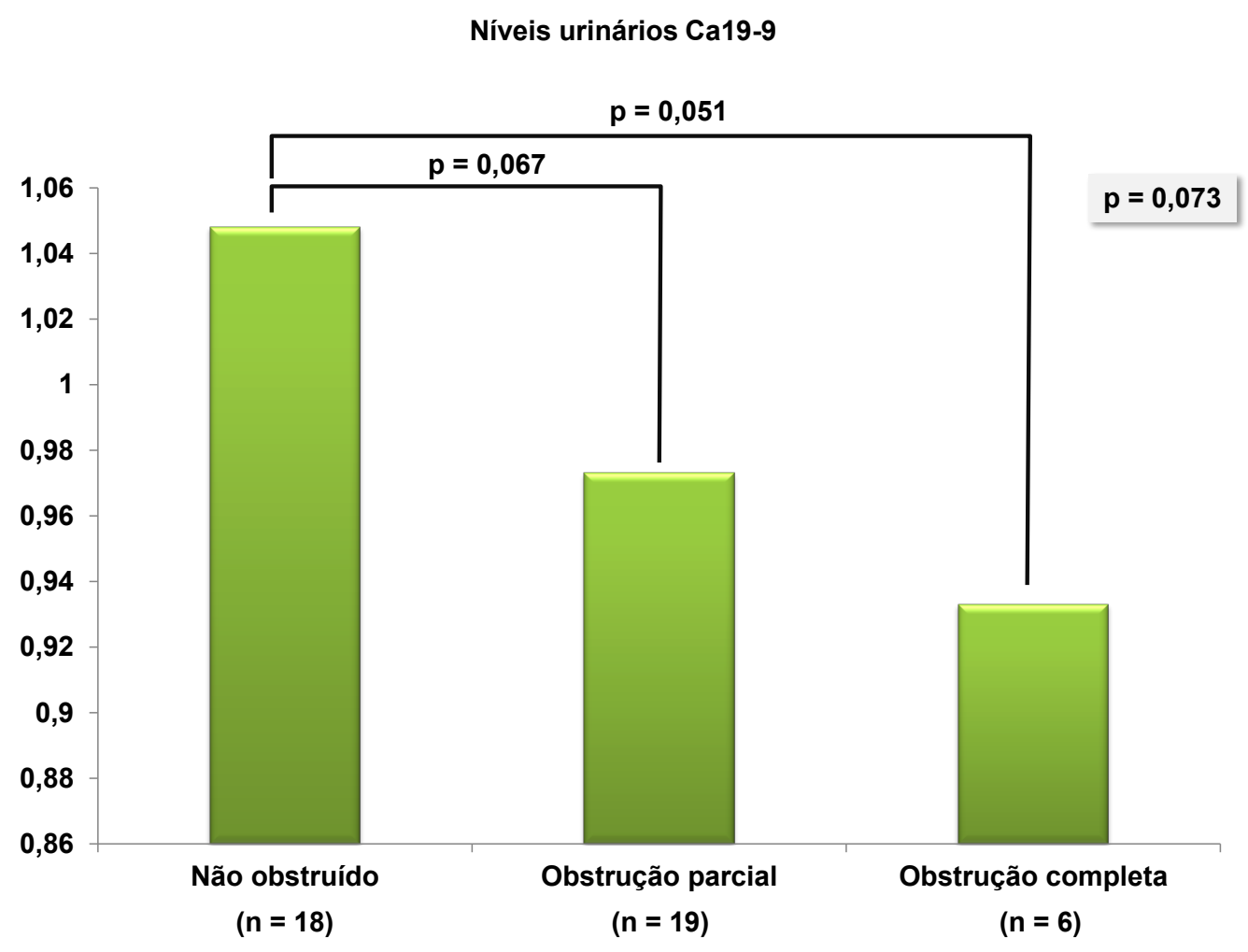

Figura 20 -Comparação dos ratos com obstrução completa (n=6) e obstrução parcial (n=19) com ratos não obstruídos ( $\mathrm{n}=18)$

O tempo de obstrução (obstrução por 14 ou 28 dias) não influenciou na concentração do TGF $\beta 1$ sérico $(\mathrm{p}=0,624)$, do TGF $\beta 1$ urinário $(\mathrm{p}=0,378)$, do CA 19-9 sérico $(\mathrm{p}=0,140)$ e do CA 19-9 urinário $(\mathrm{p}=0,604)$.

\subsection{ESTUDO IMUNO-HISTOQUÍMICO DO RIM E DO SISTEMA}

\section{COLETOR}

O estudo imuno-histoquímico com anticorpos anti-CA 19.9 das unidades renais revelou que houve subexpressão do CA 19-9 nas unidades renais com obstrução completa 
em relação aos rins não obstruídos e com obstrução parcial. Considerando as unidades renais separadamente em nosso estudo, seis unidades renais apresentavam obstrução completa, 26 unidades renais apresentavam obstrução parcial e 54 unidades renais não apresentavam obstrução. Não foi possível a leitura da expressão em um rim do grupo não obstrutivo, já que não houve aderência adequada do tecido renal nesta lâmina, resultando em 53 unidades renais no grupo não obstrutivo. Houve subexpressão nas unidades renais com obstrução completa $(\mathrm{n}=6)$, que foi de $16,7 \%(1 / 6)$ em relação às unidades renais com obstrução parcial $(n=26)$ que apresentaram 69,2\% $(18 / 26)$ de positividade do CA 19-9 e em relação às unidades renais sem obstrução $(n=53)$ que apresentaram $67,9 \%(36 / 53)$ de expressão positiva deste marcador. Utilizando-se o teste chi-quadrado, a expressão qualitativa do CA 19-9 variou significativamente entre os grupos (Figura 21).

\section{Unidade renal Ca19-9}

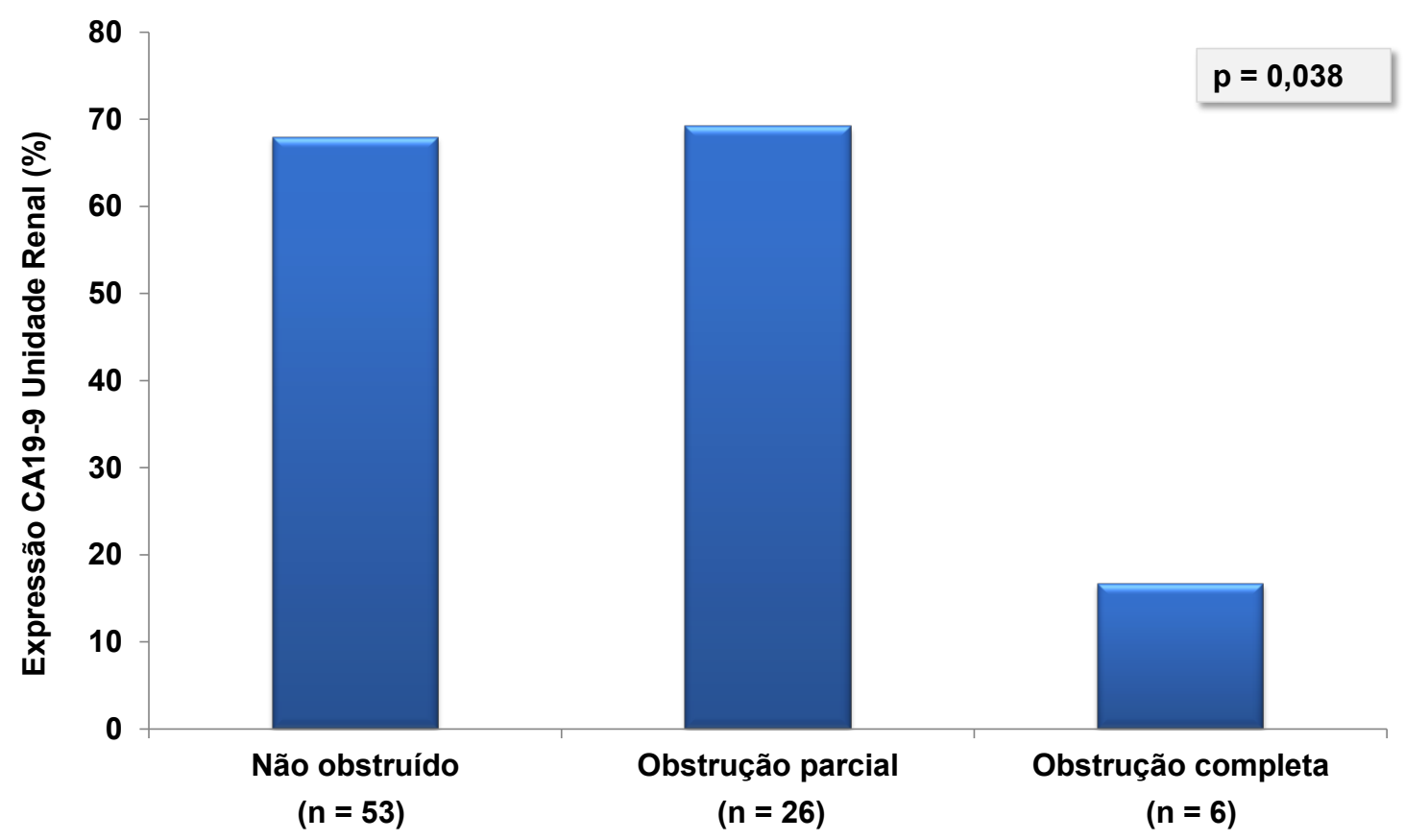

Figura 21 -Expressão do CA 19-9 em unidades renais não obstruídas, com obstrução parcial e com obstrução completa 
A localização da imunoexpressão do CA 19-9 foi semelhante em todos os grupos, havendo expressão do antígeno no citoplasma das células epiteliais tubulares, principalmente proximais e houve expressão em menor intensidade nos dutos coletores (Figuras 22 e 23). Não houve expressão urotelial ou endotelial de CA 19-9.
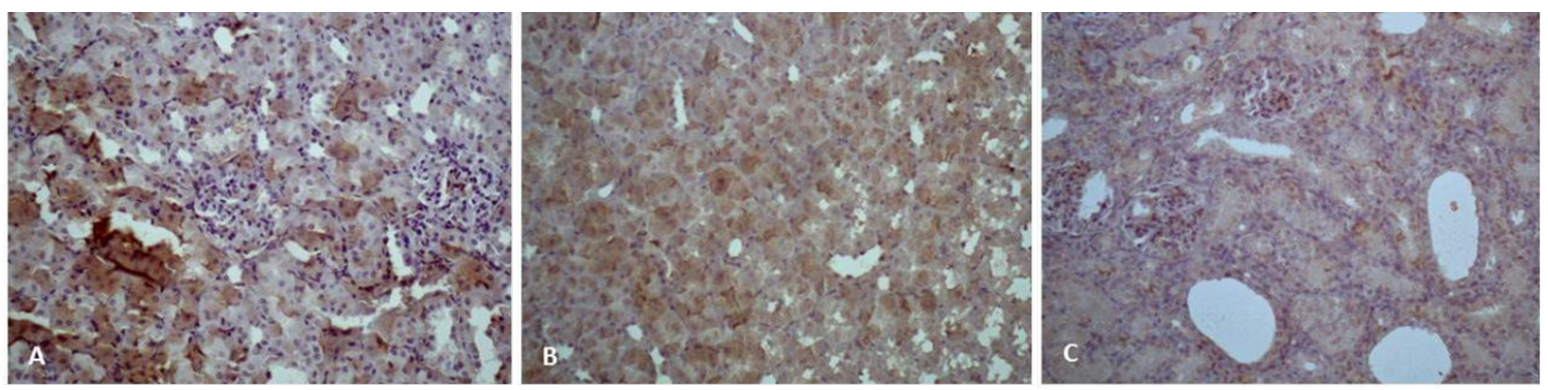

Figura 22 - Fotomicrografia exemplificando a expressão de CA 19-9 no citoplasma de células epiteliais tubulares (cor amarronzada) dos grupos 1 (A), 2 (B) e 3 (C); Imunohistoquímica $100 \mathrm{X}$
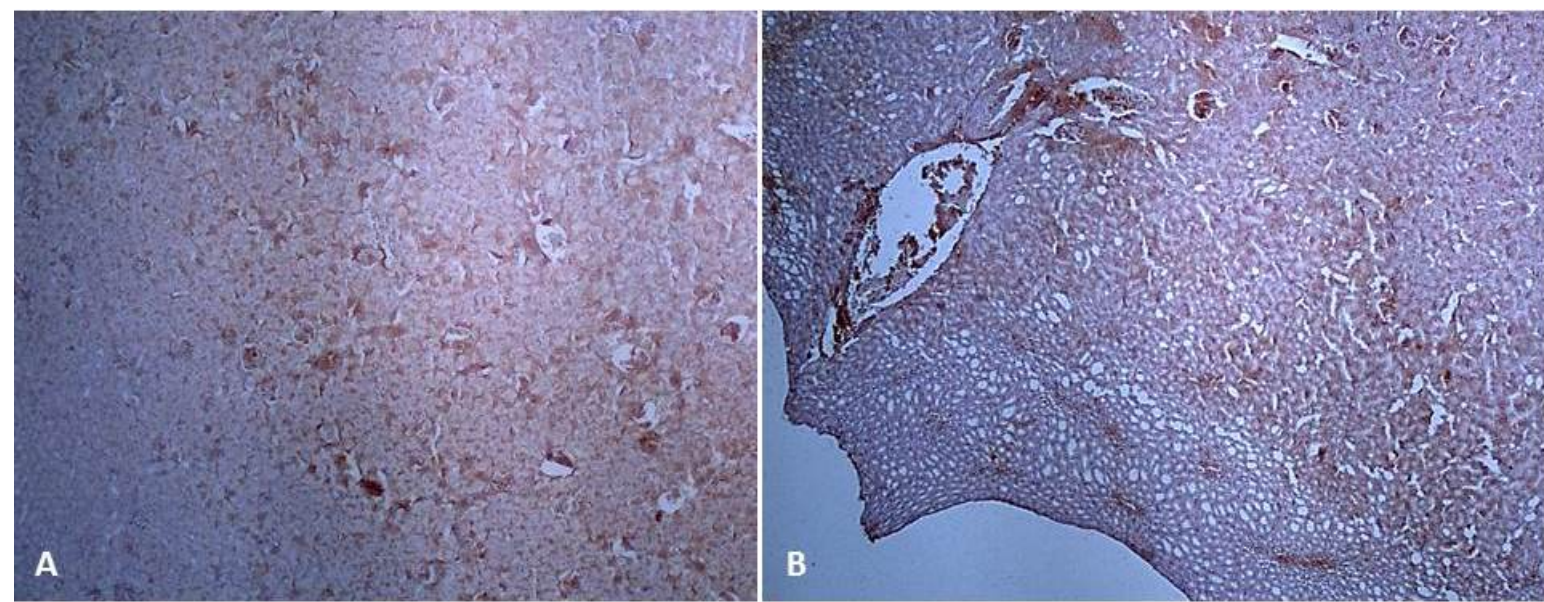

Figura 23 - Fotomicrografia exemplificando a expressão de CA 19-9 no citoplasma de células tubulares renais em rins de ratos do grupo 5 à direita (A) e à esquerda (B). Imunohistoquímica $40 \mathrm{X}$ 
5.DISCUSSÃO 
A maior parte do conhecimento acumulado sobre uropatia obstrutiva na literatura provém de estudos experimentais usando uma variedade de modelos animais. Enquanto o modelo de obstrução completa é mais fácil de ser reproduzido a partir de ligadura completa do ureter, diversos modelos de obstrução ureteral parcial foram criados com o objetivo de simular esse tipo de obstrução, mais comum na prática clínica. Muitas espécies animais foram utilizadas em modelos de obstrução ureteral completa e parcial incluindo o rato (Chevalier et al., 1998; Yeh et al., 2011; Morsing et al., 1987; Guerin et al., 2008), coelho (Cheng et al., 1993), porco (Dissing et al., 2001; Eskild-Jensen., 2002), cão (Shokeir et al., 1995; Matsui et al., 1986; Harada et al., 1992; Ryan et al., 1987), ovelha e macaco (Wen et al., 2002), entre outros. A maioria desses modelos foi induzida após o nascimento, porém alguns modelos com uropatias obstrutivas congênitas foram utilizados (Miller et al., 2004; Ingraham et al., 2010). Modelos antenatais também foram criados para simular uropatias obstrutivas que se iniciam durante a nefrogênese ou em animais que apresentam nefrogênese incompleta após o nascimento (Wen et al., 2002).

Diversas técnicas foram utilizadas para criar obstrução parcial, desde a utilização de cateteres intra-ureterais diminuindo o lúmen ureteral (Shokeir et al., 1995; Matsui et al., 1986; Ryan et al., 1987), passando por técnicas de compressão extrínseca sobre tubos plásticos (Cheng et al., 1993), até finalmente o encompassamento de um segmento de ureter pelo músculo psoas, primeiramente descrita por Ulm e Miller em cães (Ulm et al., 1962) e aplicada posteriormente em porcos (Djurhuus et al., 1976; Dissing et al., 2001) e ratos (Josephson et al., 1982; Beharrie et al., 2004). Posteriormente, outros modelos de obstrução ureteral com embebição do ureter nesse túnel de músculo psoas foram adaptados para criar obstruções ureterais parciais de severidade variável de acordo com o tamanho do segmento ureteral envolvido por músculo. O quarto superior do ureter é envolvido para criar 
obstrução leve, enquanto os dois terços proximais são envolvidos para criar obstrução parcial severa (Wen et al., 1998; Wen et al., 2002). Em outro modelo de obstrução parcial variável, graus diferentes de obstrução (leve, moderada e grave) foram criados a partir de ligadura sobre jelcos de diferentes tamanhos (Thornhill et al., 2007) ou por ligaduras com compressão variada (Pettersson et al., 1984).

Outro motivo de controvérsia na criação de uropatia obstrutiva experimental é a seleção do modelo neonatal ou adulto. Na obstrução congênita, a obstrução desenvolve-se ao mesmo tempo em que o rim está em processo de formação, que cria um paradigma completamente diferente em relação à obstrução do rim maduro. Ao contrário dos humanos, que nascem com rins e trato urinário completamente desenvolvido, ratos e camundongos nascem com rins e trato urinário imaturos. Nos ratos, somente $10 \%$ dos néfrons está presente ao nascimento e a nefrogênese continua até o $14^{\circ}-18^{\circ}$ dia pós-natal e a formação de músculo liso na pelve renal começa após o nascimento e conclui-se no $10^{\circ}$ dia pós-natal (Chevalier et al., 1998; Thornhill et al., 2005). Obstrução ureteral unilateral nas primeiras 48 horas de vida do rato prejudica o desenvolvimento renal e atrasa a maturação renal (Chevalier et al., 1998). A vantagem do modelo neonatal seria a maior similaridade com patologias que acontecem intra-útero como a estenose de junção ureteropiélica, com a obstrução nos primeiros dias de vida do rato sendo similar ao segundo trimestre de gravidez no humano, visto que nesses períodos ocorre a maior parte da nefrogênese nessas espécies.

A obstrução unilateral em ratos neonatos mimetiza até certo ponto a uropatia obstrutiva no humano, já que o rim do rato é unipapilar e o crescimento renal pode ser prejudicado levando à displasia, de acordo com a duração e a severidade da obstrução (Wen et al., 2002). Chevalier et al., demonstraram que ratos neonatos submetidos a obstrução 
ureteral completa apresentaram maior severidade da atrofia renal de acordo com a duração da obstrução, com aumento de 100 x em rins obstruídos por 28 dias (Chevalier et al., 1999). O grau de displasia renal decorrente da obstrução pode ser muito elevado, com perda de aproximadamente $50 \%$ dos néfrons de ratos neonatos submetidos a 21 dias de obstrução parcial severa. Em ratos com obstruções parciais mais leves, a perda glomerular foi mais gradual e continuou entre 14 e 28 dias de obstrução. Essa perda foi relacionada à desconexão glomérulo-tubular e transformação celular fenotípica, com atrofia tubular e fibrose intersticial ocorrendo antes de dilatação pélvica significativa (Thornhill et al., 2005; Thornhill et al., 2007). Obstrução ureteral unilateral completa em ratos neonatos por período de um ano ocasionou a perda de $40 \%$ dos glomérulos do rim obstruído e a queda na taxa de filtração glomerular de $80 \%$. Apesar do crescimento compensatório do rim contralateral, não houve aumento compensatório na taxa de filtração glomerular e houve aumento da proteinúria. Além disso, a esclerose glomerular, atrofia tubular, infiltração macrofágica e fibrose intersticial aumentaram não somente no rim obstruído como no rim contralateral, levando a insuficiência renal na vida adulta (Chevalier et al., 2000). Taki et al. demonstraram que obstrução ureteral unilateral parcial crônica resultou em diminuição da taxa de filtração glomerular de modo inversamente proporcional à idade. $\mathrm{O}$ efeito da obstrução ureteral parcial crônica foi mais grave em animais mais jovens, principalmente a nível glomerular e nos túbulos proximais, enquanto as funções dos segmentos de túbulos mais distais foram afetadas de modo similar em todas as idades (Taki et al., 1983).

A morfogênese renal é um processo coordenado que é regulado por fatores estimulatórios e inibitórios. Foi demonstrado que células do mesênquima metanéfrico secretam fatores da superfamília do TGF $\beta$ durante a nefrogênese e que a administração de TGF $\beta 1$ apresenta efeito inibitório no crescimento e na arborização do broto ureteral, com 
efeito dose-dependente. Enquanto a apoptose foi discretamente alterada, a proliferação celular sofreu diminuição importante pela administração de TGF $\beta 1$ no tecido renal em formação, fato que corrobora que durante a fase de morfogênese renal de ratos neonatos, a obstrução ureteral pode resultar em displasia (Bush et al., 2004). Em autópsias de pacientes com rins multicísticos displásicos associados à uropatia obstrutiva, o estudo imunohistoquímico para TGF $\beta 1$ foi negativo em todos os casos (Rojas et al., 2011).

Em ratos adultos, predomina a atrofia renal com obstrução ureteral ao invés de displasia. Chuang et al demonstraram que existe correlação temporal da severidade do hidroureter e da hidronefrose com as alterações histopatológicas clássicas associadas à obstrução, como hipertrofia da camada muscular e proliferação do tecido conectivo submucoso, criando um modelo animal reprodutível de obstrução ureteral unilateral utilizando ratos adultos (Chuang et al., 1995).

Nosso estudo confirmou que o grau de obstrução leva a achados anatomopatológicos mais graves e existe correlação da severidade do hidroureter e hidronefrose e atrofia de parênquima com o tempo de obstrução. Escolhemos realizar a avaliação dos marcadores séricos, urinários e do tecido renal com 2 semanas e 4 semanas após procedimento inicial com base em estudos prévios que demonstraram expressão aumentada de TGF $\beta 1$ mRNA, expressão tubular de mRNA dos receptores do TGFß, TGF ßR1 e TGF ßR2 relacionada ao tempo de obstrução (Walton et al., 1992; Kaneto et al., 1993; Sutaria et al., 1998). Em ratos adultos submetidos à UUO completa em período de duração de até 42 dias, observou-se que o pico de expressão do TGF $\beta 1$ e seus receptores TGF ßR1, TGF ßR2 e TGF ßR3 foi no $21^{\circ}$ dia após a ligadura ureteral, que acompanharam achados histopatológicos de gravidade como severidade da hidronefrose, peso renal, espessamento da serosa e da camada muscular além de fibrose renal (Chuang et al., 2000). 
Em nosso estudo, decidimos pelo uso de ratos adultos para avaliação de marcadores na uropatia obstrutiva, devido à presença de alto índice de displasia em ratos neonatos submetidos à obstrução do trato urinário. Selecionamos, portanto, ratos adultos como nosso modelo de obstrução variável (unilateral ou bilateral, contemplando inclusive a situação clínica de obstrução parcial em rim único) a fim de verificar se uma obstrução mais severa ou bilateral influenciaria de modo mais intenso substâncias que participam do processo de remodelamento renal associado à obstrução ureteral (como o TGF ß1) e substâncias possivelmente secretadas pelo rim ou epitélio renal em resposta à obstrução. Por esse motivo, foram sete grupos de ratos submetidos a procedimentos cirúrgicos diversos para tentar responder a nossa pergunta.

Em diversos estudos experimentais em ratos adultos submetidos à obstrução ureteral unilateral, demonstrou-se a expressão aumentada do TGF ß1 mRNA (Walton et al., 1992; Kaneto et al., 1993; Fukuda et al., 2001), aumento da expressão tubular de mRNA dos receptores do TGF ß, TGF ßR1 e TGF ßR2 (Sutaria et al., 1998), além do aumento do nível de TGF $\beta 1$ de extratos renais (Zhou et al., 2002), que acompanharam achados histopatológicos de gravidade como severidade da hidronefrose, peso renal, espessamento da serosa e da camada muscular além de fibrose renal. No entanto, nenhum estudo avaliou níveis séricos e urinários do TGF $\beta 1$ em ratos.

Em estudos clínicos, também se observou a correlação positiva dos níveis do TGF ß1 com uropatia obstrutiva, com aumento dos níveis urinários de TGF $ß 1$ em crianças com estenose da junção ureteropiélica submetidas à pieloplastia (Palmer et al., 1997; Furness et al., 1999;El-Sherbiny et al., 2002; Sager et al., 2009; Taha et al., 2007; Almodhen et al., 2009). 
No entanto, alguns estudos não demonstraram aumento dos níveis do TGFß1 associados à presença de obstrução ureteral. Pacientes foram submetidos à endopielotomia com faca fria para tratamento de UPJO. Nesse estudo, observou-se que o TGF $ß 1$ urinário de amostras vesicais coletadas de pacientes submetidos à endopielotomia mal-sucedida é similar ao dos controles (pacientes ajustados para sexo e idade sem obstrução urinária) e significativamente menor que nos pacientes em que a endopielotomia foi bem sucedida (Liatsikos et al., 2001). Em outro estudo, com análise densitométrica comparativa de junções ureteropiélicas de pacientes submetidos à pieloplastia, houve down-regulation da expressão de TGF ß (Tadros et al., 2003).

Em nosso estudo, não observamos diferenças nas concentrações do TGF $\beta 1$ sérico e urinário entre os grupos do estudo, inclusive quando agrupamos os ratos com obstrução completa, obstrução parcial e comparamos os valores destas substâncias a ratos sem obstrução urinária. Os grupos apresentavam clearance de creatinina similares e, portanto, os resultados obtidos devem estar relacionados à falha no processo de remodelação e produção estável do TGF $\beta 1$ em ratos adultos conforme sugerido por Furness et al., autor que demonstrou níveis urinários de TGF $ß 1$ mais baixos em crianças mais velhas (Furness et al., 1999). Adicionalmente, a obstrução em ratos mimetiza até certo ponto a uropatia obstrutiva no humano, já que o rim do rato é unipapilar e consequentemente a acomodação de pressão intratubular é diferente do humano, que pode explicar resultados variados em espécies diferentes.

Outros estudos experimentais, similares ao nosso, encontraram resultados com marcadores urinários como MCP-1, demonstrando discordância na utilidade destas substâncias em trabalhos experimentais em relação a estudos clínicos. Enquanto em crianças com UPJO, a concentração urinária vesical da proteína quimiotática de monócitos 
(MCP-1) estava muito aumentada (Grandaliano et al., 2000), em um estudo com grupos de ratos adultos submetidos à obstrução ureteral parcial, obstrução ureteral completa ou sham operation, por período de até 3 semanas, não houve aumento da concentração urinária vesical de MCP-1 (Stephan et al., 2002). Essa proteína associa-se com a infiltração macrofágica em resposta à uropatia obstrutiva e parece estar relacionada ao remodelamento renal, como supracitado para o TGF $ß 1$. Somente a expressão de mRNA no tecido renal e a concentração urinária pélvica de MCP-1 estavam aumentadas nos grupos obstrutivos de acordo com a severidade da obstrução, o que Stephan et al., consideraram como marcadores prognósticos na avaliação da uropatia obstrutiva. No entanto, o autor considerou a aplicabilidade clínica dessa medida limitada, visto que amostras de urina pélvica requerem aspiração percutânea ou cateterização retrógrada e para obtenção de tecido renal, é necessária biópsia percutânea (Stephan et al., 2002). Por esse motivo, optamos por não realizar dosagem da urina pélvica em nosso estudo, visto que é relativamente invasivo, requer tempo prolongado para obtenção de volume necessário das amostras dos marcadores para aplicação dos kits, fato que poderia interferir nas outras etapas do procedimento cirúrgico e evidentemente aumentaria muito o custo do estudo. Com base nos dados de literatura, apesar da uropatia obstrutiva promover translação (mRNA) e tradução (proteína) aumentadas de substâncias como MCP-1, a excreção deste marcador no estudo de Stephan et al., bem como do TGF $\beta 1$ em nosso estudo não se relacionaram com a concentração urinária vesical.

A presença de hidronefrose foi correlacionada ao aumento CA 19-9 sérico e urinário em poucos estudos clínicos (Suzuki et al., 2002; Aybek et al., 2006;Akgül et al., 2007; Kajbafzadeh et al., 2010). Não existem estudos experimentais na literatura avaliando o comportamento do CA 19-9 em modelo de obstrução ureteral. Adicionalmente, o CA 19-9 
ou antígeno sanguíneo de Lewis é negativo em $10 \%$ da população humana (Hess et al., 2008) e em ratos não é conhecido nem se ocorre há expressão deste antígeno no sangue e urina.

Kajbafzadeh et al. demonstraram valores de CA 19-9 urinários elevados (na urina vesical) e sugeriram a origem renal e não sistêmica para o aumento da produção ou declínio da degradação. Demonstraram também que a função renográfica inicial apresentou correlação inversa com CA 19-9 da urina intrapélvica e com CA 19-9 urinário da bexiga, mas ressaltaram que a exceção a esse padrão ocorreria em rins severamente obstruídos com lesão renal extensa (Kajbafzadeh et al., 2010). Foi feita a hipótese de que apesar de níveis elevados do CA 19-9 na urina da pelve renal, devido à drenagem prejudicada e falta de clearance tubular adequado, os níveis de CA 19-9 na urina vesical seriam muito baixos.

Em nosso estudo, obtivemos dados de provável produção renal e não sistêmica do CA 19-9 que corroboram a maior parte das hipóteses anteriores. Apesar de não haver diferenças entre os grupos de estudo para o CA 19-9 sérico e urinário, quando agrupamos os ratos com obstrução e comparamos a concentração do CA 19-9 sérico e urinário com ratos sem obstrução, houve redução progressiva do CA 19-9 urinário, enquanto não houve alteração dos níveis de CA 19-9 sérico. Quando comparados ratos com obstrução completa a ratos com obstrução parcial e ratos sem obstrução, houve diminuição progressiva da concentração urinária de CA 19-9, sem alteração dos valores séricos deste marcador. O clearance de creatinina total, que considera ambas as unidades renais não variou entre os grupos, porém no estudo imuno-histoquímico, obtivemos subexpressão do CA 19-9 no grupo de obstrução completa, em rins claramente atrofiados pela obstrução severa, o que também sugere origem renal do CA 19-9. Para o grupo de obstrução parcial, apesar de níveis similares de produção do CA 19-9, os níveis urinários de CA 19-9 também 
apresentaram redução, fato oposto observado em estudos com humanos. Isso pode ocorrer devido a características diferentes das espécies, em que uma obstrução parcial teoricamente planejada para ser similar pode resultar em dano renal mais severo no rato devido a características deste órgão. O número de glomérulos em ratos varia de cerca de 26 a 36 mil (com coeficiente de variação de $11,5 \%$ ) e o volume renal varia de $650-1033 \mathrm{~mm}^{3}$ (coeficiente de variação de 14\%). No rim humano, o número de glomérulos varia de 391.000 a 1.424 .000 (coeficiente de variação de $25 \%$ ) e o peso renal varia de 80 a $206 \mathrm{~g}$ (coeficiente de variação de 26\%). De modo esperado, a variação biológica humana excede a do rato laboratorial geneticamente mais homogêneo (Yoo et al., 2006). Outra hipótese para explicar que em ratos com obstrução parcial, houve nível tecidual do CA 19-9 similar ao controle com níveis urinários vesicais mais baixos é a alteração da excreção tubular deste antígeno alterada por mecanismos não elucidados, fato que talvez não ocorra em humanos. Estudos nesta área serão necessários para entender melhor este processo.

A imunoexpressão do CA 19-9 ocorreu no citoplasma das células epiteliais tubulares, principalmente proximais e em menor grau nos dutos coletores. Não houve expressão urotelial ou endotelial, o que também sugere a produção renal de CA 19-9.

Nosso estudo sobre o uso de marcadores séricos e urinários na uropatia obstrutiva inicia possivelmente uma série de trabalhos nesse campo em desenvolvimento, o que poderá contribuir na elucidação da fisiopatologia da obstrução urinária, na aplicação clínica desses marcadores e eventualmente até no alívio do sofrimento que um diagnóstico de hidronefrose antenatal gera a famílias de pacientes com esta afecção. 


\section{PERSPECTIVAS EXPERIMENTAIS}

Um estudo com obstrução ureteral variável em ratos neonatos será realizado com a finalidade de verificar a influência do remodelamento renal sobre os marcadores séricos e urinários (CA 19-9, TGFß1), visto que a nefrogênese nestes ratos ainda está ocorrendo com consequente remodelamento mais intenso, apesar de um risco de displasia renal maior.

\section{PERSPECTIVAS CLÍNICAS}

Estamos criando um banco de armazenamento de amostras séricas, urinárias e de tecidos de junções ureteropiélicas e ureterovesicais no Laboratório de Investigação Médica da Disciplina de Urologia da Faculdade de Medicina da Universidade de São Paulo (FMUSP), LIM-55. A partir desse banco de espécimes, poderemos aplicar diversos marcadores promissores na investigação de uropatias obstrutivas.

Estudaremos a expressão translacional (mRNA) e proteica do CA 19-9, do TGFß1 e das principais metaloproteinases em junções ureteropiélicas de crianças submetidas a pieloplastia como tratamento de estenose da junção ureteropiélica e compararemos a junções ureteropiélicas de pacientes controles, com o objetivo de encontrar marcadores úteis no diagnóstico e seguimento de pacientes com uropatia obstrutiva. 
6.CONCLUSÕES 
Quando comparados ratos com obstrução completa a ratos com obstrução parcial e ratos sem obstrução, houve diminuição progressiva da concentração urinária de CA 19-9 com a severidade da obstrução, sem alteração dos valores séricos deste marcador. O estudo imuno-histoquímico do CA 19-9 demonstrou imunoexpressão no citoplasma das células epiteliais tubulares, principalmente proximais e em menor grau nos dutos coletores, sem expressão urotelial ou endotelial. Houve subexpressão do CA 19-9 no grupo de obstrução completa, em rins claramente atrofiados pela obstrução, o que também sugere origem renal do CA 19-9. Para o grupo de obstrução parcial, apesar de níveis similares de expressão do CA 19-9 no tecido renal em relação a ratos não obstruídos, os níveis urinários de CA 19-9 também apresentaram redução, fato oposto ao que é observado em estudos com humanos.

O TGFß1 sérico e urinário não apresentaram modificações de acordo com o grau de severidade e tempo de obstrução nesse modelo experimental em ratos adultos, o que pode estar relacionado a remodelamento renal menos intenso em resposta à uropatia obstrutiva nestes ratos. 
7.ANEXOS 
Anexo A - Termo de aprovação da CAPPesq

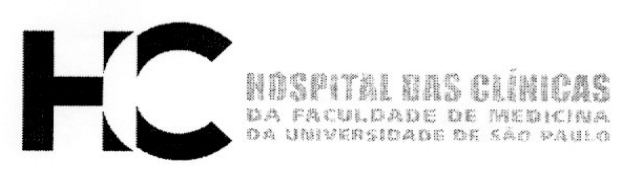

\section{APROVAÇÃO}

A Comissão de Ética para Análise de Projetos de Pesquisa CAPPesq da Diretoria Clínica do Hospital das Clínicas e da Faculdade de Medicina da Universidade de São Paulo, em sessão de 10/02/2010, APROVOU o Protocolo de Pesquisa n० 1326/09, intitulado: "AVALIAÇÃO DOS VALORES SÉRICOS E URINÁRIOS DE CA 19-9 E TGF $\beta 1$ NA OBSTRUÇÃO PARCIAL E COMPLETA DE URETERES EM RATOS", apresentado pelo Departamento de CIRURGIA.

Cabe ao pesquisador elaborar e apresentar à CAPPesq, os relatórios parciais e final sobre a pesquisa (Resolução do Conselho Nacional de Saúde n 196, de 10/10/1996, inciso (X.2, letra "c").

Pesquisador (a) Responsável: DR. FRANCISCO TIBOR DENES

CAPPesq, 11 de fevereiro de 2010

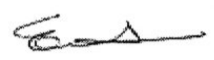

PROF. DR. EDUARDO MASSAD

Presidente

Comissão de Ética para Análise de Projetos de Pesquisa

Clínicas de Ética para Análise de Projetos de Pesquisa do HCFMUSP da Diretoria Clínica do pospital dás andar - CEP 05403010 - São Paulo - SP Fone: 01130696442 Fax: 01130696492 \&mail:

cappesq@hcnet.usp.br / secretariacappesq2@hcnet.usp.br 


\section{REFERÊNCIAS BIBLIOGRÁFICAS}


Aida Y, Kudo O, Yamakawa K, Kato K, Tadokoro M, Takahashi T. Papillary adenocarcinoma of the ureter producing carcinoembryonic antigen and carbohydrate antigen 19-9. J Urol. 2002; 168(6): 2535-6.

Akgül T, Nuhoğlu B, Ayyildiz A, Balci U, Ayyildiz SN, Germiyanoğlu C. Do hydronephrosis and extracorporeal shock wave lithotripsy affect carbohydrate antigens? Int Urol Nephrol. 2007; 39(4): 1001-4.

Aldheni F, Spitzner M, Martins JR, Barro-Soria R, Schreiber R, Kunzelmann K. Bestrophin 1 promotes epithelial-to-mesenchymal transition of renal collecting duct cells. J Am Soc Nephrol. 2009; 20(7): 1556-64.

Altman DG. Practical Statistics for Medical Research.London: Chapman \& Hall, 1991.

Almodhen F, Loutochin O, Capolicchio JP, Jednak R, El-Sherbiny M. The role of bladder urine transforming growth factor- $\beta 1$ concentrations in diagnosis and management of unilateral prenatal hydronephrosis. J Urol. 2009; 182(1): 292-8.

Aoki D, Nomata K, Kanda S, Sawase K, Kanetake H, Saito Y, Tsuda N. A case of pyonephrosis caused by ureteral stones with elevated serum levels of CA19-9. Hinyokika Kiyo. 1999; 45(9): 629-32.

Arap S, Nahas WC, Alonso G, Denes FT, Martins LR, Menezes de Góes G. Assessment of hydroureteronephrosis by renographic evaluation under diuretic stimulus. Urol Int. 1984; 39(3): 170-4.

Aybek H, Aybek Z, Sinik Z, Demir S, Sancak B, Tuncay L. Elevation of serum and urinary carbohydrate antigen 19-9 in benign hydronephrosis. Int J Urol. 2006; 13(11): 1380-4. 
Bartoli F, Penza R, Aceto G, Niglio F, D’Addato O, Pastore V, Campanella V, Magaldi S, Lasalandra C, Di Bitonto G, Gesualdo L. Urinary epidermal growth factor, monocyte chemotactic protein-1 and $\beta 2$-microglobulin in children with ureteropelvic junction obstruction. J Pediatr Surg. 2011; 46(3): 530-6.

Bascands JL, Schanstra JP. Obstructive nephropathy: insights from genetically engineered animals. Kidney International. 2005; 68(3): 925-37.

Bedi MM, Gandhi MD, Jacob G, Lekha V, Venugopal A, Ramesh H. CA 19-9 to differentiate benign and malignant masses in chronic pancreatitis: is there any benefit? Indian J Gastroenterol. 2009; 28(1): 24-7.

Beharrie A, Franc-Guimond J, Rodriguez MM, Au J, Zilleruelo G, Abitbol CL. A functional immature model of chronic partial ureteral obstruction. Kidney Int. 2004; 65(4): 1155-61.

Bernhard J, Dietrich D, Glimelius B, Hess V, Bodoky G, Scheithauer W, Herrmann R. Estimating prognosis and palliation based on tumour marker CA 19-9 and quality of life indicators in patients with advanced pancreatic cancer receiving chemotherapy. $B r J$ Cancer. 2010; 103(9): 1318-24.

Bessa Júnior J, Dénes FT, Chammas MC, Cerri L, Schneider-Monteiro D, Buchpiguel CA, Cerri GG, Srougi M. Diagnostic accuracy of color Doppler sonographic study of the ureteric jets in evaluation of hydronephrosis. J Pediatr Urol. 2008; 4(2): 113-7. 
Bor MV, Shi Y, Sorensen BS, Wen JG, Frokiaer J, Djurhuus JC, Nexo E. Increased TGF- $\alpha$ and EGF receptor mRNA expression in response to neonatal unilateral partial ureter obstruction in rats. Nephron Exp Nephrol. 2006; 104(2): e76-82.

Bush KT, Sakurai H, Steer DL, Leonard MO, Sampogna RV, Meyer TN, Schwesinger C, Qiao J, Nigam SK. TGF- $\beta$ superfamily members modulate growth, branching, shaping, and patterning of the ureteric bud. Dev Biol. 2004; 266(2): 285-98.

Caubet C, Lacroix C, Decramer S, Drube J, Ehrich JH, Mischak H, Bascands JL, Schanstra JP. Advances in urinary proteome analysis and biomarker discovery in pediatric renal disease. Pediatr Nephrol. 2010; 25(1): 27-35.

Chae YM, Park KK, Lee IK, Kim JK, Kim CH, Chang YC. Ring-Sp1 decoy oligonucleotide effectively suppresses extracellular matrix gene expression and fibrosis of rat kidney induced by unilateral ureteral obstruction. Gene Ther. 2006; 13(5): 430-9.

Cheng EY, Maizels M, Chou P, Hartanto V, Shapiro E. Response of the newborn ureteropelvic junction complex to induced and later reversed partial ureteral obstruction in the rabbit model. J Urol. 1993; 150(2 Pt 2): 782-9.

Cheng J, Truong LD, Wu X, Kuhl D, Lang F, Du J. Serum- and glucocorticoid-regulated kinase 1 is upregulated following unilateral ureteral obstruction causing epithelialmesenchymal transition. Kidney Int. 2010; 78(7): 668-78.

Chevalier RL. Growth factors and apoptosis in neonatal ureteral obstruction. J Am Soc Nephrol. 1996; 7(8): 1098-105. 
Chevalier RL, Goyal S, Wolstenholme JT, Thornhill BA. Obstructive nephropathy in the neonatal rat is attenuated by epidermal growth factor. Kidney Int. 1998; 54(1): 38-47.

Chevalier RL, Thornhill BA, Wolstenholme JT, Kim A. Unilateral ureteral obstruction in early development alters renal growth: dependence on the duration of obstruction. $J$ Urol. 1999; 161(1): 309-13.

Chevalier RL, Goyal S, Thornhill BA. EGF improves recovery following relief of unilateral ureteral obstruction in the neonatal rat. J Urol. 1999; 162(4): 1532-6.

Chevalier RL, Goyal S, Kim A, Chang AY, Landau D, LeRoith D. Renal tubulointerstitial injury from ureteral obstruction in the neonatal rat is attenuated by IGF-1. Kidney Int. 2000; 57(3): 882-90.

Chevalier RL, Thornhill BA, Chang AY. Unilateral ureteral obstruction in neonatal rats leads to renal insufficiency in adulthood. Kidney Int. 2000; 58(5): 1987-95.

Chevalier RL. Biomarkers of congenital obstructive nephropathy: past, present and future. $J$ Urol. 2004; 172(3): 852-7.

Chevalier RL. Pathogenesis of renal injury in obstructive nephropathy. Curr Opin Pediatr. 2006; 18(2): 153-60.

Chevalier RL. Chronic partial ureteral obstruction and the developing kidney. Pediatr Radiol. 2008; 38(Suppl 1): S35-40.

Chevalier RL, Thornhill BA, Forbes MS, Kiley SC. Mechanisms of renal injury and progression of renal disease in congenital obstructive nephropathy. Pediatr Nephrol. 2010; 25(4): 687-97. 
Chiou YY, Chiu NT, Wang ST, Cheng HL, Tang MJ. Factors associated with the outcomes of children with unilateral ureteropelvic junction obstruction. J Urol. 2004; 171(1): 397402.

Choi YJ, Baranowska-Daca E, Nguyen V, Koji T, Ballantyne CM, Sheikh-Hamad D, Suki WN, Truong LD. Mechanism of chronic obstructive uropathy: increased expression of apoptosis-promoting molecules. Kidney Int. 2000; 58(4): 1481-91.

Chuang YH, Chuang WL, Huang SP, Liu KM, Huang CH. The temporal relationship between the severity of hydroureter and the dynamic changes of obstructed ureters in a rat model. Br J Urol. 1995; 76(3): 303-10.

Chuang YH, Chuang WL, Liu KM, Chen SS, Huang CH. Early genetic and cellular responses in the smooth muscle layer of obstructed ureters in a rat model of obstructive uropathy. Br J Urol. 1997; 80(4): 548-53.

Chuang YH, Chuang WL, Liu KM, Chen SS, Huang CH. Tissue damage and regeneration of ureteric smooth muscle in rats with obstructive uropathy. Br J Urol. 1998; 82(2): 261-6.

Chuang YH, Chuang WL, Chen SS, Huang CH. Expression of transforming growth factor$\beta 1$ and its receptors related to the ureteric fibrosis in a rat model of obstructive uropathy. $J$ Urol. 2000; 163(4): 1298-303.

Daïkha-Dahmane F, Dommergues M, Muller F, Narcy F, Lacoste M, Beziau A, Dumez Y, Gubler MC. Development of human fetal kidney in obstructive uropathy: correlations with ultrasonography and urine biochemistry. Kidney Int. 1997; 52(1): 21-32. 
Decramer S, Wittke S, Mischak H, Zürbig P, Walden M, Bouissou F, Bascands JL, Schanstra JP. Predicting the clinical outcome of congenital unilateral ureteropelvic junction obstruction in newborn by urinary proteome analysis. Nat Med. 2006; 12(4): 398-400.

Decramer S, Bascands JL, Schanstra JP. Non-invasive markers of ureteropelvic junction obstruction. World J Urol. 2007; 25(5): 457-65.

Diamond JR, van Goor H, Ding G, Engelmyer E. Myofibroblasts in experimental hydronephrosis. Am J Pathol. 1995; 146(1): 121-9.

Diamond JR. Macrophages and progressive renal disease in experimental hydronephrosis. Am J Kidney Dis. 1995; 26(1): 133-40.

Diamond JR, Kees-Folts D, Ricardo SD, Pruznak A, Eufemio M. Early and persistent upregulated expression of renal cortical osteopontin in experimental hydronephrosis. Am $J$ Pathol. 1995; 146(6): 1455-66.

Dissing TH, Eskild-Jensen A, Pagh C, Frokiaer J, Rehling M, Jørgensen HS, Jørgensen TM, Djurhuus JC. Partial unilateral ureteropelvic junction obstruction induced in 2-weekold piglets. J Urol. 2001; 166(6): 2354-8.

Djurhuus JC, Nerstrom B, Gyrd-Hansen N, Rask-Anderson H. Experimental hydronephrosis. An electrophysiologic investigation before and after release of obstruction. Acta Chir Scand Suppl. 1976; 427: 17-28. 
Doi S, Zou Y, Togao O, Pastor JV, John GB, Wang L, Shiizaki K, Gotschall R, Schiavi S, Yorioka N, Takahashi M, Boothman DA, Kuro-o M. Klotho inhibits transforming growth factor- $\beta 1$ (TGF- $\beta 1)$ signaling and suppresses renal fibrosis and cancer metastasis in mice. $J$ Biol Chem. 2011; 286(10): 8655-65.

Dommergues M, Muller F, Ngo S, Hohlfeld P, Oury JF, Bidat L, Mahieu-Caputo D, Sagot P, Body G, Favre R, Dumez Y. Fetal serum $\beta 2$-microglobulin predicts postnatal renal function in bilateral uropathies. Kidney Int. 2000; 58(1): 312-6.

Drube J, Zürbig P, Schiffer E, Lau E, Ure B, Glüer S, Kirschstein M, Pape L, Decramer S, Bascands JL, Schanstra JP, Mischak H, Ehrich JH. Urinary proteome analysis identifies infants but not older children requiring pyeloplasty. Pediatr Nephrol. 2010; 25(9): 1673-8.

El-Dahr SS, Gomez RA, Gray MS, Peach MJ, Carey RM, Chevalier RL. Renal nerves modulate renin gene expression in the developing rat kidney with ureteral obstruction. $J$ Clin Invest. 1991; 87(3): 800-10.

El-Dahr SS, Gee J, Dipp S, Hanss BG, Vari RC, Chao J. Upregulation of renin-angiotensin system and downregulation of kallikrein in obstructive nephropathy. Am J Physiol. 1993; 264(5 Pt 2): F974-81.

El-Sherbiny MT, Mousa OM, Shokeir AA, Ghoneim MA. Role of urinary transforming growth factor-beta1 concentration in the diagnosis of upper urinary tract obstruction in children. J Urol. 2002; 168(4 Pt 2):1798-800. 
Ercan S, Kaymaz Ö, Yücel N, Orçun A. Serum concentrations of CA 125, CA 15-3, CA 19-9 and CEA in normal pregnancy: a longitudinal study. Arch Gynecol Obstet. 2012; 285(3): 579-84.

Eskild-Jensen A,Frøkiær J, Djurhuus JC, Jørgensen TM, Nyengaard JR. Reduced number of glomeruli in kidneys with neonatally induced partial ureteropelvic obstruction in pigs. $J$ Urol. 2002; 167(3): 1435-9.

Everaert K, Kerckhaert W, Delangue J, Lameire N, Sturley W, Van de Wiele C, Dierckx RA, Van de Voorde J, Oosterlinck W. Elevated tubular proteinuria, albuminuria and decreased urinary $\mathrm{N}$-acetyl- $\beta$-D-glucosaminidase activity following unilateral total ureteral obstruction in rats. Urol Res. 1998; 26(4): 285-9.

Fujinaka H, Miyazaki Y, Matsusaka T, Yoshida H, Fogo AB, Inagami T, Ichikawa I. Salutary role for angiotensin in partial urinary tract obstruction. Kidney Int. 2000; 58(5): 2018-27.

Fukuda K, Yoshitomi K, Yanagida T, Tokumoto M, Hirakata H. Quantification of TGF- $\beta 1$ mRNA along rat nephron in obstructive nephropathy. Am J Physiol Renal Physiol. 2001; 281(3): F513-21.

Furness PD 3rd, Maizels M, Han SW, Cohn RA, Cheng EY. Elevated bladder urine concentration of transforming growth factor-betal correlates with upper urinary tract obstruction in children. J Urol. 1999; 162(3 Pt 2):1033-6. 
Grandaliano G, Gesualdo L, Bartoli F, Ranieri E, Monno R, Leggio A, Paradies G, Caldarulo E, Infante B, Schiena FP. MCP-1 and EGF renal expression and urine excretion in human congenital obstructive nephropathy. Kidney Int. 2000; 58(1): 182-92.

Grenda R, Wühl E, Litwin M, Janas R, Śladowska J, Arbeiter K, Berg U, Caldas-Afonso A, Fischbach M, Mehls O, Sallay P, Schaefer F; ESCAPE Trial group. Urinary excretion of endothelin-1 (ET-1), transforming growth factor- $\beta 1$ (TGF- $\beta 1)$ and vascular endothelial growth factor (VEGF ${ }_{165}$ ) in paediatric chronic kidney diseases: results of the ESCAPE trial. Nephrol Dial Transplant. 2007; 22(12): 3487-94.

Guerin F, Azoulay R, Berrebi D, Sebag G, Aigrain Y, Peuchmaur M, El-Ghoneimi A. Partial unilateral ureteral obstruction in newborn mice: magnetic resonance imaging and pathology studies. J Urol. 2008; 179(4): 1553-63.

Harada T, Issa MM, Kigure T, Tsuchida S. Ureteral compliance and histology in partial obstruction in a canine model. J Urol. 1992; 148(4): 1274-8.

Hess V, Glimelius B, Grawe P, Dietrich D, Bodoky G, Ruhstaller T, Bajetta E, Saletti P, Figer A, Scheithauer W, Herrmann R. CA 19-9 tumour marker response to chemotherapy in patients with advanced pancreatic cancer enrolled in a randomized controlled trial. Lancet Oncol. 2008; 9(2): 132-8.

Hwang M, Kim HJ, Noh HJ, Chang YC, Chae YM, Kim KH, Jeon JP, Lee TS, Oh HK, Lee YS, Park KK. TGF- $\beta 1$ siRNA suppresses the tubulointerstitial fibrosis in the kidney of ureteral obstruction. Exp Mol Pathol. 2006; 81(1): 48-54. 
Iimura O, Takahashi H, Yashiro T, Madoiwa S, Sakata Y, Asano Y, Kusano E. Effect of ureteral obstruction on matrix metalloproteinase-2 in rat renal cortex. Clin Exp Nephrol. 2004; 8(3): 223-9.

Imaji R, Dewan PA. Calyx to parenchyma ratio in pelvi-ureteric junction obstruction. BJU Int. 2002; 89(1): 73-7.

Inamoto $\mathrm{T}$, Itoh S, Azuma H, Katsuoka Y, Takasaki N. Giant hydronephrosis with increased carbohydrate antigen 19-9 both in serum and fluid. Hinyokika Kiyo. 2004; 50(7): $485-8$.

Inayama $\mathrm{Y}$, Uesato $\mathrm{M}$, Takase $\mathrm{K}$, Motono $\mathrm{N}$, Nakatani $\mathrm{Y}$, Kitamura $\mathrm{H}$. Immunohistochemical study of CA 19-9 and SPan-1 in cases of hydronephrosis. Urol Int. 1996; 57(2): 93-8.

Ingraham SE, Saha M, Carpenter AR, Robinson M, Ismail I, Singh S, Hains D, Robinson ML, Hirselj DA, Koff SA, Bates CM, McHugh KM. Pathogenesis of renal injury in the megabladder mouse: a genetic model of congenital obstructive nephropathy. Pediatr Res. $2010 ; 68(6): 500-7$.

Inoue T, Okada H, Takenaka T, Watanabe Y, Suzuki H. A case report suggesting the occurrence of epithelial-mesenchymal transition in obstructive nephropathy. Clin Exp Nephrol. 2009; 13(4): 385-8.

Isaka Y, Tsujie M, Ando Y, Nakamura H, Kaneda Y, Imai E, Hori M. Transforming growth factor- $\beta 1$ antisense oligodeoxynucleotides block interstitial fibrosis in unilateral ureteral obstruction. Kidney Int. 2000; 58(5): 1885-92. 
Ito S, Nishikawa K, Goto T, Tsujita M, Takegaki Y, Kishimoto $\mathrm{T}$. A case of hydronephrosis caused by renal stones with elevated serum levels of CA-19-9 and CA-125. Hinyokika Kiyo. 1994; 40(10): 885-8.

Iwaki H, Wakabayashi Y, Kushima R, Okada Y, Tomoyoshi T. Primary adenocarcinoma of the ureter producing carbohydrate antigen 19-9. J Urol. 1996; 156(4): 1437.

Iwano M, Plieth D, Danoff TM, Xue C, Okada H, Neilson EG. Evidence that fibroblasts derive from epithelium during tissue fibrosis. J Clin Invest. 2002; 110(3): 341-50.

Josephson S, Wolgast M, Ojteg G. Experimental obstructive hydronephrosis in newborn rats. II. Long-term effects on renal blood flow distribution. Scand J Urol Nephrol. 1982: 16: $179-85$.

Kajbafzadeh A, Elmi A, Shafaattalab S, Emami H, Tourchi A, Mohseni M. Serum and urinary carbohydrate antigen $19-9$ in ureteropelvic junction obstruction in children. $J$ Pediatr Urol. 2009; 5(Suppl1): S59.

Kajbafzadeh AM, Elmi A, Talab SS, Emami H, Esfahani SA, Saeedi P. Urinary and serum carbohydrate antigen 19-9 as a biomarker in ureteropelvic junction obstruction in children. J Urol. 2010; 183(6): 2353-60.

Kaneto H, Morrissey J, Klahr S. Increased expression of TGF- $\beta 1$ mRNA in the obstructed kidney of rats with unilateral ureteral ligation. Kidney Int. 1993; 44(2): 313-21.

Kang HJ, Lee HY, Jin MH, Jeong HJ, Han SW. Decreased interstitial cells of Cajal-like cells, possible cause of congenital refluxing megaureters: Histopathologic differences in refluxing and obstructive megaureters. Urology. 2009; 74(2): 318-23. 
Kawai S, Suzuki K, Nishio K, Ishida Y, Okada R, Goto Y, Naito M, Wakai K, Ito Y, Hamajima N. Smoking and serum CA 19-9 levels according to Lewis and secretor genotypes. Int J Cancer. 2008; 123(12): 2880-4.

Kelly PJ, Archbold P, Price JH, Caldwell C, McCluggage WG. Serum CA 19.9 levels are commonly elevated in primary ovarian mucinous tumors but cannot be used to predict the histological subtype. J Clin Pathol. 2010; 63(2): 169-73.

Kim BJ, Lee KT, Moon TG, Kang P, Lee JK, Kim JJ, Rhee JC. How do we interpret an elevated carbohydrate antigen 19-9 in asymptomatic subjects? Dig Liver Dis. 2009; 41(5): 364-9.

Kim HG, Paick SH, Kwak C, Kim HH, Lho YS. Serial microscopic changes in cell proliferation and apoptosis in obstructed ureter of rat. J Endourol. 2006; 20(8): 590-7.

Kis E, Verebély T, Kövi R, Máttyus I. The role of ultrasound in the follow-up of postoperative changes after pyeloplasty. Pediatr Radiol. 1998; 28(4): 247-9.

Klahr S. Obstructive nephropathy. Intern Med. 2000; 39(5): 355-61.

Klahr S, Ishidoya S, Morrissey J. Role of angiotensin II in the tubulointerstitial fibrosis of obstructive nephropathy. Am J Kidney Dis. 1995; 26(1): 141-6.

Kondo N, Murakami Y, Uemura K, Hayashidani Y, Sudo T, Hashimoto Y, Nakashima A, Sakabe R, Shigemoto N, Kato Y, Ohge H, Sueda T. Prognostic impact of perioperative serum CA 19-9 levels in patients with resectable pancreatic cancer. Ann Surg Oncol. 2010; 17(9): 2321-9. 
Kondoh K, Noguchi S, Shuin T, Masuda M, Kubota Y, Hosaka M. A case of hydronephrosis with high level of serum Span-1 antigen and CA19-9. Hinyokika Kiyo. 1996; 42(1): 51-3.

Kuemmerle NB, Brandt RB, Chan W, Krieg RJ Jr, Chan JC. Inhibition of transforming growth factor $\beta 1$ induction by dietary vitamin $\mathrm{E}$ in unilateral obstruction in rats. Biochem Mol Med. 1997; 61(1): 82-6.

Kurdoglu Z, Gursoy R, Kurdoglu M, Erdem M, Erdem O, Erdem A. Comparison of the clinical value of CA 19-9 versus CA 125 for the diagnosis of endometriosis. Fertil Steril. 2009; 92(5): 1761-3.

Kuwabara T, Mori K, Mukoyama M, Kasahara M, Yokoi H, Saito Y, Yoshioka T, Ogawa Y, Imamaki H, Kusakabe T, Ebihara K, Omata M, Satoh N, Sugawara A, Barasch J, Nakao K. Urinary neutrophil gelatinase-associated lipocalin levels reflect damage to glomeruli, proximal tubules, and distal nephrons. Kidney Int. 2009; 75(3): 285-94.

Lan HY, Mu W, Tomita N, Huang XR, Li JH, Zhu HJ, Morishita R, Johnson RJ. Inhibition of renal fibrosis by gene transfer of inducible Smad7 using ultrasound-microbubble system in rat UUO model. J Am Soc Nephrol. 2003; 14(6): 1535-48.

La'ulu SL, Roberts WL. Performance characteristics of five automated CA 19-9 assays. Am J Clin Pathol. 2007; 127(3): 436-40.

Liatsikos EN, Dinlenc CZ, Bernardo NO, Kapoor R, Jabbour ME, Smith AD, Kushner L. Endopyelotomy failure is associated with reduced urinary transforming growth factor-beta1 levels in patients with upper urinary tract obstruction. J Endourol. 2001; 15(6): 567-70. 
Lin SL, Kisseleva T, Brenner DA, Duffield JS. Pericytes and perivascular fibroblasts are the primary source of collagen-producing cells in obstructive fibrosis of the kidney. Am $J$ Pathol. 2008; 173(6): 1617-27.

Madsen MG, Nørregaard R, Frøkiaer J, Jørgensen TM. Urinary biomarkers in prenatally diagnosed unilateral hydronephrosis. J Pediatr Urol. 2011; 7(2): 105-12.

Madsen MG, Nørregaard R, Stødkilde L, Christensen JH, Jørgensen TM,Frøkiaer J. Urine and kidney cytokine profiles in experimental unilateral acute and chronic hydronephrosis. Scand J Urol Nephrol. 2012; 46(2): 91-96.

Marshall SM, Flyvbjerg A, Frokioer J, Ørskov H. Insulin-like growth factor 1 and renal growth following ureteral obstruction in rat. Nephron. 1991; 58(2): 219-24.

Matsui S, Hiratsuka Y, Ariyoshi A, Sakamoto K. Chronic incomplete obstruction of the ureter: a new experimental model. Urol Int. 1986; 41: 426-9.

Meldrum KK, Misseri R, Metcalfe P, Dinarello CA, Hile KI, Meldrum DR. TNF- $\alpha$ neutralization ameliorates obstruction-induced renal fibrosis and dysfunction. Am J Physiol Regul Integr Comp Physiol. 2007; 292(4): R1456-64.

Mesrobian HG, Mitchell ME, See WA, Halligan BD, Carlson BE, Greene AS, Wakim BT. Candidate urinary biomarker discovery in ureteropelvic junction obstruction: a proteomic approach. J Urol. 2010; 184(2): 709-14.

Mesrobian HG. Urinary proteome analysis and the management of ureteropelvic junction obstruction. Pediatr Nephrol. 2010; 25(9): 1595-6. 
Meyer A, Kausch I, Krüger S, Fetscher S, Böhle A, Jocham D. Elevation of CA 19-9 in giant hydronephrosis induced by a renal calculus. Urology. 2004; 63(2): 381-2.

Miklovicova D, Cervenova O, Cernianska A, Jancovicova Z, Dedik L, Vasilenkova A. Long-term follow-up of renal function in patients after surgery for obstructive uropathy. Pediatr Nephrol. 2008; 23(6): 937-45.

Miller J, Hesse M, Diemer T, Haenze J, Knerr I, Rascher W, Weidner W. Congenital unilateral ureteropelvic junction obstruction of the rat: a useful animal model for human ureteropelvic junction obstruction? Urology. 2004; 63(1): 190-4.

Miyajima A, Chen J, Lawrence C, Ledbetter S, Soslow RA, Stern J, Jha S, Pigato J, Lemer ML, Poppas DP, Vaughan ED, Felsen D. Antibody to transforming growth factor- $\beta$ ameliorates tubular apoptosis in unilateral ureteral obstruction. Kidney Int. 2000; 58(6): $2301-13$.

Moon JA, Kim HT, Cho IS, Sheen YY, Kim DK. IN-1130, a novel transforming growth factor- $\beta$ type I receptor kinase (ALK5) inhibitor, suppresses renal fibrosis in obstructive nephropathy. Kidney Int. 2006; 70(7): 1234-43.

Morsing P, Stenberg A, Müller-Suur C, Persson AE. Tubuloglomerular feedback in animals with unilateral, partial ureteral occlusion. Kidney Int. 1987; 32(2): 212-8.

Murer L, Benetti E, Centi S, Della Vella M, Artifoni L, Capizzi A, Zucchetta P, Del Prete D, Carasi C, Montini G, Rigamonti W, Zaccello G. Clinical and molecular markers of chronic interstitial nephropathy in congenital unilateral ureteropelvic junction obstruction. $J$ Urol. 2006; $176(6$ Pt 1): 2668-73. 
Naruse T, Yuzawa Y, Akahori T, Mizuno M, Maruyama S, Kannagi R, Hotta N, Matsuo S. P-selectin-dependent macrophage migration into the tubulointerstitium in unilateral ureteral obstruction. Kidney Int. 2002; 62(1): 94-105.

Nicksa GA, O’Neil E, Yu DC, Curatolo AS, McNeish BL, Barnewolt CE, Zurakowski D, Buchmiller TL, Moses MA, Rosen S, Fauza DO. Correlation between prenatal urinary matrix metalloproteinase activity and the degree of kidney damage in a large animal model of congenital obstructive uropathy. J Pediatr Surg. 2010; 45(6): 1120-5.

Oka A, Tanji N, Toshino A, Miyauchi Y, Yokoyama M. Expression of growth factors after the release of ureteral obstruction in the rat kidney. Int J Urol. 1999; 6(12): 607-15.

Pais Jr. VM, Strandhoy JW, Assimos DG. Pathophysiology of urinary tract obstruction. In: Kavoussi LR, Novick AC, Partin AW, Peters CA, editors. Campbell-Walsh Urology. 9th edition. Philadelphia: Elsevier (Saunders), 2007. p. 1155-1225.

Pal K, Roy S, Mondal SA, Chatterjee U, Tiwari P, Bera M. Urinary level of CA 19-9 as a tumor marker in urothelial carcinoma of the bladder. Urol J. 2011; 8(3): 203-8.

Palmer LS, Maizels M, Kaplan WE, Firlit CF, Cheng EY. Urine levels of transforming growth factor-beta 1 in children with ureteropelvic junction obstruction. Urology. 1997; 50(5): 769-73.

Peters CA, Chevalier RL. Congenital urinary obstruction: pathophysiology and clinical evaluation. In: Kavoussi LR, Novick AC, Partin AW, Peters CA, editors. Campbell-Walsh Urology. 10th edition. Philadelphia: Elsevier (Saunders), 2012. p. 3028-3047. 
Pettersson BA, Aperia A, Elinder G. Pathophysiological changes in rat kidneys with partial ureteral obstruction since infancy. Kidney Int. 1984; 26(2): 122-7.

Picard N, Baum O, Vogetseder A, Kaissling B, Le Hir M. Origin of renal myofibroblasts in the model of unilateral ureter obstruction in the rat. Histochem Cell Biol. 2008; 130(1): $141-5$.

Pope JC 4th, Hernanz-Schulman M, Showalter PR, Cole TC, Schrum FF, Szurkus D, Brock JW 3rd. The value of Doppler resistive índex and peak systolic velocity in the evaluation of porcine renal obstruction. J Urol. 1996; $156(2$ Pt 2): 730-3.

Ricardo SD, Levinson ME, DeJoseph MR, Diamond JR. Expression of adhesion molecules in rat renal cortex during experimental hydronephrosis. Kidney Int. 1996; 50(6): 2002-10.

Rice EK, Nikolic-Paterson DJ, David JR, Bucala R, Metz CN, Atkins RC, Tesch GH. Macrophage accumulation and renal fibrosis are independent of macrophage migration inhibitory factor in mouse obstructive nephropathy. Nephrology. 2004; 9(5): 278-87.

Rodriguez-Peña AB, Grande MT, Eleno N, Arévalo M, Guerrero C, Santos E, LópezNovoa JM. Activation of Erk1/2 and Akt following unilateral ureteral obstruction. Kidney Int. 2008; 74(2): 196-209.

Rojas CP, Urbiztondo AK, Bruce JH, Rodriguez MM. Comparative immunohistochemical study of multicystic dysplastic kidneys with and without obstruction. Fetal Pediatr Pathol. 2011; 30(4): 209-19. 
Rosen S, Peters CA, Chevalier RL, Huang WY. The kidney in congenital ureteropelvic junction obstruction: a spectrum from normal to nephrectomy. $J$ Urol. 2008; 179(4): 125763.

Ryan PC, Fitzpatrick JM. Partial ureteric obstruction: a new variable canine experimental model. J Urol. 1987; 137(5): 1034-8.

Ryan PC, Maher K, Hurley GD, Fitzpatrick JM. The Whitaker test: experimental analysis in a canine model of partial ureteric obstruction. J Urol. 1989; 141(2): 387-90.

Sager C, Lopez JC, Duran V, Burek C, Perazzo E. Transforming growth factor- $\beta 1$ in congenital ureteropelvic junction obstruction: diagnosis and follow-up. Int Braz J Urol. $2009 ; 35(3): 315-25$.

Sakairi T, Hiromura K, Yamashita S, Takeuchi S, Tomioka M, Ideura H, Maeshima A, Kaneko Y, Kuroiwa T, Nangaku M, Takeuchi T, Nojima Y. Nestin expression in the kidney with an obstructed ureter. Kidney Int. 2007; 72(3): 307-18.

Serel TA, Savaş C, Delibaş N, Koşar A, Arican A, Tahoğlu M. Free insulin-like growth factor-1 and unilateral complete ureteral obstruction in the rat. Urology. 2000; 56(5): 863-6.

Shappell SB, Mendoza LH, Gurpinar T, Smith CW, Suki WN, Truong LD. Expression of adhesion molecules in kidney with experimental chronic obstructive uropathy: the pathogenic role of ICAM-1 and VCAM-1. Nephron. 2000; 85(2): 156-66.

Shikata K, Suzuki Y, Wada J, Hirata K, Matsuda M, Kawashima H, Suzuki T, Iizuka M, Makino H, Miyasaka M. L-selectin and its ligands mediate infiltration of mononuclear cells into kidney interstitium after ureteric obstruction. J Pathol. 1999; 188(1): 93-9. 
Shin GT, Kim WH, Yim H, Kim MS, Kim H. Effects of suppressing intrarenal angiotensinogen on renal transforming growth factor- $\beta 1$ expression in acute ureteral obstruction. Kidney Int. 2005; 67(3): 897-908.

Shin GT, Kim DR, Lim JE, Yim H, Kim H. Upregulation and function of GADD45 $\gamma$ in unilateral ureteral obstruction. Kidney Int. 2008; 73(11): 1251-65.

Shokeir AA. Partial ureteral obstruction: a new variable and reversible canine experimental model. Urology. 1995; 45(6): 953-7.

Shokeir AA, El-Sherbiny MT, Gad HM, Dawaba M, Hafez AT, Taha MA, Saida M, Ghaly AM. Postnatal unilateral pelviureteral junction obstruction: impact of pyeloplasty and conservative management on renal function. Urology. 2005; 65(5): 980-5.

Shokeir AA. Role of urinary biomarkers in the diagnosis of congenital upper urinary tract obstruction. Indian J Urol. 2008; 24(3): 313-9.

Shokeir AA, Taha MA. Role of urinary tubular enzymes in evaluation of children with ureteropelvic junction narrowing under conservative management. Urology. 2009; 73(5): 1016-20.

Shudo R, Saito T, Takahashi K, Horita K, Waku K, Honma I, Sato T. Giant hydronephrosis due to a ureteral stone, and elevated serum levels of CA 19-9. Intern Med. 1999; 38(11): 887-91.

Silverstein DM, Travis BR, Thornhill BA, Schurr JS, Kolls JK, Leung JC, Chevalier RL. Altered expression of immune modulator and structural genes in neonatal unilateral ureteral obstruction. Kidney Int. 2003; 64(1): 25-35. 
Singer JM, Andrade DF. Analysis of Longitudinal Data. In: Handbook of statistics: bioenvironmental and public health statistics, eds.Sen PK, Rao CR.. Amsterdam: North Holland; 2000. v.18. p.115-60.

Singh S, Tang SJ, Sreenarasimhaiah J, Lara LF, Siddiqui A. The clinical utility and limitations of serum carbohydrate antigen (CA 19-9) as a diagnostic tool for pancreatic cancer and cholangiocarcinoma. Dig Dis Sci. 2011; 56(8): 2491-6.

Stephan M, Conrad S, Eggert T, Heuer R, Fernandez S, Huland H. Urinary concentration and tissue messenger RNA expression of monocyte chemoattractant protein-1 as an indicator of the degree of hydronephrotic atrophy in partial ureteral obstruction. $J$ Urol. 2002; 167(3): 1497-502.

Sutaria PM, Ohebshalom M, McCaffrey TA, Vaughan ED Jr, Felsen D. Transforming growth factor- $\beta$ receptor types I and II are expressed in renal tubules and are increased after chronic unilateral ureteral obstruction. Life Sci. 1998; 62(21): 1965-72.

Suzuki K, Muraishi O, Tokue A. The correlation of serum carbohydrate antigen 19-9 with benign hydronephrosis. J Urol. 2002; 167(1):16-20.

Suzuki K. Elevation of serum and urinary carbohydrate antigen 19-9 in benign hydronephrosis. Int J Urol. 2007; 14(7): 668-9.

Tadros Y, Ruiz-Deya G, Crawford BE, Thomas R, Abdel-Mageed AB. In vivo proteomic analysis of cytokine expression in laser capture-microdissected urothelial cells of obstructed ureteropelvic junction procured by laparoscopic dismembered pyeloplasty. $J$ Endourol. 2003; 17(5): 333-6. 
Taha MA, Shokeir AA, Osman HG, Abd el-Aziz Ael-A, Farahat SE. Diagnosis of ureteropelvic junction obstruction in children: role of endothelin-1 in voided urine. Urology. 2007; 69(3): 560-5.

Taha MA, Shokeir AA, Osman HG, Abd El-Aziz Ael-A, Farahat SE. Pelvi-ureteric junction obstruction in children: the role of urinary transforming growth factor-beta and epidermal growth factor. BJU Int. 2007; 99(4): 899-903.

Taha MA, Shokeir AA, Osman HG, Abd El-Aziz Ael-A, Farahat SE. Obstructed versus dilated nonobstructed kidneys in children with congenital ureteropelvic junction narrowing: role of urinary tubular enzymes. J Urol. 2007; 178(2): 640-6.

Takase K, Inayama Y, Misaki H, Kitamura H, Nakatani Y, Hosaka M. Hydronephrosis and hydroureter with extremely high levels of serum carbohydrate antigens 19-9 and SPan-1: a case report. J Urol. 1996; 155(4): 1386.

Taki M, Goldsmith DI, Spitzer A. Impact of age on effects of ureteral obstruction on renal function. Kidney Int. 1983; 24(5): 602-9.

Thornhill BA, Burt LE, Chen C, Forbes MS, Chevalier RL. Variable chronic partial ureteral obstruction in the neonatal rat: a new model of ureteropelvic junction obstruction. Kidney Int. 2005; 67(1): 42-52.

Thornhill BA, Forbes MS, Marcinko ES, Chevalier RL. Glomerulotubular disconnection in neonatal mice after relief of partial ureteral obstruction. Kidney Int. 2007; 72(9): 1103-12.

Ulm AH, Miller F. An operation to produce experimental reversible hydronephrosis in dogs. J Urol. 1962; 88: 337-41. 
Waanders E, van Keimpema L, Brouwer JT, van Oijen MG, Aerts R, Sweep FC, Nevens F, Drenth JP. Carbohydrate antigen CA 19-9 is extremely elevated in polycystic liver disease. Liver Int. 2009; 29(9): 1389-95.

Walton G, Buttyan R, Garcia-Montes E, Olsson CA, Hensle TW, Sawczuk IS. Renal growth factor expression during the early phase of experimental hydronephrosis. $J$ Urol. 1992; $148(2$ Pt 2): 510-4.

Wang W, Huang XR, Li AG, Liu F, Li JH, Truong LD, Wang XJ, Lan HY. Signaling mechanism of TGF- $\beta 1$ in prevention of renal inflammation: role of Smad7. J Am Soc Nephrol. 2005; 16(5): 1371-83.

Wasilewska A, Taranta-Janusz K, Dębek W, Zoch-Zwierz W, Kuroczycka-Saniutycz E. KIM-1 and NGAL: new markers of obstructive nephropathy. Pediatr Nephrol. 2011; 26(4): $579-86$.

Wen JG, Chen Y, Frøkiær J, Jørgensen TM, Djurhuus JC. Experimental partial unilateral ureter obstruction. I. Pressure flow relationship in a rat model with mild and severe acute ureter obstruction. J Urol. 1998; 160(4): 1567-71.

Wen JG, Frøkiaer J, Jørgensen TM, Djurhuus JC. Obstructive nephropathy: an update of the experimental research. Urol Res. 1999; 27(1): 29-39.

Wen JG. Partial unilateral ureteral obstruction in rats. Neurourol Urodyn. 2002; 21(3): 23150. 
Wen JG, Ringgaard S, Jørgensen TM, Stødkilde-Jørgensen H, Djurhuus JC, Frøkiær J. Long-term effects of partial unilateral ureteral obstruction on renal hemodynamics and morphology in newborn rats: a magnetic resonance imaging study. Urol Res. 2002; 30(4): 205-12.

Wen JG,Frøkiær J, Zhao JB, Ringgaard S, Jørgensen TM,Djurhuus JC. Severe partial ureteric obstruction in newborn rats can produce renal dysplasia. BJU Int. 2002; 89(7): 7405.

Yamashita S, Maeshima A, Nojima Y. Involvement of renal progenitor tubular cells in epithelial-to-mesenchymal transition in fibrotic rat kidneys. J Am Soc Nephrol. 2005; 16(7): 2044-51.

Yang SP, Woolf AS, Quinn F, Winyard PJ. Deregulation of renal transforming growth factor-beta1 after experimental short-term ureteric obstruction in fetal sheep. Am J Pathol. 2001; 159(1): 109-17.

Yang Y, Hou Y, Wang CL, Ji SJ. Renal expression of epidermal growth factor and transforming growth factor-betal in children with congenital hydronephrosis. Urology. 2006; 67(4):817-22.

Yang Y, Hou Y, Niu ZB, Wang CL. Long-term follow-up and management of prenatally detected, isolated hydronephrosis. J Pediatr Surg. 2010; 45(8): 1701-6.

Yarger WE, Schocken DD, Harris RH. Obstructive nephropathy in the rat: possible roles for the renin-angiotensin system, prostaglandins, and thromboxanes in postobstructive renal function. J Clin Invest. 1980; 65(2): 400-12. 
Yeh CH, Chiang HS, Lai TY, Chien CT. Unilateral ureteral obstruction evokes renal tubular apoptosis via the enhanced oxidative stress and endoplasmic reticulum stress in the rat. Neurourol Urodyn. 2011; 30(3): 472-9.

Yeh YC, Wei WC, Wang YK, Lin SC, Sung JM, Tang MJ. Transforming growth factor- $\beta 1$ induces Smad3-dependent $\beta 1$ integrin gene expression in epithelial-to-mesenchymal transition during chronic tubulointerstitial fibrosis. Am J Pathol. 2010; 177(4): 1743-54.

Yokoi H, Sugawara A, Mukoyama M, Mori K, Makino H, Suganami T, Nagae T, Yahata K, Fujinaga Y, Tanaka I, Nakao K. Role of connective tissue growth factor in profibrotic action of transforming growth factor- $\beta$ : a potential target for preventing renal fibrosis. Am $J$ Kidney Dis. 2001; 38(4 Suppl 1): S134-8.

Yoo KH, Thornhill BA, Chevalier RL. Angiotensin stimulates TGF- $\beta 1$ and clusterin in the hydronephrotic neonatal rat kidney. Am J Physiol Regul Integr Comp Physiol. 2000; 278(3): R640-5.

Zhang D, Sun L, Xian W, Liu F, Ling G, Xiao L, Liu Y, Peng Y, Haruna Y, Kanwar YS. Low-dose paclitaxel ameliorates renal fibrosis in rat UUO model by inhibition of TGFß/Smad activity. Lab Invest. 2010; 90(3): 436-47.

Zhang G, Kim H, Cai X, López-Guisa JM, Alpers CE, Liu Y, Carmeliet P, Eddy AA. Urokinase receptor deficiency accelerates renal fibrosis in obstructive nephropathy. $J A m$ Soc Nephrol. 2003; 14(5): 1254-71. 
Zhou Y, Takahashi G, Shinagawa T, Okuhara T, Yonamine K, Aida Y, Tadokoro M. Increased transforming growth factor-betal and tubulointerstitial fibrosis in rats with congenital hydronephrosis. Int J Urol. 2002; 9(9): 491-500.

Zieg J, Blahova K, Seeman T, Bronsky J, Dvorakova H, Pechova M, Janda J, Matousovic K. Urinary transforming growth factor- $\beta 1$ in children with obstructive uropathy. Nephrology. 2011; 16(6): 595-8. 
APÊNDICE 
Trabalho relacionado à tese apresentado em congresso internacional:

$24^{\text {th }}$ Congress of the European Society for Pediatric Urology 2013 - indicado ao Highlights da sessão de Basic Science.

Artigo submetido para publicação:

Lopes RI, Dénes FT, Bartolamei MG, Reis S, Sanchez TR, Leite KR, Srougi M, Seguro AC. Seric and urinary values of CA $19-9$ and TGF $\beta 1$ in a rat model of partial or complete ureteral obstruction. Submetido ao Journal of Pediatric Urology. 